\title{
Decision -making in the use of instructional technology by novice and experienced public school teachers
}

Amy L. Kuhn

West Virginia University

Follow this and additional works at: https://researchrepository.wvu.edu/etd

\section{Recommended Citation}

Kuhn, Amy L., "Decision -making in the use of instructional technology by novice and experienced public school teachers" (2006). Graduate Theses, Dissertations, and Problem Reports. 2702.

https://researchrepository.wvu.edu/etd/2702

This Dissertation is protected by copyright and/or related rights. It has been brought to you by the The Research Repository @ WVU with permission from the rights-holder(s). You are free to use this Dissertation in any way that is permitted by the copyright and related rights legislation that applies to your use. For other uses you must obtain permission from the rights-holder(s) directly, unless additional rights are indicated by a Creative Commons license in the record and/ or on the work itself. This Dissertation has been accepted for inclusion in WVU Graduate Theses, Dissertations, and Problem Reports collection by an authorized administrator of The Research Repository @ WVU.

For more information, please contact researchrepository@mail.wvu.edu. 


\title{
Decision-Making in the Use of Instructional Technology by Novice and Experienced Public School Teachers
}

Amy L. Kuhn, Ed.D.

\author{
Dissertation submitted to the \\ College of Human Resources and Education \\ at West Virginia University \\ in partial fulfillment of the requirements \\ for the degree of \\ Doctor of Education \\ in \\ Technology Education
}

\author{
R. Neal Shambaugh, Ph.D., Chair \\ David L. McCrory, Ph.D. \\ Diana Bennett, Ed.D. \\ Cheryl L. Prichard, Ed.D. \\ Jaci L. Webb-Dempsey, Ph.D. \\ Department of Technology Education
}

Morgantown, West Virginia

2006

Keywords: teacher decision-making, instructional technology, case study Copyright 2006 Amy L. Kuhn 


\begin{abstract}
Decision-Making in the Use of Instructional Technology

by Novice and Experienced Public School Teachers
\end{abstract}

Amy L. Kuhn, Ed.D.

The body of research on instructional technology (IT) reveals "what" influences teachers to use technologies and "which" technologies they use. Investigations into IT have not explored "how" and "why" teachers make decisions about teaching with technology. This study was not designed as yet another investigation into instructional technologies teachers use or to persuade teachers to use technology, but focused on teachers' decision-making to promote students' learning and the role of instructional technologies in this educational process.

Three novice (each with two years of teaching experience) and three experienced teachers (with an average of 26 years teaching experience) participated in this study. Qualitative methodology was employed, using interviews and observations as primary sources of data, and lesson plans and student work as secondary sources. Data were collected and analyzed using Clark and Peterson's (1986) research as a platform. Their research revealed teachers make preactive (prior to teaching), interactive (during teaching), and postactive (after teaching) decisions. A multiple case study framework was used to describe the teachers' decision-making in the use of instructional technology.

Discussed are similarities and differences in novice and experienced public school teachers' decision-making in the use of technology. Novices focused on classroom management and other immediate concerns, such as adhering to curriculum. Experienced teachers had mastered classroom management and curriculum, allowing them to focus on other issues, such as how technology could potentially improve a lesson by allowing them to teach something more effectively than before or teach something they could not have taught without technology.

Three implications emanated from this study. Teacher education students can learn from experienced teachers how to make literate decisions in the classroom and in the use of instructional technology. Second, experienced teachers who do not use technology at all, or do not use technology in ways that enhance students' learning, can learn to make literate decisions in the use of instructional technology. Third, the case study approach is appropriate for revealing teachers' decision-making in the use of instructional technology. 


\section{ACKNOWLEDGEMENTS}

First and foremost I have to express my gratitude and appreciation to the six teachers who so willingly gave their time to participate in my research. Teaching is complex, dynamic, and intensive, but you always made time to work with me. Without all of you, I would not have been able to study a topic that has been of interest to me for years.

When people ask who will be evaluating my research, my immediate response is that five great people are serving on my committee from whom I have learned so much. Many thanks to Dr. Diana Bennett for your invaluable insight as a public school teacher and encouragement when I was struggling. Thanks to Dr. David McCrory for remaining on my committee through your retirement, sticking with me as I struggled to define my study, and supporting me when I finally realized what I wanted to research. Thank you, Dr. Cheryl Prichard, for treating me as a colleague over the years, inviting me to participate in research, and helping to build my confidence as a professional. I want to thank Dr. Jaci Webb-Dempsey for being a mentor and for helping me to experience life in academia, from assisting you in teaching a course to being part of a research project for the West Virginia Department of Education. Without Dr. Neal Shambaugh, I would not be where I am today. You have guided me through the years with a true mentor's spirit, knowing when I needed to struggle and when I needed help. I thank you also for the opportunities you provide for me to grow as a teacher and a learner.

Working with Van and Sarah in the Benedum Collaborative has been a wonderful experience. From day one you have treated me as a colleague and granted me opportunities that graduate assistants are usually not fortunate enough to experience. 
While working on a doctorate, a person is still dealing with life outside of classes and writing a dissertation. My friends and family helped me to survive life challenges as well as the doctoral process. Thanks to Lee for your uncanny sense of knowing when I needed to talk and when I needed to laugh. Thank you, Carey, for continuing to motivate me, the person who often takes herself for granted, by reminding me that earning a doctorate is quite an accomplishment. Thank you, John, for challenging me intellectually and initiating my renaissance. Kay, you helped me to become Amy again. Thanks to Rie and Frank for taking me under your wings and always knowing when I needed a decent meal. Dr. Sharon Ryan, your advice on writing broke my mental block and provided momentum to finish my dissertation. Thanks to Christine for your suggestions about chapters 4 and 5 and helping me to battle through mental fatigue.

My family has been absolutely amazing. Thanks to Aunt Pat for your pep talks. Gram, I appreciate you understanding my lack of time to spend with you and for your support. I thank my brothers Jeff, Dave, and Steve for encouraging me throughout this process by cheering me on and telling me how proud you are of me. Thanks to Steve for our philosophical conversations and helping me to realize how lucky I am to have found my passion.

How can I ever thank my parents? You believed in me as I struggled to determine "what I want to be when I grow up.” Thanks, Mom, for intuitively being aware of what I needed and providing me with care packages, as well as offering to do anything and everything you could to help so I could focus on my doctorate. Dad, thank you for taking such great interest in my dissertation and my work. From your exemplary teaching and passion for learning stems my love for helping people to learn. 


\section{TABLE OF CONTENTS}

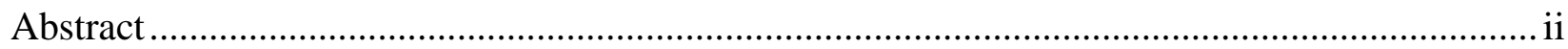

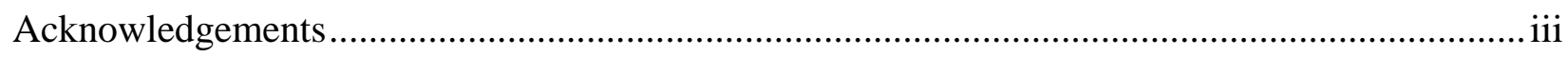

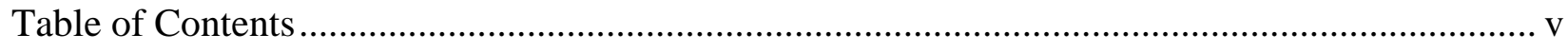

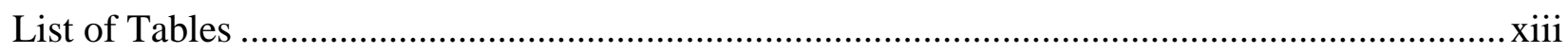

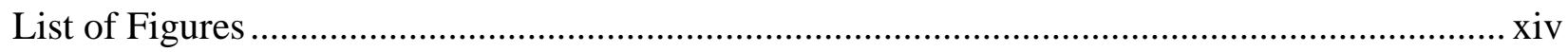

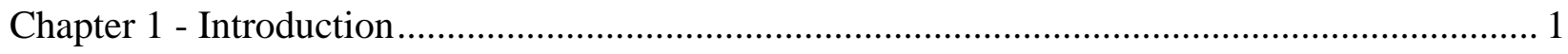

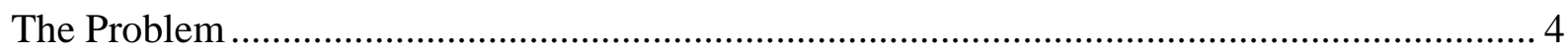

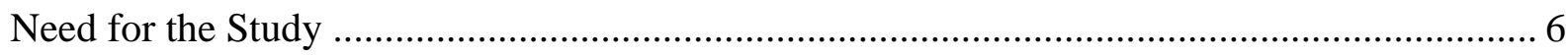

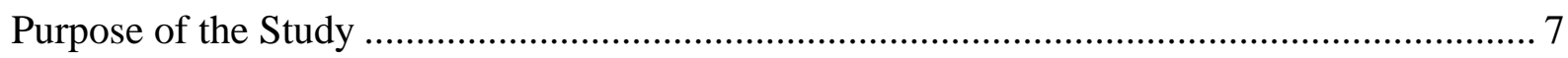

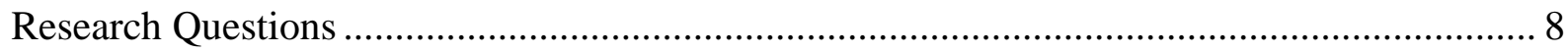

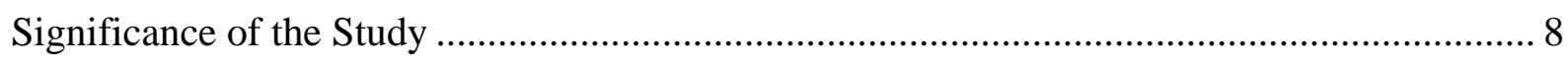

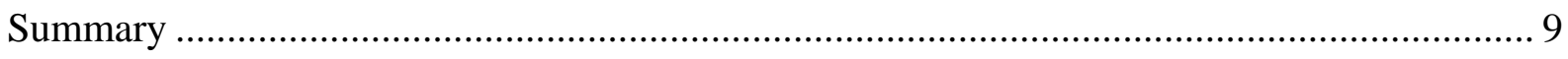

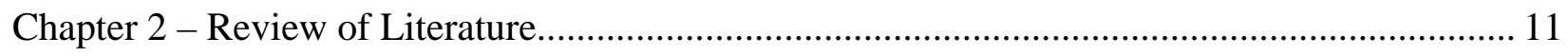

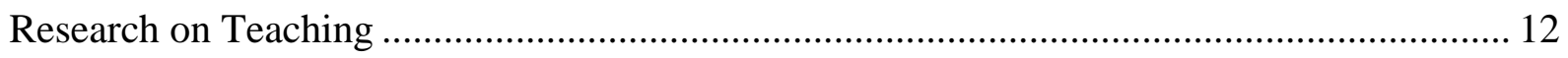

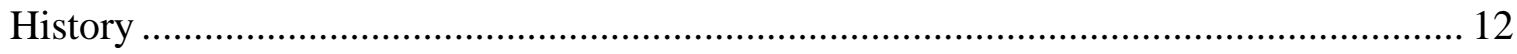

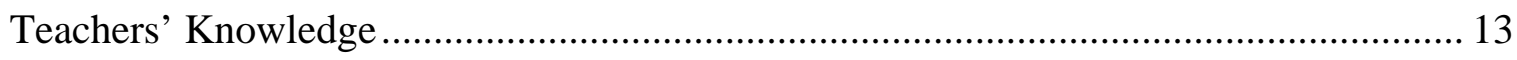

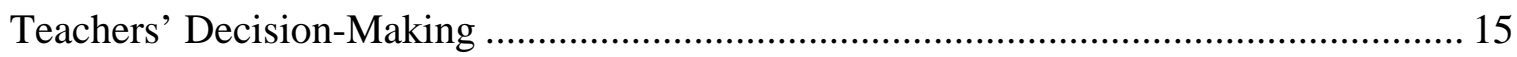

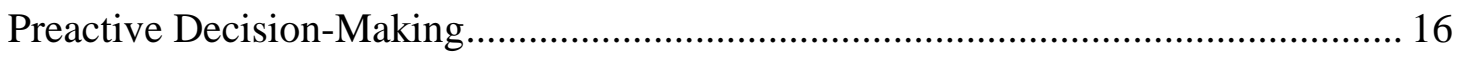

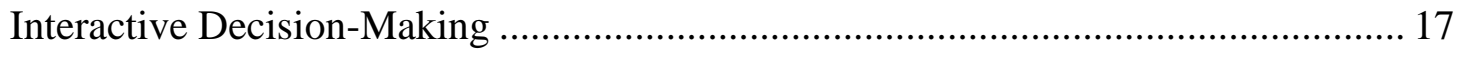

Postactive Decision-Making ....................................................................... 18

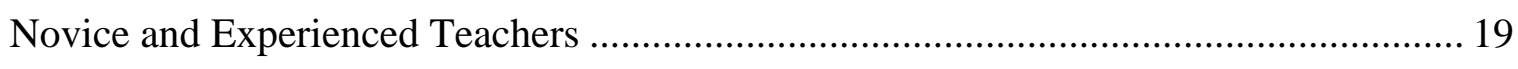

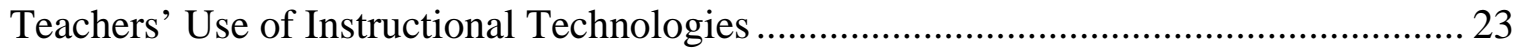




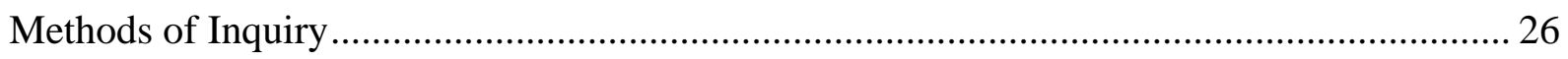

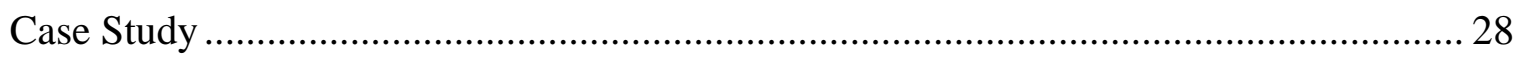

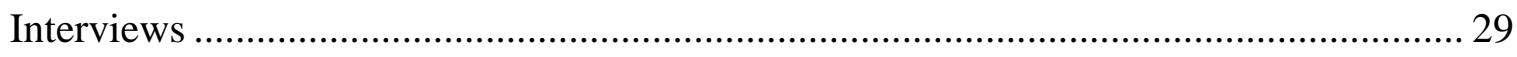

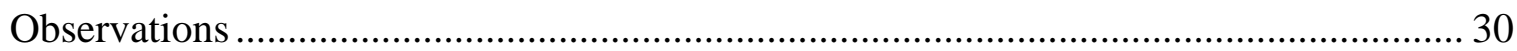

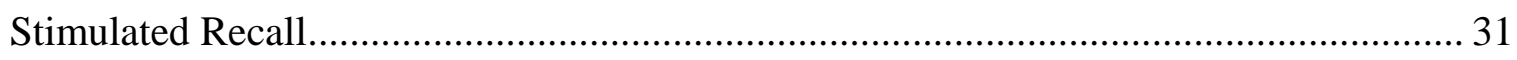

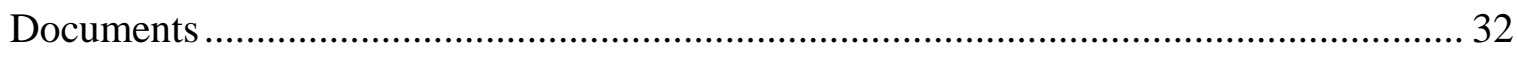

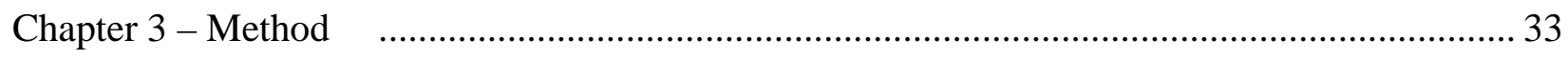

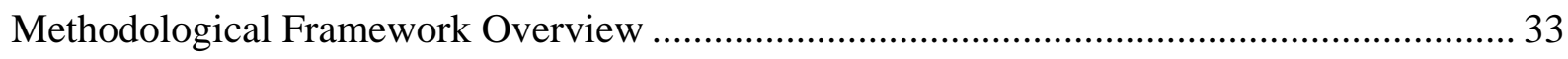

Case Study and Teacher Decision-Making ........................................................................ 33

Researcher and Participants......................................................................................... 35

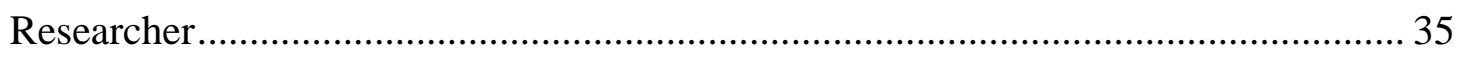

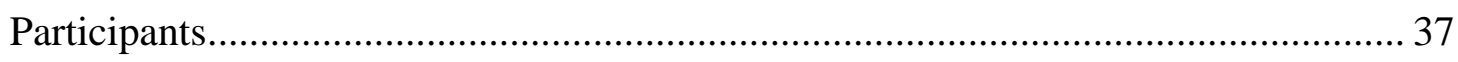

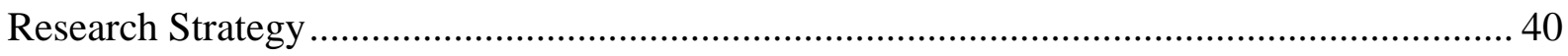

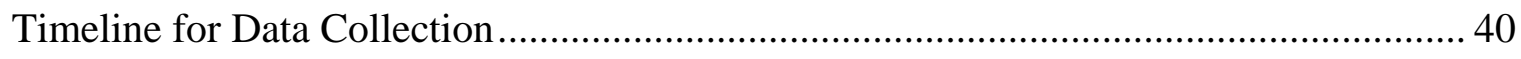

Data Sources and Data Collection Procedure................................................................ 41

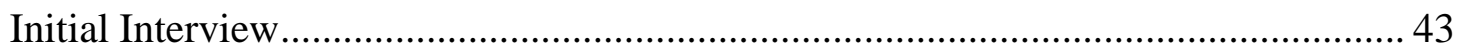

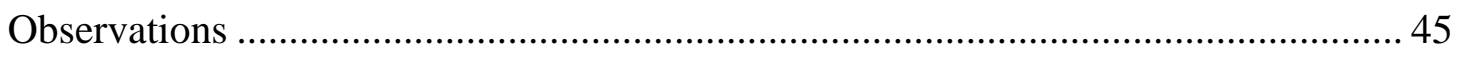

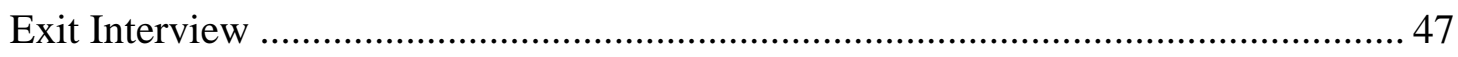

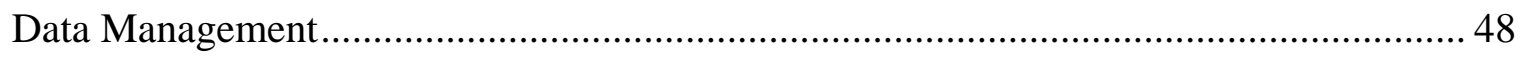

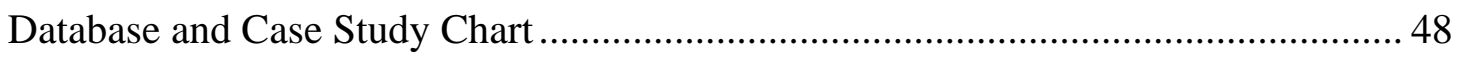

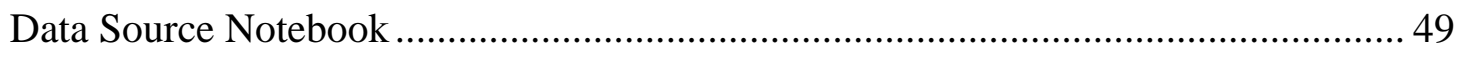

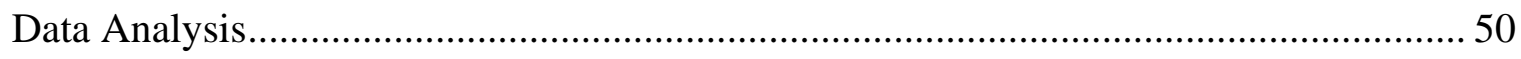

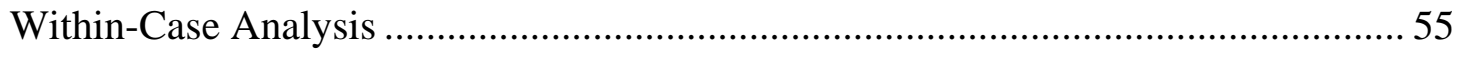




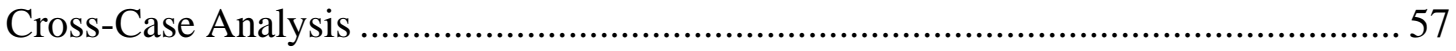

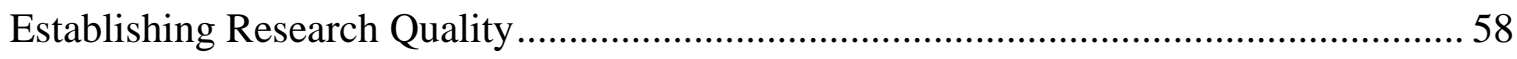

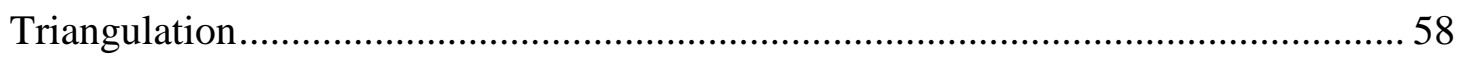

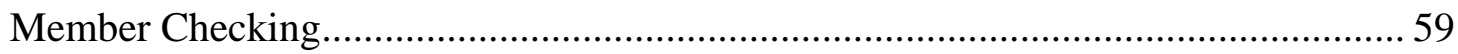

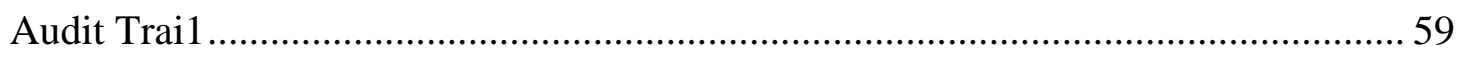

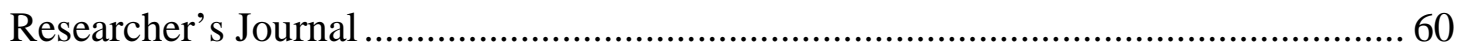

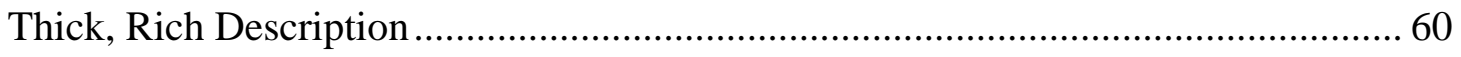

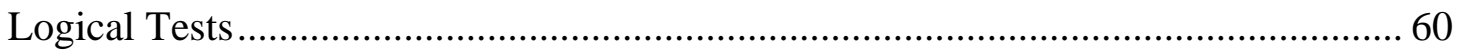

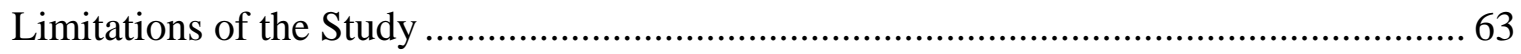

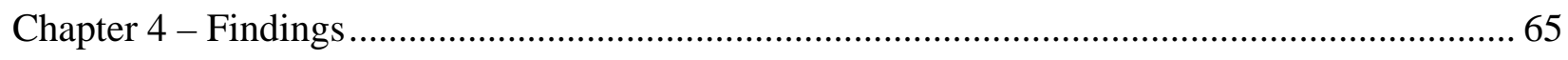

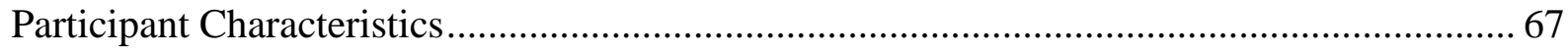

Data Analysis and Reduction Procedure ................................................................... 68

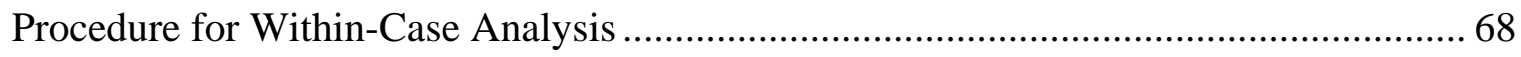

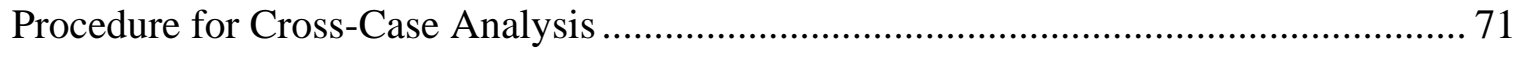

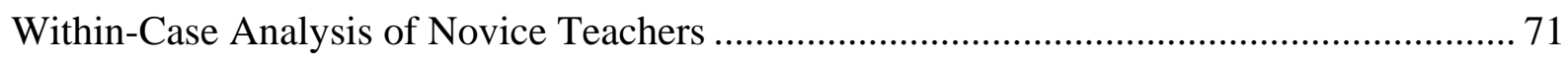

Case Study 1 Narrative: Lucy - Novice Elementary School Teacher............................ 71

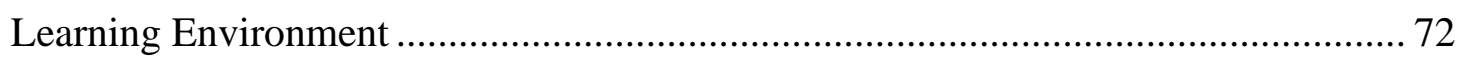

Inside the School and Lucy’s Classroom .................................................... 72

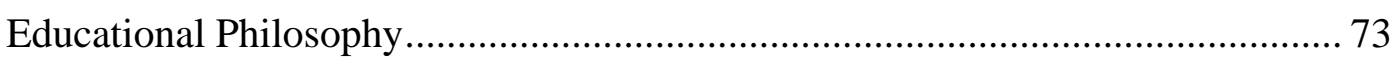

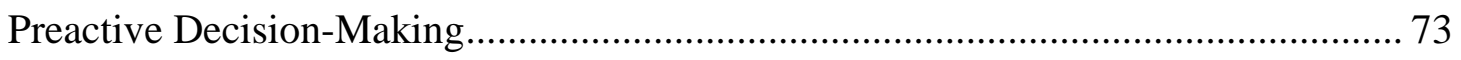

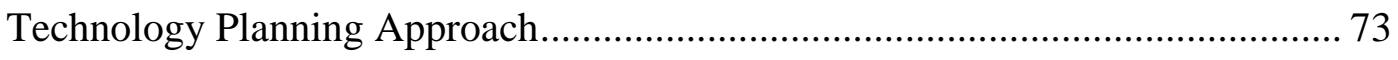

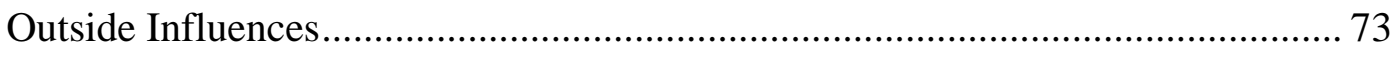

Teaching and Learning Decisions ............................................................. 74 


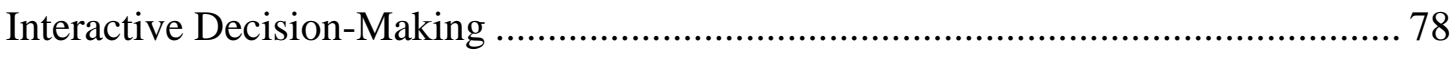

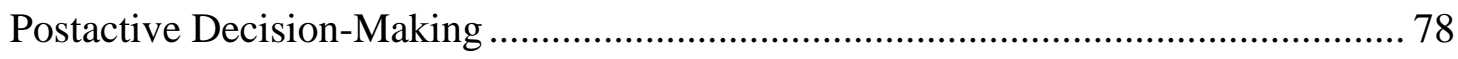

Case Study 2 Narrative: Jennifer - Novice Middle School Teacher................................... 83

Learning Environment .......................................................................................... 83

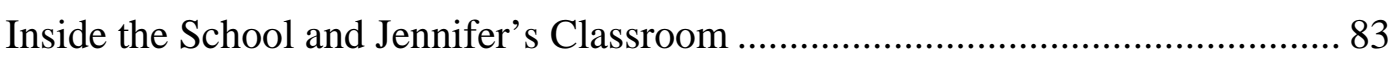

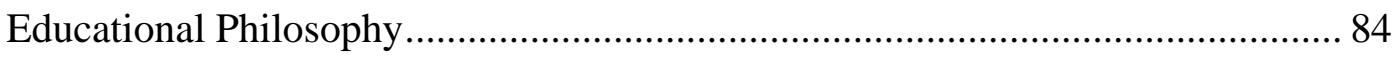

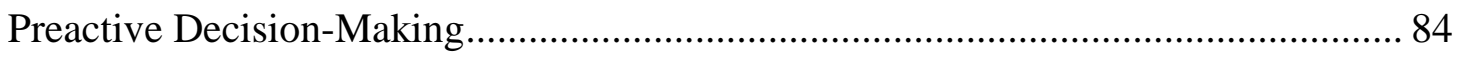

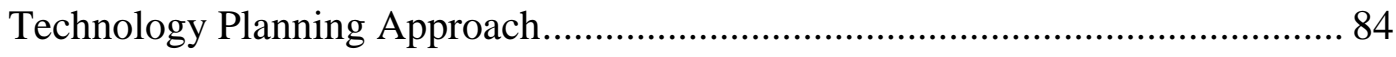

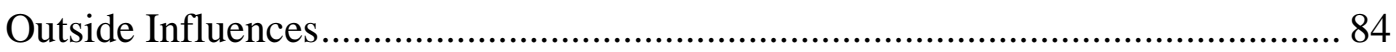

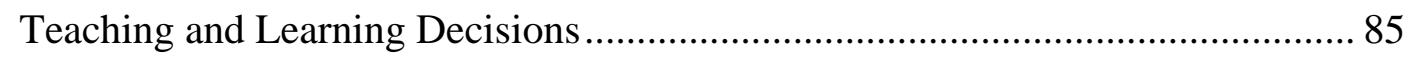

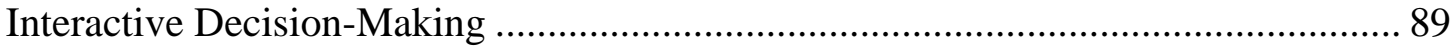

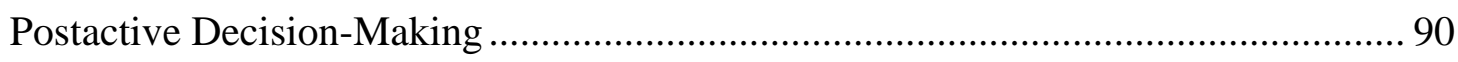

Case Study 3 Narrative: Kristi - Novice High School Teacher .......................................... 95

Learning Environment .......................................................................................... 95

Inside the School and Kristi’s Classroom ............................................................... 95

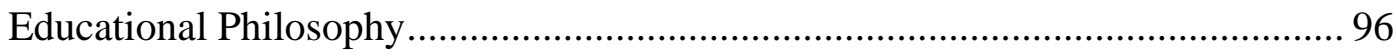

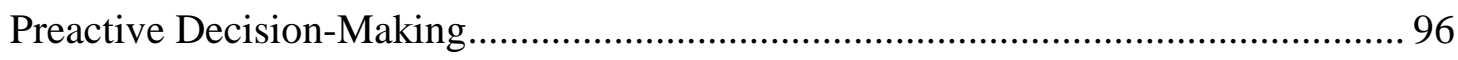

Technology Planning Approach........................................................................... 96

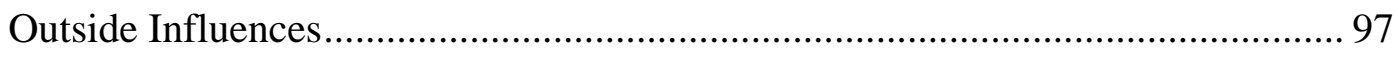

Teaching and Learning Decisions ......................................................................... 97

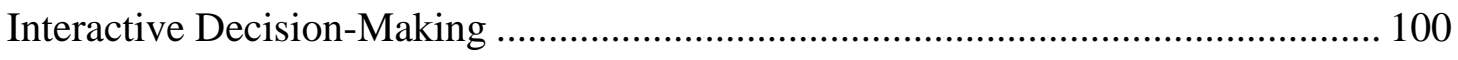

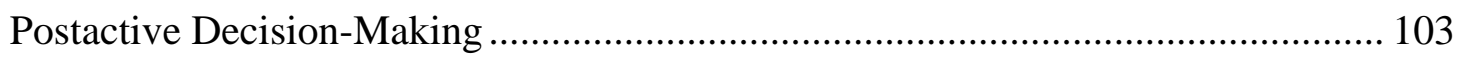


Novice Teachers’ Descriptive Code Analysis ................................................................. 107

Same Decisions within the Preactive Phase ……………………………………….... 108

Same Decisions within the Three Phases....................................................................... 109

Teacher Specific Decisions.................................................................................. 110

Novice Teachers’ Pattern Code Analysis ........................................................................ 116

Summary of Novice Teachers’ Decision-Making ........................................................... 118

Within-Case Analysis of Experienced Teachers...................................................................... 121

Case Study 4 Narrative: Derk - Experienced Elementary/Middle School Teacher........ 121

Learning Environment ..................................................................................... 122

Inside the School and Derk’s Classroom ............................................................ 122

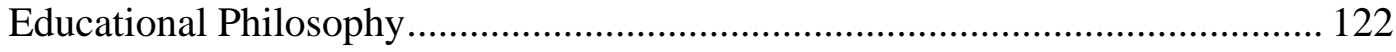

Preactive Decision-Making...................................................................................... 122

Technology Planning Approach........................................................................ 122

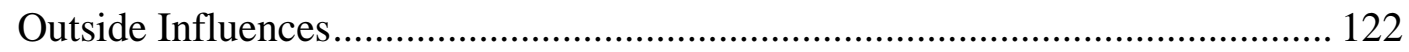

Teaching and Learning Decisions .................................................................... 123

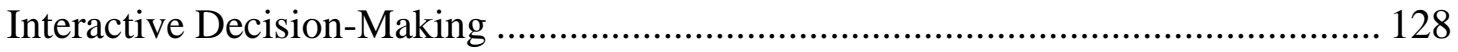

Postactive Decision-Making .................................................................................... 129

Case Study 5 Narrative: Georgia - Experienced Elementary/Middle School Teacher ... 134

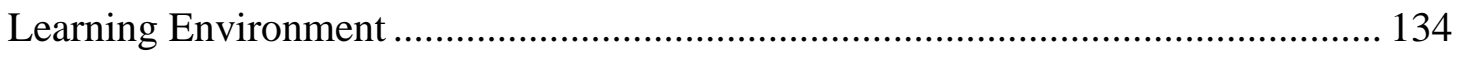

Inside the School and Georgia’s Classroom ....................................................... 134

Educational Philosophy.................................................................................... 135

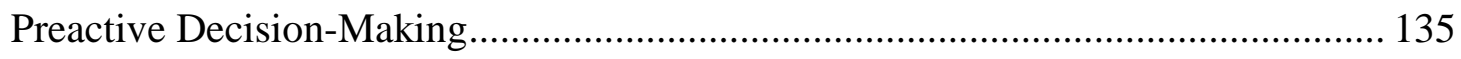

Technology Planning Approach............................................................................. 135 


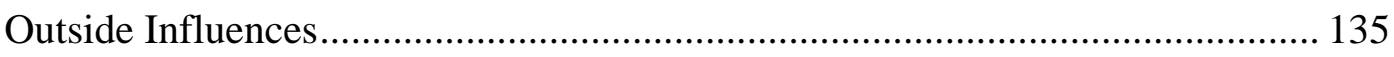

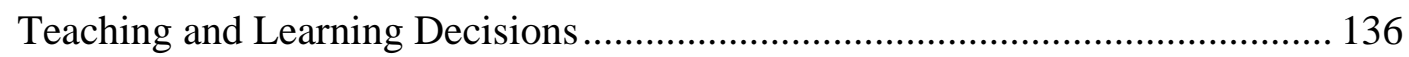

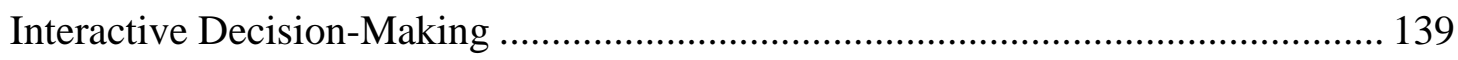

Postactive Decision-Making .................................................................................... 140

Case Study 6 Narrative: Frieda - Experienced High School Teacher............................... 150

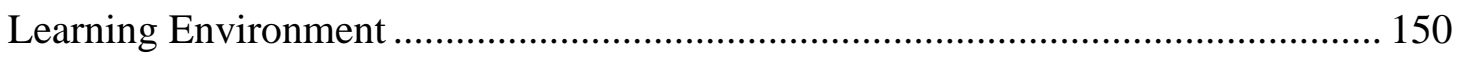

Inside the School and Frieda's Classroom ........................................................... 150

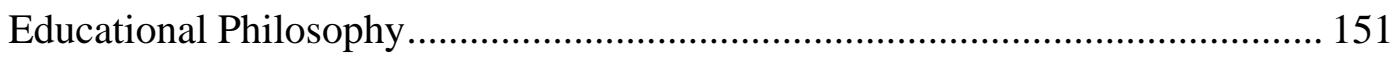

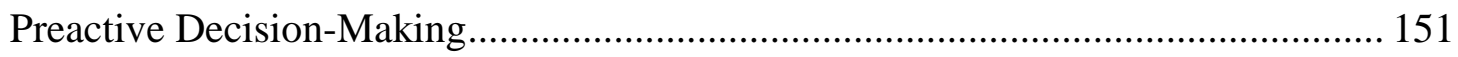

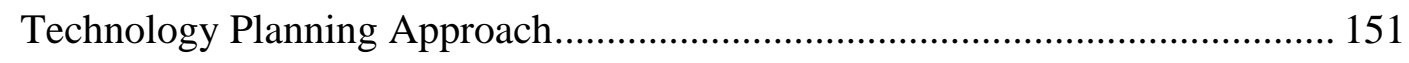

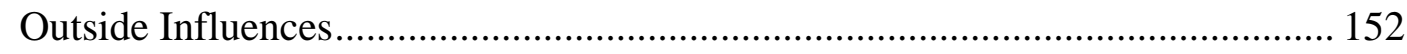

Teaching and Learning Decisions ........................................................................ 152

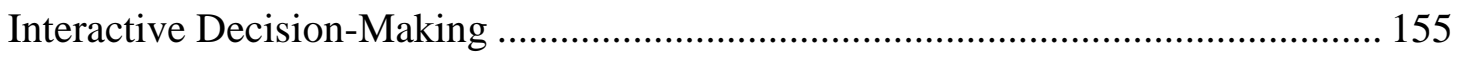

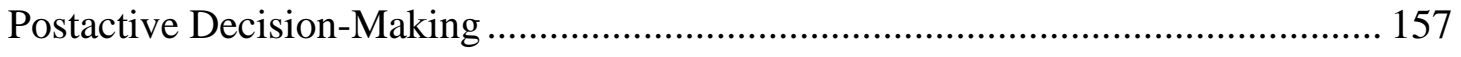

Experienced Teachers’ Descriptive Code Analysis............................................................ 164

Same Decisions within the Preactive Phase ………………………………………... 165

Same Decisions within the Interactive Phase ……………………………………... 167

Same Decisions within the Postactive Phase ................................................................... 168

Same Decisions within the Three Phases................................................................... 168

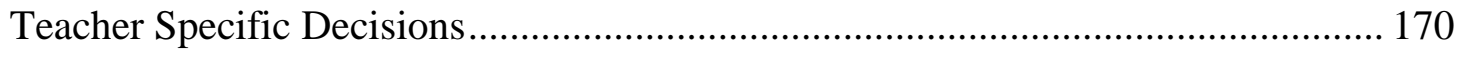

Experienced Teachers’ Pattern Code Analysis................................................................. 177

Summary of Experienced Teachers’ Decision-Making...................................................... 179

Cross-Case Analysis of Novice and Experienced Teachers..................................................... 182 
Chapter 5 - Conclusions, Implications, Limitations, and Further Research

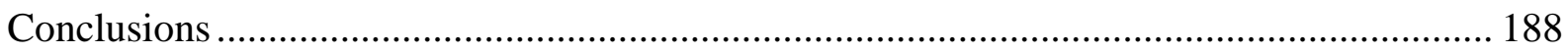

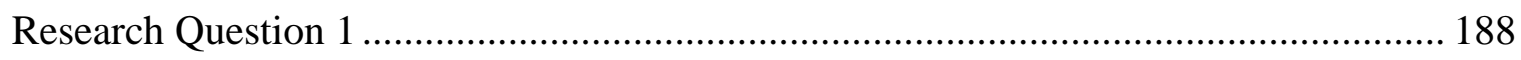

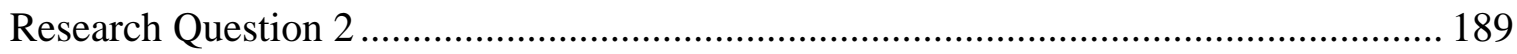

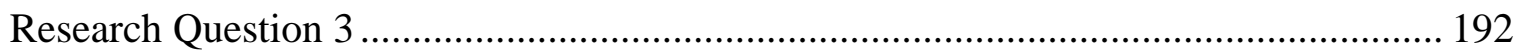

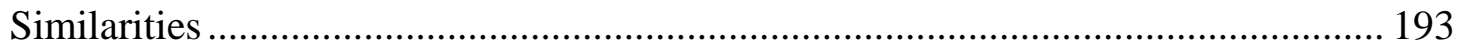

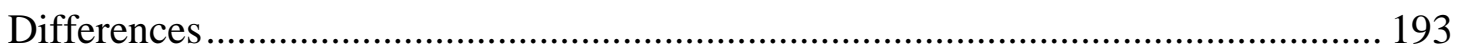

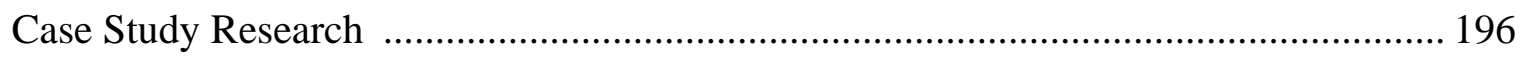

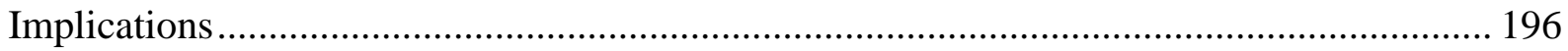

Teacher Education and Professional Development.......................................................... 197

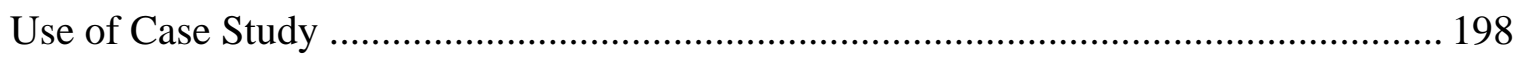

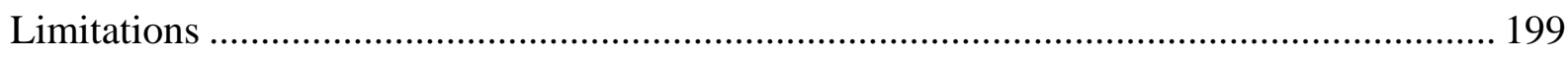

Researcher and Participants...................................................................................... 199

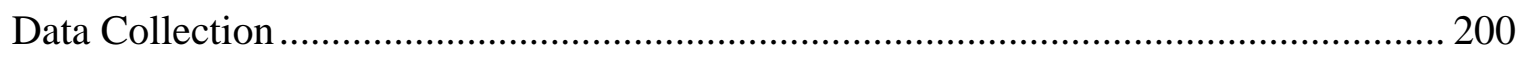

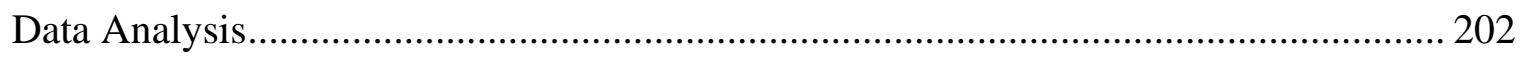

Further Research ............................................................................................................... 202

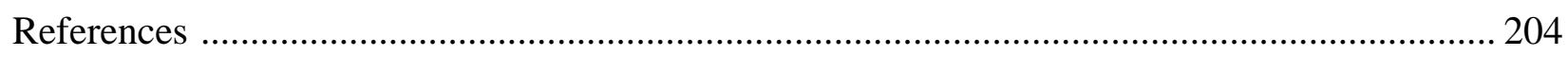

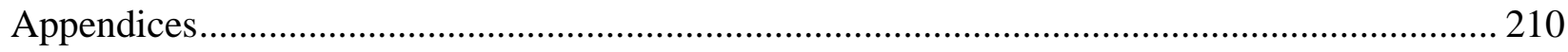

Appendix A - Letter to Teachers .................................................................................. 210

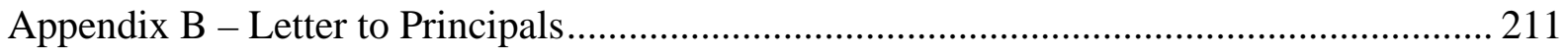

Appendix C - Initial Interview Protocol ............................................................................... 212

Appendix D - Observation Guide................................................................................. 213

Appendix E - Exit Interview Protocol ................................................................................. 214 
Appendix F - Descriptive and Pattern Codes Representing Novice Teachers’ Decision-

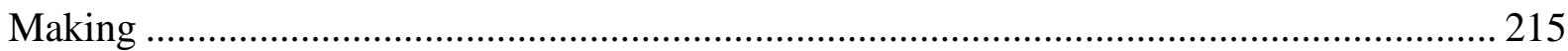
Appendix G - Descriptive and Pattern Codes Representing Experienced Teachers’ Decision-

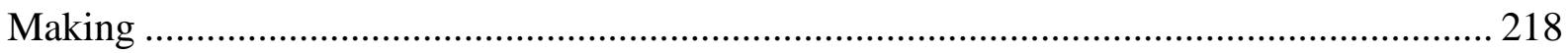

Appendix H - Descriptive Codes and Definitions for Novice and Experienced Teachers .... 221 


\section{LIST OF TABLES}

Table 1 Participants and Data Sources ............................................................................ 42

Table 2 Case Study Data Management Chart .................................................................. 49

Table 3 Data Sources and Method of Within-Case Analysis................................................ 56

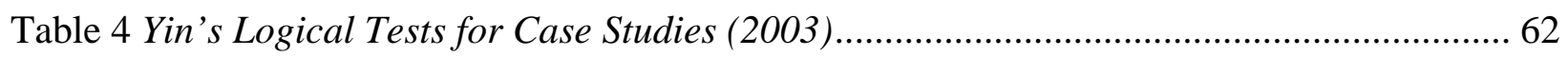

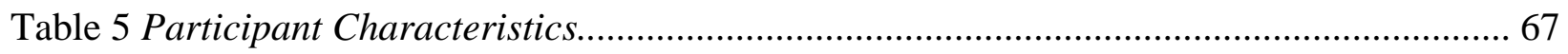

Table 6 Case 1: Descriptive Codes for Preactive, Interactive, and Postactive Instructional

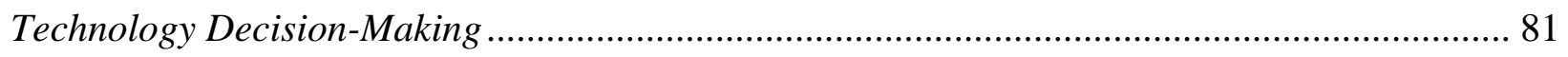

Table 7 Case 2: Descriptive Codes for Preactive, Interactive, and Postactive Instructional

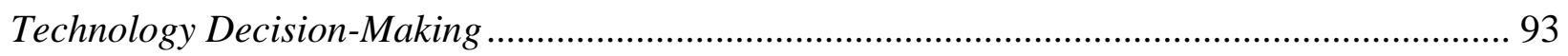

Table 8 Case 3: Descriptive Codes for Preactive, Interactive, and Postactive Instructional

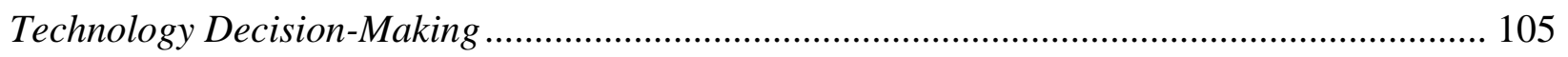

Table 9 Summary of Teacher Specific Decisions for Novice Teachers .................................. 111

Table 10 Summary of Novice Teachers Decision-Making.................................................... 119

Table 11 Case 4: Descriptive Codes for Preactive, Interactive, and Postactive Instructional

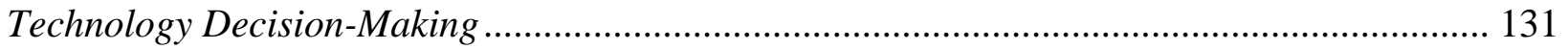

Table 12 Case 5: Descriptive Codes for Preactive, Interactive, and Postactive Instructional

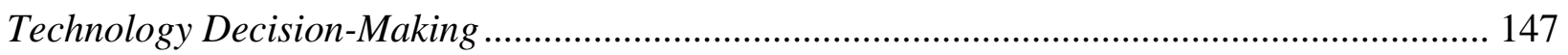

Table 13 Case 6: Descriptive Codes for Preactive, Interactive, and Postactive Instructional

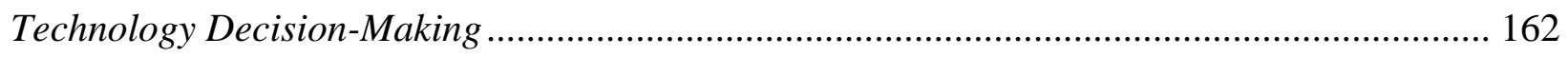

Table 14 Summary of Teacher Specific Decisions for Experienced Teachers .......................... 171

Table 15 Summary of Experienced Teachers Decision-Making ........................................... 180

Table 16 Summary of Novice and Experienced Teachers Decision-Making............................ 182 


\section{LIST OF FIGURES}

Figure 1. Data Source Collection Timeline .......................................................................... 41

Figure 2. Within-Case Data Analysis and Reduction for Research Question 1........................ 52

Figure 3. Cross-Case Data Analysis and Reduction for Research Question 3.......................... 53

Figure 4. Within-Case Data Analysis and Reduction for Novice Teachers ............................... 70

Figure 5. Descriptive Code Decisions Made by Novice Teachers .......................................... 115

Figure 6. Pattern Code Decisions Made by Novice Teachers ............................................... 117

Figure 7. Descriptive Code Decisions Made by Experienced Teachers ................................. 176

Figure 8. Pattern Code Decisions Made by Experienced Teachers....................................... 178 


\section{CHAPTER ONE - INTRODUCTION}

Many forms of technology, ranging from pencils and paper, to books, radio, television, and computers, have been used in education. Since the advent of film in the 1920s, education has been attracted by the promise and potential of technologies (Kent \& McNergney, 1999). In the 1950s, television was viewed as the technology that would transform teaching and learning. Computers assumed this role in the 1980s.

Whereas belief in the possibilities of film and television to reinvent education faded, hopes remain strong, despite those who perceive this to be another fad, for computer-based communications to advance education. Sustained interest in the use of technology in education is due to the permeation of computers throughout society and their impact on culture and the workforce. Society that was once referred to as industrial has evolved into an information society, where the goal of education is no longer as much about acquiring skills as it is about helping learners develop the ability to think (Bransford, Brown, \& Cocking, 2000). Computers and information technologies can transform education because of the capacity for communicating with people throughout the world, in a sense expanding the walls of the classroom without leaving the school.

The impact of technology on society and culture is reflected in initiatives and resources dedicated to developing the use of technology in education (Loveless, 2000). For example, the mission of the United States Department of Education Office of Educational Technology (OET), housed within the Office of the Secretary of Education, is to maximize the contribution of technology to improving education and to develop and implement national educational technology policy (Retrieved June 14, 2005, from http://www.ed.gov/about/offices/list/os/ technology/index.html). 
In 1996, under the initiative of President Clinton and Vice President Gore, the OET released the first national educational technology plan. Titled Getting Students Ready for the $21^{\text {st }}$ Century: Meeting the Technology Literacy Challenge, the goal was to provide resources necessary for teachers to use technology to increase student learning, including up-to-date computers with Internet connections in every classroom, software and on-line curriculum, and professional development and support (Retrieved June 14, 2005, from http://www.ed.gov/ about/offices/list/os/technology/ plan/national/index.html).

Four years later, the national educational technology plan was revisited with the intent of revising and moving beyond the initial goals. The 2000 national educational technology plan, $e$ Learning: Putting a World-Class Education at the Fingertips of All Children, listed goals for effectively using technology in education (Retrieved June 14, 2005, from http://www.ed.gov/ about/offices/list/os/technology/ reports/e-learning.html):

- Teachers will use technology to increase academic standards

- Students will have technology and information literacy skills

- $\quad$ Research and evaluation will be used to improve the next generation of teaching and learning technology applications

- Teaching and learning will be transformed by digital content and network applications.

The No Child Left Behind (NCLB) Act of 2001 required the Secretary of Education to develop a third national education technology plan, with the goal of researching and disseminating the use of technology to improve student academic achievement (Retrieved June 14, 2005, from http://www.ed.gov/news/pressreleases/2003/05/05232003.html). Released in January 2005, Toward a New Golden Age in American Education: How the Internet, the Law 
and Today's Students are Revolutionizing Expectations, this latest national educational technology plan recommends seven steps to better prepare students to use technologies: 1) strengthen leadership, 2) consider innovative budgeting, 3) improve teacher training, 4) support e-learning and virtual schools, 5) encourage broadband access, 6) move toward digital content, and 7) integrate data systems (Retrieved June 14, 2005, from http://www.ed.gov/about/ offices/list/os/technology/ plan/2004/index.html).

The educational reform efforts addressed above, which are national in scope, fostered development of initiatives designed to accomplish the integration of technologies into learning. Emergent from these reform efforts have been funding, research, and organizations to support the use of technology in learning and teaching.

Funding initiatives at the national level included the United States Department of Education's Preparing Tomorrow's Teachers to Use Technology (PT3) program. Developed in 1999, PT3 was to address the challenge of changing the way future teachers learn in order to meet the demand for teachers prepared to educate 21st century learners (Retrieved November 28, 2004, from http://www.pt3.org/). State and Local Technology Grants designed to support the use of instructional technology in the classrooms formerly existed within Title II of the No Child Left Behind Act.

Organizational efforts include the International Society for Technology in Education (ISTE), a nonprofit, worldwide professional organization whose members include current and potential leaders in educational technology. ISTE is dedicated to improving teaching and learning through the effective integration of technology in schools and teacher education (Retrieved November 28, 2004, from http://iste.org/). ISTE has developed National Educational Technology Standards (NETS) for current teachers, future teachers, students, and administrators, 
which are designed to "guide educational leaders in recognizing and addressing the essential conditions for effective use of technology to support Pre K-12 education.”

The National Council for Accreditation of Teacher Education (NCATE), official organization for accreditation of teacher preparation programs, has adopted and integrated ISTE recommendations and NETS into NCATE standards, which are the foundation for quality teacher preparation. The National Board for Professional Teaching Standards (NBPTS) integrates technology as part of their expectations for exemplary teaching and learning.

Numerous states have adopted NETS into their curriculum standards. Counties have developed technology integration plans and funded positions dedicated to the use of technology in learning and teaching. Schools have established technology plans and professional development opportunities designed to help teachers use instructional technologies to promote learning.

The Problem

Instructional technology (IT) is a term commonly used in educational literature but does not have a mutually agreed upon definition. The Association for Educational Communications and Technology (AECT) definition of instructional technology is "the theory and practice of design, development, utilization, management, and evaluation of processes and resources for learning” (Retrieved November 10, 2004 from http://www.aect-members.org/standards/ knowledgebase.html). This definition of instructional technology refers not only to the tool, but also to the way these tools are designed into instruction to promote learning. For the purposes of this study, this definition of IT was used and the research participants determined specific instructional technologies studied. 
Teachers' use of instructional technologies (ITs) has been studied from various perspectives. Research on the instructional use of technologies in K-12 initially focused on the impact of technologies on student achievement to determine if the investment of resources was worthwhile. Research into teachers' use of technology often occurs outside the classroom, with surveys used as a means of gathering information about technologies available to teachers, which ones they use, and factors that influence their choice of technologies. Visionaries have written about the potential of technology to transform learning.

Missing from research on instructional technology (IT) are experiences of practicing teachers. Teacher preparation and professional development should be grounded in issues of learning with technologies (Loveless, 2000), where the focus is on using ITs to support pedagogy as opposed to just learning technical skills. Also missing is an extensive body of literature that looks at teaching with technology from inside the classroom and from teachers' perspectives. A substantial body of research exists on teacher decision-making, but what is lacking is evidence and insight into teachers' decisions when designing instruction that uses ITs (Loveless).

Teachers in K-12 often do not perceive research on teaching to be of value because of the disconnect between research and practice (Bransford et al., 2000; Bruer, 1993; Riel (2000); Shulman, 1992). This division is often the result of researchers' agendas differing from educators' interests. Riel indicates that teaching and research on teaching have not been closely aligned and teachers typically do not have time to contribute their knowledge, which often results in researchers answering questions that are not useful to teachers. Educators' interests lie in the application of study design within the dynamic environment of the classroom (Bransford et 
al.). Another reason for the gap between theory and practice is that language used by researchers usually differs from the language of educators (Bransford et al.).

To bridge the gap between theory and practice, practicing K-12 teachers and researchers could work together to conduct investigations so both parties contribute to the research agenda. Bruer (1993) indicates that the gap between research and practice can occur only with close professional collaboration between researchers and classroom teachers. Collaborative research design is also beneficial in that it can reveal teachers' knowledge and experiences within the dynamics of the classroom.

\section{Need for the Study}

Collectively the body of research on ITs has revealed "what" has influenced teachers to use technologies and “which” technologies they use. Investigations into ITs have not explored "how" and "why” teachers make decisions about teaching with technologies.

Arguments exist that teaching is too complex to study because teachers make countless numbers of decisions every day and to investigate this phenomenon is too involved. Opponents also state that studying teachers’ cognitive processes cannot be accurate because it is difficult for teachers to articulate their decision-making. However, there is a substantial body of literature on teachers' decision-making that provides evidence to the contrary.

Shulman (1992) portrays teachers as professionals who are knowledgeable and able to communicate their teaching decisions to others. Bransford et al. (2000) found that "researchers are discovering ways to learn from the wisdom of practice that comes from successful teachers who share their expertise.” Clark and Lampert (1986) discuss how research on teacher thinking has broadened and deepened knowledge about the complexity of teaching and about what teachers know, along with knowledge of methods of inquiry and reflection on teacher thinking. 
Learning why and how teachers teach as they do will help us to better understand learning and teaching (Bruer, 1993). Knowing more about learning and teaching is critical for successful education of teachers. In his review of research in teacher education, Zeichner (1999) found many investigations into learning and teaching were limited by data that reported what students and teachers do, but not how and why they do what they do. Without knowing how and why teachers do what they do, a disconnect exists between what pre-service and in-service teachers need to know and to do and the information collected in research studies. Shulman (1986) states that research is only half way toward understanding the knowledge base of teaching. We need to investigate strategic pedagogical knowledge because this will help to extend understanding beyond theory and add to the wisdom of practice.

How do we learn from teachers who are good at what they do? The intent of educational researchers who study teachers' thinking, planning, and decision-making is to describe how and why teachers do what they do (Clark \& Peterson, 1986). Cognitive research can describe teachers’ implicit knowledge so that it becomes explicit. Bruer (1993) believes that if we can describe expert practices explicitly, we can incorporate them into teacher training programs.

Purpose of the Study

The purpose of this research was to better understand novice and experienced public school teachers' decision-making in the use of instructional technology. This study was not designed as yet another investigation into what instructional technologies teachers use and what influenced their use, but rather it focused on teachers’ decision-making to promote students’ learning and the role of instructional technologies in the process. 


\section{Research Questions}

Three major questions guided the design of this study:

Research Question 1: How do novice elementary, middle, and high school teachers make instructional technology decisions?

Research Question 2: How do experienced elementary, middle, and high school teachers make instructional technology decisions?

Research Question 3: What are the similarities and differences between how novice and experienced elementary, middle, and high school teachers make instructional technology decisions?

\section{Significance of the Study}

There is a substantial body of knowledge about teacher decision-making with respect to Shulman’s (1986) domains of content or subject matter knowledge, pedagogical content knowledge, contextual knowledge, and curricular knowledge. In addition to contributing to the existing body of knowledge about teacher decision-making, this study provides information about how and why teachers use instructional technologies to promote student learning. A body of literature does not exist that provides information about teachers’ pedagogical knowledge of instructional technology.

Studying teacher decision-making in the use of instructional technology has merit for inservice teachers, pre-service teachers, and teacher educators because it provides insight into the lives of teachers (Clark \& Lampert, 1986). Looking at teaching and teachers’ decision-making through the eyes of practitioners can encourage current and future teachers and teacher educators to think about their teaching and how they design instruction to promote student learning. This type of study encourages teachers to be analytical and reflective. Clark and Lampert reported 
that teachers who participated in studies of their decision-making said that the process of reflection influenced the way they taught. Thinking about teaching is an approach to professional development because reflection results in teachers changing and improving their practice (Bransford et al., 2000; Lancy, 1993).

This study also contributes detailed descriptions of teaching from the perspectives of practitioners, which can provide a framework for teachers and teacher educators to decide what information, advice, and support will be of use in the classroom (Clark \& Lampert, 1986).

Effective use of technology, where it improves learning opportunities for students, is not something that occurs by chance. Looking into teaching with technology through the eyes of reflective practitioners can provide insight into the process for other teachers. This insight can contribute to the design of professional development for practicing teachers as well as teacher education programs for future teachers and the university faculty who teach in these programs.

\section{Summary}

Chapter one provides a history of technology in education to show that the educational community has a history of activity on the subject, and that the use of instructional technologies in the classroom will continue to expand. Information is provided on the body of knowledge about teacher decision-making, the body of knowledge about instructional technologies, and gaps in the literature.

Chapter two reviews scholarly research in which this study is grounded, including research on teaching from a historical perspective, teachers' knowledge, teachers' decisionmaking, novice and experienced teachers, and use of instructional technologies. Also reviewed are methods of inquiry that have been used to study teachers’ decision-making, novice and experienced teachers, and the use of instructional technology by teachers. 
Chapter three details the methodology for this study, including methodological framework and research strategy, which describes the researcher and participants and elaborates on data source collection, management, and analysis procedures for each of the research questions. Trustworthiness of the research design is also discussed, followed by limitations of the study.

Chapter four describes teachers who participated in this research, provides an overview of the data analysis procedure, and presents the findings. Within-case analysis of novice teachers is presented first, followed by within-case analysis of experienced teachers. This data analysis chapter concludes with a cross-case analysis of novice and experienced teachers.

Chapter five discusses conclusions regarding novice and experienced public school teachers’ decision-making in the use of instructional technology. Implications are also discussed, followed by limitations of this study and suggestions for further research. 


\section{CHAPTER TWO - REVIEW OF LITERATURE}

Consider the following scenario: The K-12 teachers pack their materials and resources after they complete another professional development session on instructional technologies (ITs). As they walk toward their cars, conversation reveals frustration in learning technical aspects of technologies but not understanding the pedagogical value. They see and hear of colleagues who use ITs to promote student learning, but they do not know how and why other educators use technologies. Meanwhile, students in a teacher education program are attending their “Technology in Teaching” course, learning how to use computers and the Internet, handheld computers, and digital cameras, but are not thinking about the use of these technologies in teaching.

These scenarios are common and emphasize the growing concern about the use of technology for education. Knowing the "how-to" of technologies does not always correlate with using them to promote student learning. A need exists to learn from teachers who use technologies to enhance learning. How and why do they decide to use ITs? Describing decisionmaking with regard to pedagogical instructional technology knowledge will provide "food for thought” for pre-service and in-service teachers who are beginning to explore the use of technology in education.

The purpose of this research is to better understand novice and experienced public school teachers' decision-making in the use of instructional technologies. The review of literature is organized as follows: 
- Research on Teaching

- History

- Teachers' Knowledge

- Teachers' Decision-making

- Novice and Experienced Teachers

- Teachers' Use of Instructional Technologies

- Methods of Inquiry

- Case study method

- Interviews

- Observations

- Stimulated recall

- Documents

Research on Teaching

History

Studies of teaching initially focused on what Shulman (1992) refers to as "process-

product" research, where the intent was to investigate how teachers' actions and behaviors were related to student achievement. Teachers' behaviors and students actions were measured (Westerman, 1991) in a behaviorist manner and teaching was perceived as an independent phenomenon, where the context was not considered. This behaviorist model did not account for teachers' behaviors as related to their goals, thinking, and decision-making (Shavelson \& Stern, 1981).

In 1968 a paradigm shift in research on teaching began (Shulman, 1992; Westerman, 1991) when Philip Jackson (1968) studied teachers' thinking with the intent of being able to describe the complexity of the teaching process (Clark \& Peterson, 1986). Teachers were beginning to be viewed as "knowers" and "thinkers" and experts about their students and classrooms (Cochran-Smith, \& Lytle, 1999).

Teaching is very dynamic and complex (Bransford et al., 2000; Clark \& Lampert, 1986; Parker \& Gehrke, 1986; Riel, 2000). Teachers, especially those who enjoy their chosen 
profession and are invested in the success of their students, are mentally exhausted at the end of the day because of the dynamics of their teaching environment and the thinking and decisionmaking they undertake. Riel describes teachers as continuous learners and researchers. Shulman (1992) explains that investigations into teachers' cognitive processes began to reveal information about the complex nature of teachers' thinking, planning, problem solving, and decision-making.

Another change in research in teaching occurred in the early 1980s when instead of research being conducted on teachers, research was starting to be conducted with teachers. University researchers began to collaboratively investigate teaching with practicing K-12 teachers (Cochran-Smith, \& Lytle, 1999). Findings were being reported using an emic approach, or being true to the perspective of those being studied (Patton, 2002) by reconstructing the world of the teachers (Shulman, 1992) and including their voices (Patton), as opposed to the etic or outside approach (Patton) that reported information entirely from the perspectives of researchers (Shulman).

An accompanying shift in research methods occurred. Teaching was once studied using quantitative instruments, but was now being studied as more of a social science. Qualitative methods of inquiry, such as interviews and observations, were being implemented, along with mixed methods approaches.

The next shift in research on teaching evolved when Shulman (1986) realized that teachers' knowledge had to be studied in order to find out what teachers know and how they teach it so that learners understand.

\section{Teachers' Knowledge}

Subject matter knowledge, also referred to as content knowledge, is used to describe what teachers know and understand about the subjects they teach (Bruer, 1993; Leinhardt \& 
Greeno, 1986; Shulman, 1986). For example, in order to teach math, teachers must possess knowledge of math content and understand math concepts. Teachers must also understand which content, facts, and concepts are worth knowing and how math relates to other subject matter (Shulman).

In addition to subject matter knowledge or content knowledge, teachers possess other types of knowledge, which researchers have classified as pedagogical content knowledge (Bruer, 1993; Clark \& Lampert, 1986; Leinhardt \& Greeno, 1986; Shulman, 1986), contextual knowledge (Clark \& Lampert), and curricular knowledge (Shulman).

Shulman (1986) and Bruer (1993) explain that teachers not only know how to teach the subject, but also know which aspects are necessary for learners' future comprehension of the content. Bruer and Shulman refer to the process and strategies, where teachers make subject matter understandable to learners, as pedagogical content knowledge. Pedagogical content knowledge also includes teachers’ insight into learners, which topics are easy to teach, and which topics are more challenging to teach (Bruer; Shulman).

Realizing that teaching is not an independent phenomenon, but is influenced by the culture and context of the environment, researchers began to investigate teachers' contextual knowledge. As described by Clark and Lampert (1986), contextual knowledge is specific to the setting in which teaching occurs. The setting includes the physical and social environment (Shavelson \& Stern, 1981), where physical surroundings include not only the teacher's classroom but also the entire school. The social environment refers to teachers' interactions with and observations of students in order to assess learning (Clark \& Lampert).

Curricular knowledge is defined by Shulman (1986) as information that teachers know about curriculum and accompanying materials available for use. Shulman believed that teachers 
know the curriculum materials for the subjects they are teaching, are knowledgeable about other curricula students will encounter during the school year, and are familiar with curricula students faced in previous years and will experience in the future.

\section{Teachers’ Decision-Making}

Knowledge of subject matter, pedagogy, context, and curriculum helps teachers to think through alternatives, weigh options, consider benefits and drawbacks, and make decisions about what to teach, where, when, why, and how (Shulman, 1986). Teachers' decision-making is based on numerous factors embedded within their knowledge of subject matter, pedagogy, context, and curriculum:

- Student assessment - information about students, such as ability (Berliner, 1994;

Leinhardt \& Greeno, 1986; Kysilka, Geary, \& Schepise, 2002; Sardo-Brown, 1990), classroom behavior, and work habits, based on school data, discussions with other teachers, and their own observations (Shavelson \& Stern, 1981)

- Instructional goals - goals and objectives for an instructional task (Shavelson \& Stern, 1981)

- Educational beliefs (Shavelson \& Stern, 1981)

- Subject matter - conceptions of subject matter and models for teaching the subject (Leinhardt \& Greeno, 1986; Shavelson \& Stern, 1981)

- Contextual knowledge - such as textbooks, worksheets, standardized tests, curriculum guides, physical environment, social environment (Berliner, 1994; Kysilka, Geary, \& Schepise, 2002; Sardo-Brown, 1990; Shavelson \& Stern, 1981)

- Interactive decision-making - lesson structure and flow of activities during a lesson (Berliner, 1994; Leinhardt \& Greeno, 1986; Sardo-Brown, 1990) 
- Interruptions (Sardo-Brown, 1990)

- Timeframe for teaching (Kysilka, Geary, \& Schepise, 2002; Leinhardt \& Greeno, 1986)

Shavelson and Stern’s 1981 review of research on teachers' cognition was based on the assumption that teachers' behavior affected their thoughts, judgments, and decisions. Clark and Peterson (1986) found that teachers' thought processes and actions have a reciprocal effect where teachers' actions are shaped by their decision-making and planning, and their actions in turn influence their decision-making and planning.

Teachers’ decision-making and thinking can be considered in more detail by looking at phases of teaching. Based on their analysis of research on teachers' thinking, Clark and Peterson (1986) categorized phases of teachers’ decision-making as:

- $\quad$ Preactive - prior to teaching;

- Interactive - during teaching; and

- $\quad$ Postactive - following teaching.

\section{Preactive Decision-Making}

The preactive phase of teaching, also referred to as the planning phase, occurs when a teacher decides the content, or what is to be taught, and pedagogy, or how to teach it. While planning, teachers are thinking about goals and objectives, activities, assessment, teaching strategies, and timeframe (Kysilka, Geary, \& Schepise, 2002). During the preactive phase, teachers’ decisions are influenced by numerous factors, such as curriculum standards, administrative policies and expectations, and technology mandates. Students' abilities and needs are of great consideration and teachers must decide how to create learning opportunities for 
diverse learners (Kysilka et al.) so that students who need to be challenged are not bored and students who need more time and effort are not left behind.

Researchers have examined preactive decision-making from the aspect of what teachers think about and what they actually do because planning is both a psychological and a practical process (Clark \& Peterson, 1986). In their review of literature on teachers’ preactive decisionmaking, Clark and Peterson discovered teachers' preactive decision-making ranges from longterm to short-term, from planning for the academic year to developing weekly and daily plans, including unit and lesson plans. They also reported that details are often excluded in written plans but are part of teachers' mental preparation. Preactive decision-making determines the general approach to teaching a unit or lesson, but what actually occurs in the classroom determines the details. Learning and teaching that occurs usually varies from the original plan because of teachers’ interactive decision-making.

\section{Interactive Decision-Making}

Interactive is the term used to describe decisions teachers' make during teaching, which is distinctly different from decision-making prior to and after teaching (Parker \& Gehrke, 1986). The interactive phase is the one where teachers have the least control (Kysilka et al., 2002) because teaching is a complex endeavor that occurs in a dynamic environment, requiring cognitive processing of numerous factors at once (Clark \& Lampert, 1986; Leinhardt \& Greeno, 1986; see also Kysilka et al.; Parker \& Gehrke, 1986; Riel, 2000). Teachers never know what will happen while teaching. Will the students learn within the designated timeframe? Will activities have to be modified because learning is not occurring as was envisioned? Actual instruction usually varies from planned instruction because teachers decide to alter their lessons based on student reactions, time, or dynamics of the environment. 
Teachers make decisions throughout the school day as they interact with students; observing and assessing, and determining whether to follow their lesson plans as originally developed or make modifications based on students' learning. While teaching, teachers quickly evaluate options and make decisions on how to proceed in the event of an interruption, which is referred to as “reflection-in-action.” Schön (1987) describes “reflection-in-action” as what a teacher does when he/she pauses in the middle of an action to think. Reflection while teaching is often triggered by an element of surprise, such as an interruption, or when an element of a lesson does not go according to plan. Reflections and decisions made during the interactive phase affect teaching plans for the rest of the day, the next day, the next week, and even further into the future (Clark \& Lampert, 1986; Schön).

\section{Postactive Decision-Making}

The postactive phase occurs when teachers' reflect upon and assess the effectiveness of their teaching. Thinking about events during the lesson and observations of student actions and behavior, along with looking at students’ work, are strategies used by teachers to decide if learning went well (Kysilka et al., 2002). Feedback from students, whether informal or formal, gathered as formative assessment during the lesson or summative assessment at the conclusion, also impacts teachers’ postactive decisions.

Clark and Peterson (1986) reported that preactive and postactive phases often blend together, where decisions made by teachers following instruction are often implemented within or become the preactive planning for future lessons. “Reflection-on-action” is Schön’s (1987) phrase used to describe when teachers think back on their teaching, and their reflection on the past is used to inform their decisions for the future. 


\section{Novice and Experienced Teachers}

Investigations into differences between novice and expert K-12 teachers began when researchers realized teachers’ decision-making was influenced by subject matter, pedagogical, contextual, and curricular knowledge, all of which vary depending upon teaching experience.

Studies comparing and contrasting novice and experienced or novice and expert teachers reported that differences exist in their decision-making. In the literature reviewed, experienced teachers were those who usually had greater than five years of teaching experience, but quite often had more than twenty years of teaching experience. Expert teachers are referred to as those who are considered to be exemplary at their profession. The reasoning behind investigations into novice, experienced, and expert teachers is that there is much to learn from teachers who share their knowledge (Bransford et al., 2000) and clearly communicate how and why they do what they do (Shulman, 1986).

Looking across these studies, the most frequently discussed difference between novice and experienced or expert teachers, regardless of preactive, interactive, or postactive phase, pertained to student assessment. Experienced and expert teachers’ biggest concern at all phases of teaching was for students and their abilities, learning styles, and learning comprehension (Berliner, 1994; Fogarty, Wang, \& Creek, 1983; Hogan, Rabinowitz, \& Craven, 2003; Leinhardt \& Greeno, 1986; Sardo-Brown, 1990; Westerman, 1991). Experienced and expert teachers constantly assessed students as individuals (Berliner; Hogan et al.) and made changes to plans (Berliner; Bransford et al., 2000; Fogarty et al.; Leinhardt \& Greeno; Sardo-Brown). Novices were less concerned with abilities and comprehension of individual students, but considered the achievements of the class as a whole (Hogan et al., 2003). Sardo-Brown found that experienced teachers assessed students at all levels (yearly, term, unit, weekly, and daily) of planning. 
Bransford et al. described expert teachers who assessed their effectiveness with their students by reflecting on their teaching as well as students' learning. Westerman found that during planning, expert teachers made decisions about learning tasks by thinking about them from the perspective of the students.

Another characteristic of student assessment that was constantly considered in the decision-making of experienced and expert teachers was awareness of students' prior knowledge and helping students to make the connection between prior knowledge and new knowledge (Fogarty, Wang, \& Creek, 1983; Hogan et al., 2003; Leinhardt \& Greeno, 1986; Sardo-Brown, 1990; Westerman, 1991). Novices were not aware of what students already knew (Fogarty et al.) nor did they attempt to tie previous knowledge together with new knowledge. Experienced and expert teachers often began lessons with a review and questioning of students' knowledge on the subject matter (Leinhardt \& Greeno, 1986).

Awareness of students’ existing knowledge was also based on experienced and expert teachers' familiarity with the curriculum. Novices planned each lesson without consideration for overall curriculum because they were not yet familiar with what students learned previously and what they would be learning in the future (Westerman, 1991).

Decision-making with regard to planning was quite different between novice and experienced teachers. Expert teachers were able to see the bigger picture and plan long-term where information gained during the interactive phase contributed to the postactive and preactive phases. In contrast, planning by novices was more short-term (Hogan et al.) and sequential, where one lesson was taught, then another, without worrying about transitions between lessons (Westerman, 1991). 
Sardo-Brown (1990) examined the planning phase of experienced elementary and secondary teachers and found that decisions about the upcoming year included content and objectives. Planning for the term focused on selection of units to meet the content. When planning a unit, experienced teachers' decisions were based on instructional methods and sequencing and scheduling of content. Scheduling issues and time allotment were considered for weekly planning, along with pacing of instruction and dealing with interruptions. Specific activities, instructional materials, and teaching methods were thought about during daily planning.

Curriculum guidelines played a role in the decision-making of all teachers regardless of experience level. Differences did exist in how closely teachers adhered to the curriculum. Novices tended to follow the curriculum literally, where experts used curriculum guidelines to accomplish what was expected, but also found ways of interpreting objectives and making the instruction their own (Westerman, 1991).

Lessons of novices were followed according to plan (Westerman, 1991). Experienced and expert teachers always had contingency plans (Westerman) and adjusted plans when necessary (Bransford et al., 2000; Leinhardt \& Greeno, 1986). Hogan et al. (2003) found that experts had many teaching strategies and activities to draw upon if a student needed an alternative method of learning. When planning lessons, novices usually created written and mental details or scripts (Hogan et al.) but written lesson plans usually did not reflect the entire plan (Clark \& Peterson, 1986) and novices did not have any predictions about how learning would occur. Expert teachers did not have their plans in writing, but did have a mental picture of lessons, including ideas about how the lesson would transpire (Westerman). Leinhardt and Greeno found that experts constructed lessons around a core of activities, which usually 
consisted of presentations, reviews of information, focused discussions, guided practice, group work, and independent work. They also found that experts transitioned from presentation to guided practice, whereas novices usually went from presentation to practice without any guidance. Experienced teachers reported that unit planning was very important, with lesson planning being considerably less significant (Clark \& Peterson).

A pronounced difference in the decision-making between novice, experienced, and expert teachers was management of student behavior during the interactive phase of teaching. Expert teachers established rules, routines, and classroom management protocol (Berliner, 1994), but when necessary, expert teachers brought disruptive students back to the lesson tactfully and quickly, whereas novice teachers initially ignored students who were distracting and then often responded by reprimanding (Fogarty et al., 1983; Westerman, 1991).

During the interactive or teaching phase, Fogarty et al. (1983) found that experienced teachers were able to attend to almost everything that was happening in their classrooms. Westerman (1991) found experts to be very attuned to students' behavior and able to anticipate what to do if anyone was getting restless or losing focus.

Overall it is obvious that experienced teachers know their subject matter, pedagogy, context, and curriculum. This knowledge guides their cognition as they design instruction (Berliner, 1994; Bransford et al., 2000); however, it is interesting to note that when faced with unfamiliar content or subject matter, experts were found to behave more like novices (Hogan et al., 2003).

The synthesis of research on teaching, teachers' knowledge, teachers' decision-making, and novice and experienced teachers reveals what has been studied and learned from educators 
and how they make decisions. Research on the use of instructional technologies as learning tools and associated decision-making by teachers will now be examined.

\section{Teachers' Use of Instructional Technologies}

When the word "technology" is used, most people think of recent innovations such as computers, handheld computers, digital cameras, and cell phones. The term technology is much broader and includes not only the tool, but also the system or process for using it and the science behind its development (Anglin, 1995). Technology in education incorporates the use of media and tools in the learning process. Specific media and tools include books, paper, pencils, and pens, as well as electronic technologies such as overhead projectors and digital technologies such as computers. Regardless of the form, technology is just another tool (Kysilka et al., 2002) that can be used in education.

Instructional technology (IT) is a term commonly used in literature but does not have a mutually agreed upon definition. Initially the definition of instructional technology focused on the use of instructional media such as textbooks, pictures, film, and video. Leaders in the field then began to recognize it as a process in which people, procedures, and devices were used to solve learning problems (Reiser \& Dempsey, 2002). The Association for Educational Communications and Technology (AECT) has invested years of effort into defining the evolving field of instructional technology. The AECT definition of instructional technology is "the theory and practice of design, development, utilization, management, and evaluation of processes and resources for learning” (Retrieved October 26, 2005 from http://www.aect.org/standards/ knowledgebase.html). Instructional technology does not refer to the tool only, but the way these tools are designed into instruction to promote learning. 
Media and tools should not be used simply because of expectations from administration. Technologies should not be used as digital babysitters to give some students something to do while others are working with the teacher, or where students are "rewarded" with time on the computer. The danger exists for teachers to use technologies for mundane tasks, such as using word processing to transfer handwritten work to printed copy (Somekh \& Davis, 1997), instead of using this specific tool to improve writing. Using technologies should not drive the curriculum (Kysilka et al., 2002).

The potential of instructional technologies is in creating learning opportunities and activities that could not be accomplished as easily without technologies (Gillespie, 1998; Harris, 1997) or could not be accomplished at all (Gillespie; Harris; Shambaugh \& Magliaro, 2006;

Somekh \& Davis, 1997). Gillespie suggests that teachers think about how they can use ITs to support the learning they want to occur. While designing instruction, the focus should be on pedagogy and using the appropriate activities and tools to promote learning. Shambaugh \& Magliaro suggest teachers ask the following questions to help them make clear decisions:

1. What will students learn?

2. How will you know if students learned?

3. How will you assist students to learn?

4. How will technology help students to learn?

5. How will technology help to rethink each of these decisions?

If a chosen technology will not help students to learn, then it should not be used. Shambaugh and Magliaro (2006) indicate the purpose of media and technology is to help students to learn and therefore should support learning outcomes. As teachers use technology, 
they should evaluate their teaching and assess students' learning to determine if technology was effective in helping students to meet these objectives (Kysilka et al., 2002).

Instructional technology is believed to have potential for improving access to information and promoting collaborative learning (Bransford et al., 2000; Riel, 2000). Visionaries write about the possibility of technology being a catalyst to transform learning (Loveless, 2000), where learning is student-centered as opposed to teacher-centered; learning of skills is replaced by challenging students to think at a higher level; and the walls of the classroom are expanded via computer-based communications where learners work collaboratively with other students as well as experts on authentic, real-world projects (Somekh \& Davis, 1997). These visions are not yet reflected in the pedagogy of most teachers (Loveless).

Researchers have been investigating the instructional use of technologies with the intent of using the findings in teacher education programs for pre-service teachers and professional development for in-service teachers and university faculty in teacher education programs. However, a disconnect exists between theory and practice. Vignettes of exemplary instructional technology use by teachers are abundant in the literature (Loveless, 2000). These studies of teachers who use technologies to promote learning are often showcased in teacher education programs and professional development for teachers, but the focus often turns to developing skills in using the technologies as opposed to exploring possibilities for effectively integrating technologies into pedagogy. The existence of instructional technologies and awareness of applications in education alone do not promote use by teachers (Loveless).

Given the amount of resources invested at national and state levels to promote the use of instructional technologies, concerns exist about the slow rate of adoption by teachers (Zhao \& Frank, 2003). In their investigation into factors affecting the use of technology in schools, Zhao 
and Frank found that the use of newer technologies, such as computers, is shaped by the teaching context. For example, English teachers were most likely to use computers because they found word processing to be a natural tool for students to use while writing. Zhao and Frank's study also revealed teachers who received help from their colleagues and those who perceived computers to be compatible with their teaching style were more likely to use computers with their students.

Numerous investigations have been conducted on what technologies teachers use, when they use them, and how often they use them. What is lacking is evidence and insight into how teachers design instruction that uses technology (Loveless, 2000; Zhao \& Frank, 2003). Teacher preparation and continuing education should be grounded in issues of learning with technologies (Loveless), where the focus is on using these tools to support pedagogy, as opposed to learning technical skills. Research into teachers' use of technology often occurs outside the classroom, with surveys used to gather information about what technologies are available to teachers, which ones they use, and what factors influence their choice of technologies. Professional development for teachers is often designed based on the work of visionaries who foresee the potential of technology to transform learning, as opposed to the experiences of practicing teachers. What does not exist is an extensive body of literature that looks at teaching with technology from the inside outward and investigates decisions made by educators as to how and why they use technology.

\section{Methods of Inquiry}

Studying teachers' decision-making requires collaboration and communication between participants and researcher. To convey why specific technologies are chosen and how they are used for learning, teachers must be able to communicate the thinking behind their decisions. The 
challenge to the researcher is to design a methodology to capture valid information from teachers’ about their decision-making (Clark \& Peterson, 1986). Looking at investigations into teachers’ cognition and decision-making, it is apparent that qualitative methods and data collection strategies are dominant.

Looking at the history of research on teaching, it is clear that investigations of teachers outside of their classrooms removes the context. Studying teachers within their context is critical because as Bransford et al. (2000) explain, a person’s cognition and competencies are supported by the context. Teaching is not an independent phenomenon but is influenced by environmental and social context, which can be accommodated using qualitative research because it is intended to study humans within their natural environment (Patton, 2002; Yin, 2003).

In addition to studying teachers in their classrooms, qualitative research immerses the researcher, who functions as the data collection instrument, into the teachers’ world. Qualitative research also allows for inclusion of participants' perspectives, emergent design, inductive data analysis, and reflexivity (Hatch, 2002). Participant perspectives are important when studying teachers' decision-making because the goal is to understand and describe this phenomenon through their eyes and with their words. Having a preconceived plan for investigating teachers’ decision-making is important because it functions as a guideline, but allowing the design to emerge is essential because as the study progresses, the researcher and participants will consider improved means of collecting data. Induction during data analysis is necessary because there are no hypotheses in qualitative research, and data should not be synthesized into pre-existing categories. Reflection is critical for tracking the researcher's biases and influence on the participants (Hatch). 
Utilization of various sources of inquiry is an approach that has been implemented by investigations into teachers' cognitive processes because one source of data does not provide enough information (Clark \& Peterson, 1986). Methods and strategies that have been used to investigate teachers’ decision-making include:

- case study method

- interviews

- observations

- $\quad$ stimulated recall

- documents

- $\quad$ surveys

The case study method and specific data collection strategies are described below along with associated advantages, disadvantages, and approaches to data analysis.

\section{Case Study}

Investigations into “what”, “when”, “where”, “how many” and "how much” typically are designed to control a variable for experimental or correlational research, can be examined using a positivist or quantitative approach (Yin, 2003), and do not support studies in teachers’ decision-making that are descriptive. Studying teaching and teacher decision-making is complex because teaching itself is complex and requires methodology that allows for comprehensive investigation into the phenomenon. Yin finds that case studies are preferred when "how" or “why” questions are being posed, when the investigator has little control over what occurs, and when the focus is on a phenomenon within real-life context. Case study research is designed to investigate "how" and "why” a phenomenon occurs (Yin), making the case study method a natural approach to learning more about teachers’ decision-making. 
A major goal of research on teacher thought processes is to increase understanding of the process of teaching and how and why it looks and works as it does (Clark \& Peterson, 1986). To investigate how and why teachers use technology in their teaching, the appropriate method must be utilized. As Yin (2003) states, researching "how" can be accomplished through the case study. Yin (2003) describes the case study strategy for conducting research as utilizing multiple sources of evidence, where data need "to converge in a triangulating fashion." The phrase "case study" is often associated with qualitative research and sometimes mistakenly used as a synonym. In reality, case studies can consist entirely of quantitative or qualitative data or mixed methods. In the research reviewed for this study, qualitative data collection strategies and sources were selected for learning about teachers’ decision-making.

\section{Interviews}

The purpose of interviews is to gain insight into teachers' perspective (Patton, 2002). Interviews are frequently employed in investigations into teacher decision-making (Clark \& Peterson, 1986; Lancy, 1993), because the questions can be designed to focus on how teachers accomplish what they do (Fontana \& Frey, 2000). Interviews usually are used as a primary data source in combination with other sources of information, and data from interviews is transcribed prior to analysis. Transcriptions are printed and used for analysis procedures. An interview is typically a formal discussion between participant and researcher. Informal conversations are also used in qualitative research. In a study of novice teachers, Shulman (1996) used interviews and informal conversations when asking teachers to comment on materials related to the subject they teach. Questions for interviews must be open-ended and carefully designed. Leading questions, which entice a person to respond in a certain way, and questions that require multiple answers 
should be avoided (Merriam, 1998). Open-ended questions are those that cannot be answered with a no or yes response, but require detailed feedback.

Sardo-Brown (1990) interviewed participants after they completed questionnaires, using the data from the questionnaires to guide the open-ended questions during interviews. When interviews were conducted, teachers were asked to elaborate upon their responses to the questionnaires so that details about their decision-making in the planning phase could be captured.

Westerman (1991) used preactive and postactive interviews. Questions for preactive interviews included "Where do you start when planning a lesson?” and "How do you use your plans during teaching?” During postactive interviews, Westerman asked questions such as, "Did you gain information while teaching that you will use in planning future lessons?”

\section{Observations}

Observations, like interviews, are commonly used in studies designed to investigate teachers' decision-making. Observations are useful in studying teachers because the researcher enters the world of the teacher (Patton, 2002) and learns about the social and physical environment of the classroom and school (Merriam, 1998). Patton explains that understanding the context in which the teacher functions is important because it provides a holistic perspective and allows the researcher to reduce biases by reducing prior conceptions and to be more open to discovery.

During observations the researcher uses field notes to record information about the physical environment, participants, activities, interactions, conversations, routine occurrences, and interruptions (Merriam, 1998). The researcher also should be aware of his/her behavior and record this information. Brackets must be used to separate the researcher's thoughts and 
questions from actual observations and occurrences. Observation guides help to ensure the same types of information are collected for all participants.

Immediately following an observation the researcher should go to a quiet place and write down anything he/she did not have time to record during the observation and also record additional thoughts and questions. Field notes from observations, along with accompanying observation guides, initially exist in the handwriting of the researcher. The researcher must then revisit the field notes and create another, cleaner set. The field notes are then ready for analysis, which can be conducted with the revised set of field notes or a transcription.

Leinhardt and Greeno (1986) used classroom observations, conducted over a period of three and one half months, as their primary source of data. Field notes and videotapes were used to capture data from observations. Interviews, both prior to and following the observed lessons, were conducted to collect more information. Stimulated recall, referencing content of the videotapes, was used during the interviews. Field notes, videotapes, and interviews were transcribed for analysis.

Shulman (1988) finds that observations are often disappointing because they do not reveal in-depth information about teaching. He believes that observations do not reach their potential due to unqualified observers and lack of depth. Observations alone do not provide sufficient data and should only be used with other data sources.

\section{Stimulated Recall}

In their review of methods of inquiry into teacher decision-making, Clark and Peterson (1986) explain that the purpose of stimulated recall is to encourage teachers to recall and talk about their thoughts and decision-making that occurred while teaching. The process involves audio- or video-taping the teacher while teaching and then playing back the tape to encourage 
detailed descriptions of teachers' decision-making. Either the researcher can play the entire tape (or specific portions), or control for playing the tape can belong to the teacher (Clark \& Peterson). Westerman (1991) suggests that stimulated recall be used with an interview closely following teaching, and that the teacher be reminded that a postactive interview, where he/she will be encouraged to reflect, will be conducted in the future.

Parker and Gehrke (1986) used stimulated recall during interviews to learn about teachers' interactive decision-making. Each teacher taught a lesson of choice which was captured on audiotape. Within forty-eight hours, each teacher was interviewed about the lesson he/she taught, using the audiotape for stimulated recall. Teachers controlled playback of the audiotape and stopped the tape when they arrived at a part where they recalled making a decision. They then talked about their decision, guided by probing questions from the researcher when necessary.

\section{Documents}

Documentation is a rich source of information (Patton, 2002) that can be used in case studies and exists in many different forms. Documents can include teachers’ lesson plans, journals, student work, memos and guidelines from administration, and statewide and national curriculum standards and objectives. Documentation adds value to a study if it exists in its entirety. Lesson plans of teachers are often incomplete or do not exist at all in written form but as a mental plan. The challenge to the researcher becomes capturing the lesson plan verbally. 


\section{CHAPTER THREE - METHODOLOGY}

The purpose of this research is to better understand novice and experienced public school teachers' decision-making in the use of instructional technology. This chapter describes the research framework to answer the following questions:

Research Question 1: How do novice elementary, middle, and high school teachers make instructional technology decisions?

Research Question 2: How do experienced elementary, middle, and high school teachers make instructional technology decisions?

Research Question 3: What are the similarities and differences between how novice and experienced elementary, middle, and high school teachers make instructional technology decisions?

Chapter 3 begins with an explanation of the methodological framework, followed by the research strategy, which describes the researcher and participants and then elaborates on data sources, collection, management, and analysis procedures for each of the research questions. Trustworthiness of the research design is discussed, and then the chapter concludes with limitations of the study.

\section{Methodological Framework Overview \\ Case Study and Teacher Decision-Making}

Studying teaching and teacher decision-making is complex and requires methodological approaches that allow for a comprehensive investigation into this phenomenon (Yin, 2003). One approach to conducting research into teaching and teacher decision-making is to use the case study method, which is used to investigate "how" or "why" people do what they do. In this 
investigation, case studies were used to examine teachers' decision-making with regard to their use of instructional technologies (ITs).

A multiple case study framework was used to describe novice and experienced teachers' decision-making involving the use of instructional technology. The cases involve novice and experienced teachers at the elementary, middle, and high school levels of instruction. The description of teacher decisions was based on Clark and Peterson's (1986) view of teaching as preactive, interactive, and postactive. The terminology "preactive, interactive, and postactive" characterizes teachers' thinking in three steps: prior to teaching, during teaching, and after teaching.

- Prior to teaching/Preactive. The preactive process is defined as a planning process that teachers go through prior to teaching a lesson. Teachers’ planning for lessons may provide insight into how they make instructional technology decisions.

- During teaching/Interactive. What teachers actually do while teaching may differ from the intent of their lesson plans. Describing the actions of teachers while they are teaching may improve understanding of how teachers make instructional technology decisions.

- After teaching/Postactive. Teachers' reflections might reveal information about their actual teaching of a lesson as well as their planning for future teaching. Asking teachers to talk about what they believe went well, why they made changes during the teaching process, and revisions they plan to make may help to describe their instructional technology decision-making. 


\section{Researcher and Participants}

\section{Researcher}

As the researcher in this study, I am a graduate student working on a doctorate in Technology Education with a focus on instructional design and technology. My interest in investigating teachers’ decision-making stems from my experiences working with pre-service and in-service teachers.

For over seventeen years my work involved designing instruction and teaching workshops for faculty, staff, and students to learn to use computers and various software programs, along with providing ongoing support. Leaving my full-time job to work as a graduate assistant in the College of Human Resources and Education enabled me to focus on my education and transition from helping others gain technology skills to helping current and future educators learn to use technology to promote student learning.

In my first graduate assistantship, I invested four years working for a United States Department of Education Preparing Tomorrow's Teachers to use Technology (PT3) grant. My primary responsibilities were designing and coordinating professional development for preservice teachers, in-service teachers, and higher education faculty to learn to use technology in teaching and learning. Since completing the PT3 grant, I have been working as a Graduate Assistant for the Benedum Collaborative, which comprises the five-year teacher education program at West Virginia University (WVU). My responsibilities continue to include instructional design and support for pre-service, in-service, and higher education teachers to learn to use technology to enhance learning. As a graduate assistant I am also involved in the development of the Instructional Technology Plan for the five-year teacher education program. This plan is being designed collaboratively to help teacher education students learn how to use 
technology in teaching through their experiences with their public school host teachers and their courses at WVU.

From working with educators and reading literature pertaining to instructional technology, I have noticed a) investigations into teachers' use of technology have occurred from the outside looking in, primarily using surveys to gather information about what technologies teachers use and what factors influence their choice of technologies; and b) professional development for teachers is often designed based on the work of visionaries who foresee the potential of technology to transform learning, as opposed to the experiences of practicing teachers. What I have not encountered is an extensive body of literature that looks at teaching with technology from inside the classroom and that investigates decisions made by educators as to how and why they use technology.

A great deal can be learned from spending time with teachers in their classrooms. Realizing that I could relate better to K-12 teachers if I improved my understanding of their world, I designed three independent study opportunities within my doctoral coursework where I spent a year and a half in elementary schools. The experience provided the opportunity to learn from teachers by observing, assisting, discussing, and questioning.

In addition to my work experience, qualitative course work and qualitative research provided a knowledge base to draw upon as I designed this method of investigating how teachers make decisions in using instructional technology. Taking qualitative courses, assisting with the teaching of a qualitative course, and working on qualitative and mixed methods research projects with a faculty member who has a strong education and extensive background in qualitative research provided experience in designing interview protocols, conducting individual interviews and focus groups, performing observations, and analyzing documents. 


\section{Participants}

Participants for this study included novice and experienced public school teachers selected from twenty-eight Professional Development Schools (PDSs) in North Central West Virginia. The teachers in these PDSs, along with their principals, county superintendents, and faculty at West Virginia University (WVU), are partners in the Benedum Collaborative Model of Teacher Education at WVU. Selecting teachers from these professional development schools provided access to a population of participants I have worked with for nearly six years.

Teachers who were invited to participate in this study were purposefully selected based on their use of instructional technology to promote student learning. Purposeful sampling is a qualitative design strategy that allows for insight into a phenomenon rather than studying a large size sample to generalize from sample to population (Patton, 2002). Limiting sample size allowed me to spend more time with and study in depth each teacher's decision-making in the use of instructional technology.

Criterion sampling, a type of sampling in qualitative research that contributes to quality assurance (Patton, 2002), was used to guide the selection of participants. A total of six participants were selected for this study based on the following predetermined criteria:

- All six participants taught in one of the Benedum Collaborative's twenty-eight professional development schools

- All six participants used technology to promote student learning

- Three of the participants had fewer than three years teaching experience (novice teachers)

- Three of the participants had more than three years teaching experience (experienced teachers) 
- One novice taught at the elementary school level

- One novice taught at the middle school level

- One novice and one experienced teacher taught at the high school level

- Two experienced teachers taught at the elementary/middle school level

Initial plans were to study one novice and one experienced teacher at each of the instructional levels, but the researcher decided to include two teachers who taught at combined elementary/middle schools. These teachers were purposefully selected because of their years of experience using technology in their classrooms and helping their peers to use it as well.

For this study, a novice was defined as a public school teacher with fewer than three years of teaching experience. An experienced teacher was defined as a public school teacher who taught for more than three years. Both the state of West Virginia and the National Board for Professional Teaching Standards (NBPTS) use three years' minimum teaching experience in a pre-K12 setting to differentiate novice and experienced preK-12 teachers (National Board for Professional Teaching Standards, 2004). Selecting participants with varying teaching experience and from three different grade levels provided access to teachers' decision-making across levels of expertise and instruction.

Purposeful selection of participants occurred using the following procedure:

1. The researcher discussed the list of participant criteria with the Coordinator of Clinical Experiences for the Benedum Collaborative. Based on these criteria and her experiences working with teachers in the Professional Development Schools, the Coordinator of Clinical Experiences provided names of one or two novice and experienced teachers at the elementary, middle, and high school levels. 
2. When the Coordinator of Clinical Experiences provided more than one name for a particular experience level and grade level, the researcher contacted the first person whose name was mentioned. All potential participants were initially contacted via telephone. During the telephone conversation with a potential participant, the researcher introduced herself, provided a brief overview of her dissertation research, and then asked teachers about their use of technology to design lessons with the intent of improving student learning, as opposed to using technology primarily for administrative and classroom management purposes. If the first prospective candidate contacted met the criteria for the study, the researcher asked that teacher if he or she would be interested in participating. If the teacher declined to participate, the researcher contacted the next teacher listed for that particular experience level and grade level. If another teacher had not been listed, the researcher asked the Coordinator of Clinical Experiences to suggest another potential participant.

3. While speaking on the telephone, the researcher and each teacher who agreed to participate scheduled an initial meeting. The initial meetings, where the researcher met the teachers at their schools, were designed to establish rapport between the researcher and participants, provide further details about the study, answer participants' questions, and request the written consent of each principal. The researcher provided both the participants and principals with verbal and written details (see Appendices A and B) of the study explaining the purpose, timeline, teachers' role, data sources, data collection procedures, and data analysis. 


\section{Research Strategy}

A research strategy was planned, but flexibility was maintained because the design evolved as data were collected. Emergent design is accepted within qualitative research because of its naturalistic and inductive nature (Merriam, 1998; Patton, 2002). Studying participants within their natural settings, combined with the researcher gaining insight into the phenomenon as the research progresses, render it impossible to completely determine the strategy in advance of data collection (Patton).

\section{Timeline for Data Collection}

Figure 1 represents data sources and the data collection timeframe. Initially, data collection was to occur across one grading period, which would have been nine weeks for all six participants. The intended timeline for data collection could not be adhered to because teachers had to modify their schedules and lesson plans due to factors beyond their control, such as snow delays and closings, preparation for yearly standardized testing, and unscheduled school assemblies. This in turn affected the researcher's plans, making collection of sufficient data impossible in nine weeks. As a result, each teacher consented to participate for longer than one grading period.

Instead of gathering data across one grading period, collection began in February 2005 and concluded when the researcher gathered sufficient information, which was at the end of April for two participants, the beginning of May for one participant, the end of May for another participant, and the beginning of June for two participants. 


\begin{tabular}{|c|c|c|c|c|}
\hline \multirow[t]{2}{*}{ Data Source } & \multicolumn{4}{|c|}{ Year of 2005} \\
\hline & February & April & May & June \\
\hline \multicolumn{5}{|l|}{ Initial Interview } \\
\hline \multicolumn{5}{|l|}{$\approx$ Lesson Plans } \\
\hline \multicolumn{5}{|l|}{ Technology Mandates } \\
\hline \multicolumn{5}{|l|}{ Student Work } \\
\hline \multicolumn{5}{|l|}{ Teacher Journals } \\
\hline \multicolumn{5}{|l|}{$\begin{array}{ll}\begin{array}{l}\text { Revised Lesson } \\
\text { Plans }\end{array} \\
\end{array}$} \\
\hline \multicolumn{5}{|l|}{ Observations } \\
\hline \multicolumn{5}{|l|}{ Informal Conversations } \\
\hline Exit Interview & & & & \\
\hline
\end{tabular}

Figure 1. Data source collection timeline.

* Journals did not exist for any of the 6 teachers.

Initial interviews for all six participants were completed in February. Observations and informal conversations were conducted throughout the time spent with each teacher. Lesson plans, student work, and revised lesson plans were referred to throughout the data collection period. Technology mandates were discussed during interviews. Teacher journals were planned as part of data collection, but were not used because the participants did not keep journals. Exit interviews occurred in April, May, and June, depending on when the researcher determined adequate data had been collected for each teacher.

\section{Data Sources and Data Collection Procedure}

Data sources were collected from each participant (see Table 1) to answer Research Question one (How do novice elementary, middle, and high school teachers make instructional technology decisions?) and Research Question two (How do experienced elementary, middle, and high school teachers make instructional technology decisions?). 
Selection of data sources for investigating teachers' decision-making in the use of instructional technology was based on:

1. Relevance of the data to describe novice and experienced public school teachers’ decisions in the use of instructional technology;

2. Connection of the data to the research questions; and

3. The experience and ability of the researcher in collecting and analyzing these types of data.

Table 1

Participants and Data Sources

\begin{tabular}{|c|c|c|c|c|c|c|c|c|c|c|c|c|}
\hline \multirow[b]{3}{*}{ Participant } & & & & \multicolumn{9}{|c|}{ Data Source } \\
\hline & & & & \multicolumn{4}{|c|}{ Primary Sources } & \multicolumn{5}{|c|}{$\begin{array}{c}\text { Secondary Sources: } \\
\text { Documentation }\end{array}$} \\
\hline & \multicolumn{3}{|c|}{$\begin{array}{c}\text { Grade Level \& } \\
\text { Decision-Making }\end{array}$} & 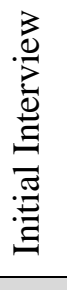 & 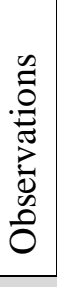 & 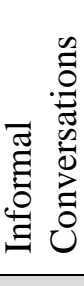 & & 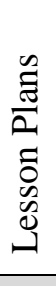 & \multirow{2}{*}{ 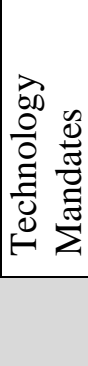 } & \multirow{2}{*}{ 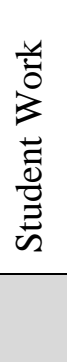 } & \multirow{2}{*}{ 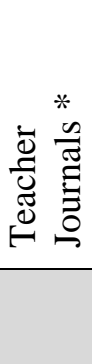 } & \multirow{2}{*}{ 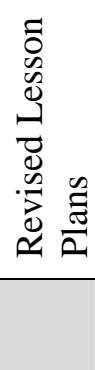 } \\
\hline $\begin{array}{l}\text { Novice } \\
\text { (3) }\end{array}$ & $\begin{array}{l}\text { Elementary } \\
\text { Case } 1\end{array}$ & $\begin{array}{l}\text { Middle } \\
\text { Case } 2\end{array}$ & $\begin{array}{l}\text { High } \\
\text { Case } 3\end{array}$ & & & & & & & & & \\
\hline \multirow{3}{*}{$\begin{array}{l}\text { Research } \\
\text { Question } 1\end{array}$} & Preactive & Preactive & Preactive & $X$ & & $\mathrm{X}$ & $\mathrm{X}$ & $\mathrm{X}$ & $\mathrm{X}$ & & NA & $\mathrm{X}$ \\
\hline & Interactive & Interactive & Interactive & & $\mathrm{X}$ & $\mathrm{X}$ & $\mathrm{X}$ & & & $\mathrm{X}$ & & \\
\hline & Postactive & Postactive & Postactive & & & $\mathrm{X}$ & $\mathrm{X}$ & & & $\mathrm{X}$ & NA & $\mathrm{X}$ \\
\hline $\begin{array}{c}\text { Experienced } \\
\text { (3) }\end{array}$ & $\begin{array}{l}\text { Elementary } \\
\text { Case } 4 \\
\end{array}$ & $\begin{array}{l}\text { Middle } \\
\text { Case } 5\end{array}$ & $\begin{array}{c}\text { High } \\
\text { Case } 6 \\
\end{array}$ & & & & & & & & & \\
\hline \multirow{3}{*}{$\begin{array}{l}\text { Research } \\
\text { Question } 2\end{array}$} & Preactive & Preactive & Preactive & $X$ & & $\mathrm{X}$ & $X$ & $X$ & $\mathrm{X}$ & & NA & $\mathrm{X}$ \\
\hline & Interactive & Interactive & Interactive & & $\mathrm{X}$ & $\mathrm{X}$ & $X$ & & & $\mathrm{X}$ & & \\
\hline & Postactive & Postactive & Postactive & & & $\mathrm{X}$ & $\mathrm{X}$ & & & $\mathrm{X}$ & NA & $\mathrm{X}$ \\
\hline
\end{tabular}

* Journals did not exist for any of the 6 teachers. 
Primary data sources included the initial interview, observations, informal conversations, and the exit interview. Documentation functioned as a secondary source of information in support of primary sources (Yin, 2003) and was valid only in combination with the main source. Documentation consisted of a range of materials that were available to the researcher, such as lesson plans, technology mandates, student work, and revised lesson plans, and were secondary sources of information (Merriam, 1998; Patton, 2002) used to corroborate evidence from the primary data sources. The documentation data also served as a stimulus to develop further inquiry within observations, informal conversations, and interviews (Patton; Yin). Each data source is elaborated upon as the data collection procedure is described.

\section{Initial Interview}

The first step in the data collection process was the initial interview. Interviews are frequently employed in case studies that investigate teacher decision-making (Clark \& Peterson, 1986; Lancy, 1993) because interviews can be designed to focus on "how" a phenomenon occurs (Fontana \& Frey, 2000). The intent of the initial interviews was to learn more about teachers' plans for the grading period, their preactive decision-making, and technology they would be using to enhance their students’ learning.

The researcher created an Initial Interview Protocol (see Appendix C) of open-ended questions that were designed to learn more about teachers’ preactive decision-making and technology they would be using when teaching. The Initial Interview Protocol was created with the same questions for each teacher to ensure the same data were obtained for all participants. The procedure for the initial interview was as follows:

1. An initial interview was scheduled between the researcher and each participant.

2. The researcher met with the teachers at their schools to conduct the initial interview. 
3. A copy of the interview protocol was provided to participants when the researcher arrived for the interview so that they could read the questions before they were asked.

4. Participants granted permission for interviews to be audiotaped. The tapes were labeled Case 1 - Case 6 so that teachers' anonymity was maintained. Following the interviews, the researcher transcribed the tapes.

5. The researcher asked about mandates at the state, county, and school level with regard to technology policies and initiatives. Awareness of mandates provided information about teachers required use of technology. The researcher used these documents as a secondary source of data, prompting teachers during interviews and informal conversations to talk about their preactive decision-making in the use of technology.

6. The researcher asked teachers if they had written lesson plans. Clark and Peterson (1986) found that research on teacher planning revealed teachers’ preparation often does not occur in written form but primarily exists as a mental plan. The researcher looked at copies of lesson plans for those teachers who had written lesson plans. The intent behind collecting and examining lesson plans was for the researcher to ask questions designed to examine teachers’ decision-making prior to teaching. Preactive decision-making data were primarily obtained through questions asked during interviews and informal conversations but were supported by lesson plans and technology mandates.

7. Biographical data for each of the six participants was collected, including educational background, years of teaching experience, grade levels and content areas taught. 
8. Teachers were asked to talk about their educational beliefs. Clark and Peterson (1986) found teachers' theories and beliefs represent knowledge they have and affect planning and interactive decisions. They also discovered that teachers develop theories and beliefs as a result of decisions made during teaching and planning.

\section{Observations}

At the conclusion of the initial interview, the participants and researcher developed a tentative plan for the researcher to visit their classrooms and conduct observations. The tentative schedule of observations was based on teacher-nominated lessons in which technology would be used. Observation dates were indefinite because while teachers knew the curriculum they would be covering, they could not always indicate exact days on which specific lessons would be taught. Teaching plans were modified throughout the data collection process according to students' progress and external influences beyond the teachers' control, requiring the researcher to remain flexible and able to shift observation dates. The researcher and participants communicated via email and telephone calls throughout the length of the study to determine exact days when the researcher would travel to the classrooms to observe lessons being taught.

Observations allowed the researcher to gather information about the classroom environment, interactive teacher decision-making, and use of technology. Observations are considered to be fundamental in social and behavioral sciences (Angrosino \& Mays de Perez, 2000), allowing the researcher to see and record information about participants in their natural setting. Observing teachers within their classrooms provided documentation of the physical environment, teacher and student actions and interactions, and occurrences during the interactive phase of teaching. Data from observations were collected using the following procedures: 
1. Prior to observing, and sometimes during observations, time permitted the teacher and researcher to discuss informally what the teacher had planned (preactive decisions) and decisions made during teaching (interactive).

2. While observing in the classroom, the researcher used an observation guide (see Appendix D) and wrote field notes consisting of detailed descriptions of the classroom, teacher, students, and their interactions. Brackets were used to offset the researcher's thoughts and questions to maintain separation from what actually occurred. The observation guide was developed by the researcher to reduce bias by ensuring similar types of data were collected for all six teachers.

3. During observations, the researcher looked at student work as a supporting source of information. Student work was not collected or analyzed by the researcher, but was referred to during informal conversations to prompt teachers to discuss their teaching decisions.

4. At the conclusion of an observation, the researcher engaged in informal conversations with the teachers. The intent of these informal conversations, based on the researcher's observations and field notes, was to inquire about interactive decisions the teachers made during the lesson and any postactive changes they planned to make in the future. On a few occasions, the teacher did not have time for informal discussions. In these circumstances, the researcher posed questions to the participant via email while the lesson was still fresh in the teacher's mind. The participants sometimes responded via email and at other times talked about the lesson when the researcher arrived for the next observation. 
5. Immediately following each observation and informal conversation, the researcher went to a quiet location and used a digital tape recorder to capture additional information. This sometimes initiated further questions that the researcher posed to the participants via email.

6. The researcher transcribed field notes and digital recordings pertaining to observations and informal conversations.

\section{Exit Interview}

After sufficient data were collected from observations and informal conversations to provide insight into teachers' interactive decision-making, an exit interview was scheduled. The purpose of the exit interview was to engage teachers' recollection of their decisions during teaching (Clark \& Peterson, 1986) in order to capture more interactive data as well as discuss postactive decisions pertaining to lesson plan changes.

The researcher created the Exit Interview Protocol (see Appendix E). Questions were open-ended and designed with the intent of capturing data pertinent to interactive and postactive decision-making by prompting teachers to reflect upon decision-making during and after the lesson. Since reflection and post-teaching decisions guide teachers’ revisions and plans for future teaching (Clark and Peterson), the exit interview also collected information about teachers’ preactive decisions.

The procedure for the exit interview was as follows:

1. An initial interview was scheduled between the researcher and each participant.

2. The researcher met with the teachers at their schools to conduct the exit interview.

3. A copy of the interview protocol was provided to participants when the researcher arrived for the interview so that they could read the questions before they were asked. 
4. Participants granted permission for interviews to be audiotaped, The tapes were labeled Case 1 - Case 6 so that teachers’ anonymity was maintained. Following the interviews, the researcher transcribed the tapes.

5. The researcher asked teachers if they had revised lesson plans. All teachers indicated that they thought about revisions they were going to make to lessons, but only one teacher had written revisions, existing in the form of notes written on her original lesson plans. The intent behind looking at revised lesson plans was to prompt teachers' to talk about their postactive decision-making. Postactive decision-making data for those without written, revised lesson plans were obtained through questions asked during informal conversations and the exit interview.

6. The researcher asked the teachers if they kept a journal. One of the teachers kept a journal, but it was not up-to-date. Had the teachers maintained journals, the researcher would have referred to them to prompt teachers to talk about preactive and postactive decisions they made.

\section{Data Management}

Well-planned management of data not only serves the purpose of organizing data for analysis, but also increases reliability of the case study method (Yin, 2003). The data were managed using a database, case study chart, and data source notebooks.

\section{Database and Case Study Chart}

A computerized case study database was used to track the collection of the data sources for each participant. The database fields consisted of participant code (Case 1 - Case 6), data source, collection date, and researcher notes. Information in the database was sorted by data source or by participant code, revealing if data were missing for any of the participants. A 
corresponding case study data management chart (see Table 2) was created and printed from the database, which provided a paper copy of the data management process.

Table 2

Case Study Data Management Chart

\begin{tabular}{|c|c|c|c|}
\hline \multirow{4}{*}{ Data Source } & $\begin{array}{c}\text { Participant } \\
\text { Code }\end{array}$ & $\begin{array}{c}\text { Date } \\
\text { Collected }\end{array}$ & Researcher Notes \\
\hline \multirow{4}{*}{ Initial Interview } & Case 1 & & \\
\hline & - & & \\
\hline & Case 6 & & \\
\hline \multirow{4}{*}{ Lesson Plans } & Case 1 & & \\
\hline & - & & \\
\hline & Case 6 & & \\
\hline \multirow{4}{*}{ Student Work } & Case 1 & & \\
\hline & - & & \\
\hline & Case 6 & & \\
\hline Revised Lesson Plans & Case 1 & & \\
\hline & - & & \\
\hline & Case 6 & & \\
\hline Observations \& & Case 1 & & \\
\hline & - & & \\
\hline & Case 6 & & \\
\hline Observation Guide & Case 1 & & \\
\hline & - & & \\
\hline & Case 6 & & \\
\hline Exit & Case 1 & & \\
\hline & - & & \\
\hline & Case 6 & & \\
\hline Interview & & & \\
\hline
\end{tabular}

\section{Data Source Notebook}

Six three-ring Participant Notebooks were used to organize data for each participant. The notebooks contained handwritten notes and transcriptions of interviews and informal conversations, handwritten and transcribed field notes from observations, and copies of supporting documentation collected, such as lesson plans, technology mandates, and student assignments. 


\section{Data Analysis}

Analysis began to occur as data were collected because early assessment helped to: (a) improve data collection strategies as the study progressed; and (b) organize and refine data for subsequent, deeper analysis (Merriam, 1998; Miles \& Huberman, 1994; Patton, 2002).

Overall data analysis procedure for a multiple case study is to conduct a within-case analysis where individual cases are examined, followed by a cross-case analysis (Merriam, 1998). Analyzing each case independently allowed for discovery of the uniqueness and details of each (Patton, 2002) and served to answer research question one (RQ1) and research question two (RQ2). After each case was analyzed, cross-case analysis was conducted to identify similarities and differences between teachers' decision-making, which answered research question three (RQ3).

Case studies typically result in a huge collection of data, necessitating a systematic data reduction strategy in concordance with data analysis. Figure 2 visualizes procedures for withincase data analysis and reduction, and Figure 3 represents cross-case data analysis and reduction. The overall strategy was to:

1. Analyze each data source for a participant.

2. Combine and analyze all data sources for each participant.

3. Combine and analyze synthesized data for the three novice teachers to answer research question 1: How do novice elementary, middle, and high school teachers make instructional technology decisions?

4. Combine and analyze synthesized data for the three experienced teachers to answer research question 2: How do experienced elementary, middle, and high school teachers make instructional technology decisions? 
5. Combine and analyze synthesized data that were used to answer RQ1 and RQ2 to answer research question 3: What are the similarities and differences between how novice and experienced elementary, middle, and high school teachers make instructional technology decisions? 
Case 1

novice elementary school teacher

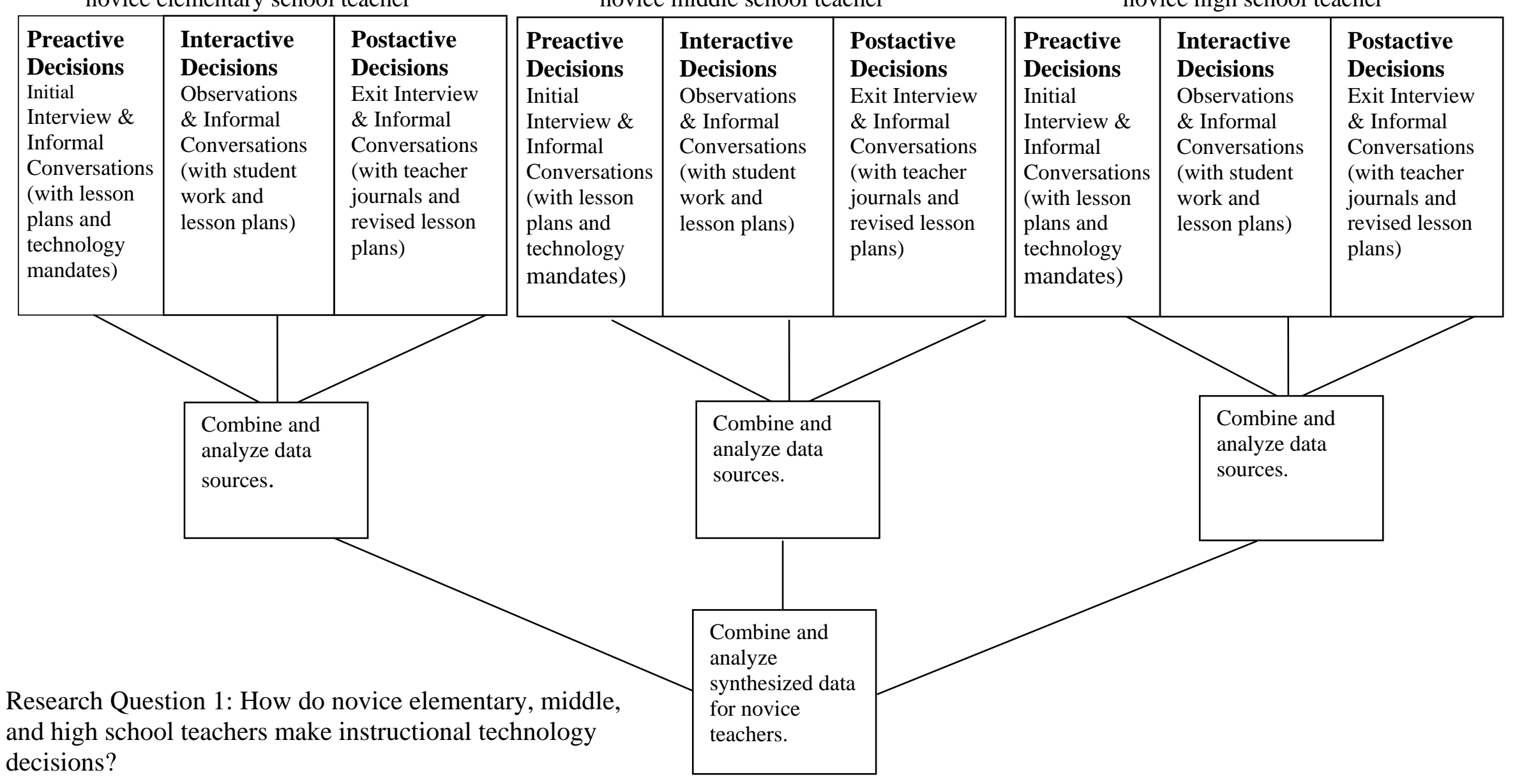

Figure 2. Within-case data analysis and reduction for research question 1. *

Case 3

novice high school teacher

\begin{tabular}{|c|c|c|c|c|c|c|c|c|}
\hline $\begin{array}{l}\text { Preactive } \\
\text { Decisions } \\
\text { Initial } \\
\text { Interview \& } \\
\text { Informal } \\
\text { Conversations } \\
\text { (with lesson } \\
\text { plans and } \\
\text { technology } \\
\text { mandates) }\end{array}$ & $\begin{array}{l}\text { Interactive } \\
\text { Decisions } \\
\text { Observations } \\
\text { \& Informal } \\
\text { Conversations } \\
\text { (with student } \\
\text { work and } \\
\text { lesson plans) }\end{array}$ & $\begin{array}{l}\text { Postactive } \\
\text { Decisions } \\
\text { Exit Interview } \\
\text { \& Informal } \\
\text { Conversations } \\
\text { (with teacher } \\
\text { journals and } \\
\text { revised lesson } \\
\text { plans) }\end{array}$ & $\begin{array}{l}\text { Preactive } \\
\text { Decisions } \\
\text { Initial } \\
\text { Interview \& } \\
\text { Informal } \\
\text { Conversations } \\
\text { (with lesson } \\
\text { plans and } \\
\text { technology } \\
\text { mandates) }\end{array}$ & $\begin{array}{l}\text { Interactive } \\
\text { Decisions } \\
\text { Observations } \\
\text { \& Informal } \\
\text { Conversations } \\
\text { (with student } \\
\text { work and } \\
\text { lesson plans) }\end{array}$ & $\begin{array}{l}\text { Postactive } \\
\text { Decisions } \\
\text { Exit Interview } \\
\text { \& Informal } \\
\text { Conversations } \\
\text { (with teacher } \\
\text { journals and } \\
\text { revised lesson } \\
\text { plans) }\end{array}$ & $\begin{array}{l}\text { Preactive } \\
\text { Decisions } \\
\text { Initial } \\
\text { Interview \& } \\
\text { Informal } \\
\text { Conversations } \\
\text { (with lesson } \\
\text { plans and } \\
\text { technology } \\
\text { mandates) }\end{array}$ & $\begin{array}{l}\text { Interactive } \\
\text { Decisions } \\
\text { Observations } \\
\text { \& Informal } \\
\text { Conversations } \\
\text { (with student } \\
\text { work and } \\
\text { lesson plans) }\end{array}$ & $\begin{array}{l}\text { Postactive } \\
\text { Decisions } \\
\text { Exit Interview } \\
\text { \& Informal } \\
\text { Conversations } \\
\text { (with teacher } \\
\text { journals and } \\
\text { revised lesson } \\
\text { plans) }\end{array}$ \\
\hline & $\begin{array}{l}\text { Combine and } \\
\text { analyze data } \\
\text { sources. }\end{array}$ & & & $\begin{array}{l}\text { Combine and } \\
\text { analyze data } \\
\text { sources. }\end{array}$ & & & $\begin{array}{l}\text { Combine and } \\
\text { analyze data } \\
\text { sources. }\end{array}$ & \\
\hline $\begin{array}{l}\text { esearch Ques } \\
\text { ad high schoo } \\
\text { ecisions? }\end{array}$ & $\begin{array}{l}\text { on } 1 \text { : How do } \\
\text { teachers mak }\end{array}$ & & $\begin{array}{l}\text { Idle, } \\
\text { yy }\end{array}$ & $\begin{array}{l}\text { Combine and } \\
\text { analyze } \\
\text { synthesized data } \\
\text { for novice } \\
\text { teachers. }\end{array}$ & & & & \\
\hline
\end{tabular}

*The above procedure was repeated for the experienced teachers (Cases 4 - 6) to answer Research Question 2. 
Novice Teachers

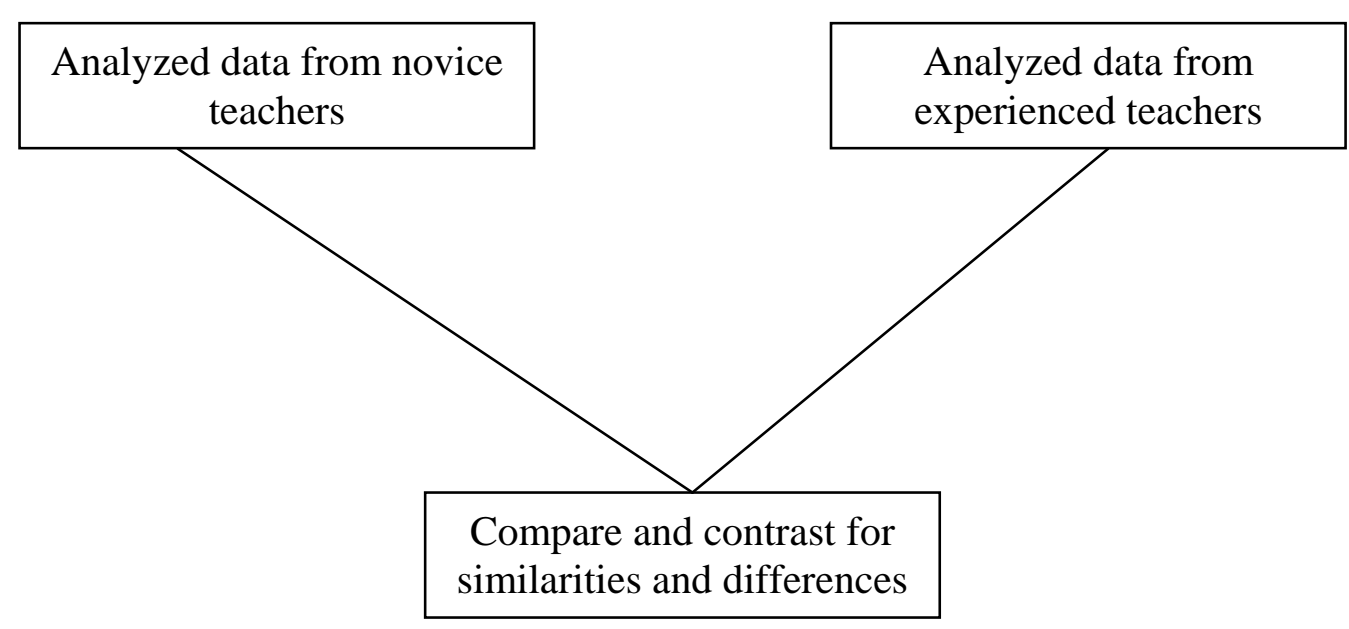

Research Question 3: What are the similarities and differences between how novice and experienced elementary, middle, and high school teachers make instructional technology decisions?

Figure 3. Cross-case data analysis and reduction for research question 3.

The intent of this study was to discover and describe (Strauss \& Corbin, 1990) the phenomenon of teacher decision-making in the use of instructional technologies. To discover and describe the phenomenon, data were analyzed and organized using categories. As Strauss and Corbin explain, categories are not pre-determined but evolve, along with relationships between categories, as data are analyzed.

Data analysis began with coding, a specific analytic technique that is used when exploring data. Coding is the term used when words, letters, numbers, and/or phrases are used to describe qualitative data, assign meaning, and convey interpretations (Merriam, 1998; Miles \& Huberman, 1994). Assigning labels or codes to data allowed the researcher to examine data in a meaningful way while maintaining relationships between the various pieces (Miles \& Huberman), think about the information collected, and generate meaning (Coffey \& Atkinson, 1996). 
The coding process began with open coding, a phrase used to describe labeling and categorizing of phenomena during data analysis (Merriam \& Associates, 2002; Strauss \& Corbin, 1990). After transcribing an initial interview, informal conversation, observation, or exit interview, the researcher read a transcript and began open coding by writing words and phrases in the margins to describe a teacher's decision-making. Rather than simply summarizing the data, the researcher used conceptual terms and phrases (Strauss \& Corbin) to describe what occurred and what the teachers said. The researcher then used different colors to highlight and differentiate preactive, interactive, and postactive decision-making. The constant comparative method (Strauss \& Corbin) was used as the researcher read the transcribed data multiple times, compared similarities and differences, questioned the phenomena (Coffey \& Atkinson, 1996; Strauss \& Corbin) and then began to assign descriptive codes (Miles \& Huberman, 1994) to the data. As descriptive codes emerged, they were labeled using words chosen by the researcher and “in vivo" codes (Strauss \& Corbin), which were terms and phrases used by participants during interviews and observations. Once descriptive codes emerged, they were defined and some were revised to clarify their meaning. A list of descriptive codes was created and the researcher assigned the codes to the transcribed data. The researcher printed the transcribed data and coded it again to determine if anything was missed or coded incorrectly. A table of descriptive codes, with corresponding definitions, was created for each teacher and from these a case study narrative was written for each teacher.

After data were labeled with descriptive codes through the open coding process, axial coding was used to make connections (Strauss \& Corbin, 1990). As described by Strauss and Corbin, axial coding creates categories when a phenomenon is assessed for context, action/interaction, and consequences. Context is the environment and conditions in which the 
phenomenon occurs, action/interaction are strategies used for a phenomenon within its context, and consequences are the result of the action/interaction. The axial coding process was used to group the descriptive codes into categories that appeared to refer to the same incidents (Strauss \& Corbin). Based on the categories that emerged, pattern codes, which are inferential and explanatory, were assigned (Miles \& Huberman, 1994).

\section{Within-Case Analysis}

Treating each case independently by collecting and analyzing comprehensive and indepth data about each participant (Merriam, 1998; Patton, 2002) and then combining the cases for the novice teachers (referred to as Case 1, Case 2, and Case 3), served to answer RQ1, “How do novice elementary, middle, and high school teachers make instructional technology decisions?” Following the same strategy for the experienced teachers' case studies (Case 4, Case 5, and Case 6) served to answer RQ2, “How do experienced elementary, middle, and high school teachers make instructional technology decisions?”

Data collected as a primary source independently provided information on teachers’ preactive, interactive, or postactive decision-making, whereas secondary data sources provided information of significance only when analyzed in conjunction with a primary source of data. For example, lesson plans alone provided some insight into teachers’ preactive decision-making, but in combination with the initial and exit interview, a more complete picture was provided (Patton, 2002).

Procedures followed for within-case analysis are described in Table 3. 
Table 3

Data Sources and Method of Within-Case Analysis

\begin{tabular}{|c|c|c|}
\hline Data Source & Method of Analysis & Result \\
\hline Initial Interview & $\begin{array}{l}\text { 1. Initial interviews were transcribed and printed. } \\
\text { 2. Key words and phrases were highlighted and notes } \\
\text { were made. } \\
\text { 3. Open coding was used to analyze further the initial } \\
\text { interview. } \\
\text { 4. Descriptive codes were assigned to transcribed } \\
\text { data. }\end{array}$ & $\begin{array}{l}\text { Preactive decisions: } \\
\text { How teachers } \\
\text { intend to use } \\
\text { instructional } \\
\text { technology. }\end{array}$ \\
\hline $\begin{array}{l}\text { Lesson Plans } \\
\text { (documentation) }\end{array}$ & $\begin{array}{l}\text { Notes were recorded to identify information relevant } \\
\text { to preactive decision-making information. Lesson } \\
\text { plans and notes were analyzed with initial interview } \\
\text { data to identify preactive decisions. }\end{array}$ & $\begin{array}{l}\text { Preactive decisions: } \\
\text { How teachers } \\
\text { intend to use } \\
\text { instructional } \\
\text { technology. }\end{array}$ \\
\hline $\begin{array}{l}\text { Technology } \\
\text { Mandates } \\
\text { (documentation): } \\
\text { School, county, } \\
\text { and state policies } \\
\text { and initiatives } \\
\text { pertaining to } \\
\text { teacher use of } \\
\text { technology. }\end{array}$ & Used in creation of interview questions. & $\begin{array}{l}\text { Preactive decisions: } \\
\text { What external } \\
\text { factors influence } \\
\text { teachers' preactive } \\
\text { decisions to use } \\
\text { technology. }\end{array}$ \\
\hline $\begin{array}{l}\text { Student Work } \\
\text { (documentation) }\end{array}$ & $\begin{array}{l}\text { 1. Student work was analyzed with lesson plans and } \\
\text { observation data to determine if a teacher made } \\
\text { any interactive decisions. } \\
\text { 2. Postactive decision-making data were gathered } \\
\text { during exit interviews. }\end{array}$ & $\begin{array}{l}\text { Interactive, and } \\
\text { postactive } \\
\text { decisions: decisions } \\
\text { made during } \\
\text { teaching and how } \\
\text { teachers plan to use } \\
\text { it in the future. }\end{array}$ \\
\hline $\begin{array}{l}\text { Teacher Journal } \\
\text { (documentation) }\end{array}$ & $\begin{array}{l}\text { None of the teachers had an up-to-date journal, so } \\
\text { these were not used a source of data. }\end{array}$ & $\begin{array}{l}\text { Preactive and } \\
\text { postactive } \\
\text { decisions: How } \\
\text { teachers intend to } \\
\text { use technology and } \\
\text { how will they use it } \\
\text { in the future. }\end{array}$ \\
\hline
\end{tabular}




\begin{tabular}{|c|c|c|}
\hline Data Source & Method of Analysis & Result \\
\hline $\begin{array}{l}\text { Revised Lesson } \\
\text { Plans } \\
\text { (documentation) }\end{array}$ & $\begin{array}{l}\text { 1. Revised lesson plans were compared to initial } \\
\text { lesson plans. } \\
\text { 2. Used to prompt discussion during exit interviews } \\
\text { about differences between intended and actual } \\
\text { lesson plans. }\end{array}$ & $\begin{array}{l}\text { Postactive and } \\
\text { preactive decisions: } \\
\text { How teachers' } \\
\text { make decisions } \\
\text { while planning } \\
\text { future use of } \\
\text { technology. }\end{array}$ \\
\hline $\begin{array}{l}\text { Observations \& } \\
\text { Observation } \\
\text { Guide }\end{array}$ & $\begin{array}{l}\text { Observation guides, field notes pertaining to } \\
\text { observations, and post-observation notes were used to } \\
\text { describe the classroom environment. These were also } \\
\text { used to describe the teacher, students, and their } \\
\text { interactions during teaching. Observation data were } \\
\text { analyzed individually and in conjunction with lesson } \\
\text { plans and student work. } \\
\text { 1. Handwritten field notes, observation guides, and } \\
\text { post-observation notes were transcribed and } \\
\text { printed. } \\
\text { 2. Key words and phrases were highlighted and notes } \\
\text { were made. } \\
\text { 3. Open coding was used to analyze further the initial } \\
\text { interview. } \\
\text { 4. Descriptive codes were assigned to transcribed } \\
\text { data. }\end{array}$ & $\begin{array}{l}\text { Interactive } \\
\text { decisions: How } \\
\text { teachers make } \\
\text { decisions while } \\
\text { teaching and using } \\
\text { the technology. }\end{array}$ \\
\hline Exit Interview & $\begin{array}{l}\text { 1. Exit interviews were transcribed and printed. } \\
\text { 2. Key words and phrases were highlighted and notes } \\
\text { were made. } \\
\text { 3. Open coding was used to analyze further the exit } \\
\text { interview. } \\
\text { 4. Descriptive codes were assigned to transcribed } \\
\text { data. }\end{array}$ & $\begin{array}{l}\text { Preactive, } \\
\text { interactive and } \\
\text { postactive } \\
\text { decisions: How } \\
\text { teachers made } \\
\text { decisions prior to } \\
\text { teaching, during } \\
\text { teaching, and } \\
\text { revisions for future } \\
\text { lessons. }\end{array}$ \\
\hline
\end{tabular}

\section{Cross-Case Analysis}

Following analysis of individual cases, cross-case analysis was conducted to answer RQ3

"What are the similarities and differences between how novice and experienced elementary, middle, and high school teachers make instructional technology decisions?” Cross-case analysis was used to investigate processes and outcomes across cases, looking at how they were influenced by local conditions, and strengthen understanding by developing more sophisticated 
descriptions and explanations (Miles \& Huberman, 1994). Procedures for cross-case analysis included:

1. Examination of analyzed data for the three novice teachers to look for similarities and differences.

2. Examination of analyzed data for the three experienced teachers to look for similarities and differences.

3. Examination of analyzed data for novice and experienced teachers to look for similarities and differences.

\section{Establishing Research Quality}

Quality in case studies was established through the research design. Common procedures used to design credible qualitative research include triangulation, member checking, audit trails, and thick description (Creswell \& Miller, 2000), each of which are described below. These strategies occurred through the lens (Creswell \& Miller; Patton, 2002) or viewpoint of different individuals, including the researcher, participants, and outside evaluators. Integrating the lens of various people contributed to the credibility of the study. Strategies for establishing research quality in this case study are described, followed by an explanation of logical tests (Yin, 2003), that were used to judge the quality of this qualitative research.

\section{Triangulation}

Triangulation occurs when the lens of the researcher uses multiple theories, methods, investigators/analysts, or sources of data to look across data for emerging themes or categories (Creswell \& Miller, 2000; Merriam, 1998; Patton, 2002), rather than a single source of information. The intent of triangulation is not to look for the same results from various sources of information, but rather to minimize misrepresentation and misunderstanding of data and 
contribute to a more comprehensive and accurate description of what was being studied (Patton; Stake, 1995).

Data triangulation for this research transpired with the collection and analysis of multiple sources of data, including pre- and post-teaching interviews, documentation, and observations. Looking across these various sources of data provided what Merriam (1998) terms a more "holistic understanding” of the data, as opposed to relying on the interpretation of a single data source (Creswell \& Miller, 2000; Merriam; Patton, 2002).

\section{Member Checking}

The phrase “member checking” (Creswell \& Miller, 2000; Stake, 1995) describes a shift in the quality procedure from the lens of the researcher to the participants (Creswell \& Miller). This strategy is described as "review by inquiry participants" and is considered to be an approach to analytical triangulation by Patton (2002). Regardless of the terminology used, this approach to establishing quality research was implemented when the researcher asked each participant to review initial data analysis of his/her case and evaluate it for accuracy (Patton; Stake). The initial analysis of all data sources was presented to each participant via email attachment. Revisions suggested by the teachers were incorporated into subsequent analysis.

\section{Audit Trail}

A written audit trail was used to document all research activities and decisions, including data collection, data analysis procedures (Creswell \& Miller, 2000), coding categories, and methodological decisions made throughout the study (Merriam \& Associates, 2002). Creating an audit trail contributed to research quality by creating a written account of the study that represented logistics of the process (Patton, 2002). This information was provided to two people outside of the research who were asked to determine if decisions and shifts in methodology were 
justifiable, if data inferences were logical, and to evaluate the degree of researcher bias (Creswell \& Miller; Patton).

Researcher's Journal

As this study progressed, the researcher created a researcher's journal that was used for reflective purposes. Reflecting in the journal helped the researcher to recognize her biases. Being aware of biases contributed to trustworthiness of the research. Hunches, intuition, and insight that the researcher had during the study were captured in the journal and referred to during data analysis.

\section{Thick, Rich Description}

Yet another approach to establishing qualitative research quality was the use of thick, rich description by describing in detail the environment, participants, and data codes (Creswell \& Miller, 2000; Merriam, 1998; Patton, 2002). Patton referred to thick description as the "foundation for qualitative analysis and reporting.” The case study narratives and other descriptions of analyzed data went beyond basic detail and simple reporting of facts to create for the reader a sense of experiencing what occurred during the study (Creswell \& Miller; Patton).

\section{Logical Tests}

Strategies can be used to lend credibility to a study, and logical tests can be used to judge the quality. There are four logical tests that have been commonly used to assess social research, such as the use of case studies (Yin, 2003):

1. Construct validity - establishing operational measures that correspond with the concept being studied.

2. Internal validity - for explanatory or causal studies (not descriptive or exploratory), where certain conditions are shown to lead to other conditions. 
3. External validity - establishing the domain to which a study's findings can be generalized. In case studies, analytical generalization is used to generalize to a broader theory (as opposed to survey research which relies on statistical generalization which seeks to generalize findings to a larger population).

4. Reliability - designed as a means to reduce errors and biases, reliability is achieved by demonstrating that operational measures of a study, such as data collection, can be repeated, with the same results. If a subsequent investigator follows the same procedures as the initial researcher and conducts the same case study again, the same findings and conclusions should be reached (Yin).

Table 4 is adopted from Yin (2003). The first three columns of the table indicate the logical test, case study tactic, and research phase in which the tactic occurred. The last column has been added to illustrate how this research design addresses the logical tests. 
Table 4

Yin's Logical Tests for Case Studies (2003)

\begin{tabular}{|c|c|c|c|}
\hline Tests & Case Study Tactic & $\begin{array}{l}\text { Phase of research } \\
\text { in which tactic } \\
\text { occurs }\end{array}$ & $\begin{array}{l}\text { My Research } \\
\text { Design }\end{array}$ \\
\hline $\begin{array}{l}\text { 1. Construct } \\
\text { validity }\end{array}$ & $\begin{array}{l}\text { Use multiple sources of } \\
\text { evidence } \\
\text { Establish chain of evidence } \\
\text { Have key informants review } \\
\text { draft case study report }\end{array}$ & Composition & $\begin{array}{l}\text { Achieved by } \\
\text { collecting multiple } \\
\text { sources of data. } \\
\text { Audit trail } \\
\text { documented all } \\
\text { aspects of } \\
\text { research. } \\
\text { Participants } \\
\text { reviewed initial } \\
\text { data analysis. }\end{array}$ \\
\hline 2. Internal validity & $\begin{array}{l}\text { Do pattern-matching } \\
\text { Do explanation-building } \\
\text { Address rival explanations } \\
\text { Use logic models }\end{array}$ & $\begin{array}{l}\text { Data analysis } \\
\text { Data analysis } \\
\text { Data analysis } \\
\text { Data analysis }\end{array}$ & $\begin{array}{l}\text { Not applicable; } \\
\text { specific to } \\
\text { causative and } \\
\text { explanatory } \\
\text { studies }\end{array}$ \\
\hline $\begin{array}{l}\text { 3. External } \\
\text { validity }\end{array}$ & $\begin{array}{l}\text { Use theory in single-case } \\
\text { studies } \\
\text { Use replication logic in } \\
\text { multiple-case studies }\end{array}$ & $\begin{array}{l}\text { Research design } \\
\text { Research design }\end{array}$ & $\begin{array}{l}\text { Not applicable; } \\
\text { the goal of this } \\
\text { study is not to } \\
\text { generalize } \\
\text { findings to a } \\
\text { larger population } \\
\text { because } \\
\text { pedagogical } \\
\text { knowledge is } \\
\text { contextualized and } \\
\text { not easily } \\
\text { generalizable } \\
\text { (Berliner, 1994). }\end{array}$ \\
\hline 4. Reliability & $\begin{array}{l}\text { Use case study protocol } \\
\text { Develop case study database }\end{array}$ & Data collection & $\begin{array}{l}\text { Demonstrated } \\
\text { through the use of } \\
\text { a case study } \\
\text { protocol. } \\
\text { A case study } \\
\text { database will be } \\
\text { used in order to } \\
\text { track and manage } \\
\text { data. }\end{array}$ \\
\hline
\end{tabular}




\section{Limitations of the Study}

Due to the challenging nature of designing and conducting research, especially when human subjects are involved, all studies contain limitations. Limitations of this study were:

1. Purposeful sampling of participants provides a limited number of cases to be studied (Patton, 2002). For this study, a total of six teachers were asked to participate.

2. Bias in selection of participants.

3. Not being able to spend a great length of time with each participant since the amount of time spent with each participant was limited to less than one half of an academic year.

4. Observations were limited by 1) participants' communication of upcoming observation opportunities to the researcher; 2) amount of time spent in each participant's classroom.

5. Some documentation was non-existent, incomplete, or outdated. Teacher journals were non-existent for most participants and outdated for others. Revisions to lesson plans were not always complete.

6. Stimulated recall is designed to revisit teachers' thinking during instruction, which may not be accurate at times.

7. Knowledge, technical skills, and teaching experience of each participant.

8. Ability of the participants to verbalize their thinking as they design, teach, and revise instruction that uses instructional technologies.

9. Researcher's knowledge, technical skills, teaching experience, and biases. In a qualitative study, the researcher is the primary instrument, which means that all of the study's information is filtered through that person (Merriam, 1998). Therefore, it was 
critical that the researcher used brackets to distinguish her beliefs, thoughts, and biases from the data (Creswell \& Miller, 2000).

10. Researcher's interpretation of the data collected.

11. When analyzing data using the data reduction strategy, caution must be exercised not to filter out meaning from the data. 


\section{CHAPTER FOUR - FINDINGS}

This chapter reports the findings for the three research questions, which were answered by conducting a systematic analysis of the data.

Research Question 1: How do novice elementary, middle, and high school teachers make instructional technology decisions?

Research Question 2: How do experienced elementary, middle, and high school teachers make instructional technology decisions?

Research Question 3: What are the similarities and differences between how novice and experienced elementary, middle, and high school teachers make instructional technology decisions?

A multiple case study framework was used to describe novice and experienced teachers' decision-making in the use of instructional technology. Teacher decision-making is based on Clark and Peterson's (1986) view of teaching as preactive, interactive, and postactive, which characterizes teachers' thinking in three phases: prior to teaching, during teaching, and after teaching:

- Preactive decision-making is defined as the planning process that teachers go through prior to teaching a lesson (Clark \& Peterson, 1986).

- Interactive is the term used to describe decisions teachers' make during teaching, which is distinctly different from decision-making prior to and after teaching (Parker \& Gehrke, 1986).

- The postactive phase occurs when teachers' reflect upon and assess the effectiveness of their teaching. Clark and Peterson (1986) reported that preactive and postactive 
phases often blend together, where decisions made by teachers following instruction are often implemented within or become the preactive planning for future lessons. Chapter 4 begins by describing teachers who participated in this research and the data analysis procedure. Findings are presented next, starting with the within-case analysis of novice teachers, followed by within-case analysis of experienced teachers, and concluding with crosscase analysis of novice and experienced teachers. 


\section{Participant Characteristics}

Six teachers participated in this study. Three of the teachers were novices with 2 years of teaching experience each. The other three teachers were experienced, two have taught for 23 years and the other, for 31 years. All 6 teachers earned a master's degree in education. Table 5 provides information about each teacher, including grade level and content area taught at the time of this research, years of experience, and educational background. To maintain teachers’ anonymity, pseudonyms are used.

Table 5

Participant Characteristics

\begin{tabular}{|c|c|c|c|c|}
\hline & Teacher & $\begin{array}{l}\text { Grade Level \& } \\
\text { Content Area }\end{array}$ & $\begin{array}{c}\text { Years of } \\
\text { Experience }\end{array}$ & Educational Background \\
\hline \multirow{3}{*}{ 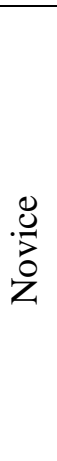 } & Case Study 1: Lucy & $1^{\text {st }}$ grade & 2 & $\begin{array}{l}\text { Bachelor's Degree: Child } \\
\text { Development } \\
\text { Master's Degree: Elementary } \\
\text { Education }\end{array}$ \\
\hline & Case Study 2: Jennifer & $\begin{array}{l}6^{\text {th }} \text { grade } \\
\text { Reading } \\
7^{\text {th }} \text { grade Math }\end{array}$ & 2 & $\begin{array}{l}\text { Bachelor's Degree: Multi- } \\
\text { disciplinary Studies } \\
\text { Master’s Degree: Education }\end{array}$ \\
\hline & Case Study 3: Kristi & $\begin{array}{l}9^{\text {th }}-12^{\text {th }} \\
\text { Applied Math } \\
\text { \& Algebra }\end{array}$ & 2 & $\begin{array}{l}\text { Bachelor's Degree: Mathematics } \\
\text { Master's Degree: Secondary } \\
\text { Education }\end{array}$ \\
\hline \multirow{3}{*}{ 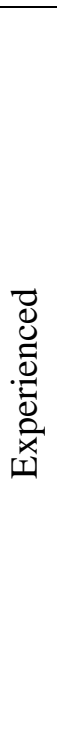 } & Case Study 4: Derk & $\begin{array}{l}6^{\text {th }}-8^{\text {th }} \text { grade } \\
\text { Math \& } \\
\text { Science } \\
\text { Teaching in an } \\
\text { elementary/ } \\
\text { middle school }\end{array}$ & 23 & $\begin{array}{l}\text { Master's Degree: Elementary } \\
\text { Education }\end{array}$ \\
\hline & Case Study 5: Georgia & $\begin{array}{l}6^{\text {th }}-8^{\text {th }} \text { grade } \\
\text { Language Arts } \\
\text { Teaching in an } \\
\text { elementary/ } \\
\text { middle school }\end{array}$ & 23 & $\begin{array}{l}\text { Bachelor's Degree: English and } \\
\text { Social Studies } \\
\text { Master's Degree: Gifted Education } \\
\text { National Board Certification: English } \\
\text { Language Arts and Early } \\
\text { Adolescence }\end{array}$ \\
\hline & Case Study 6: Frieda & $\begin{array}{l}9^{\text {th }}-12^{\text {th }} \text { grade } \\
\text { Math, Algebra, } \\
\& \\
\text { Trigonometry }\end{array}$ & 31 & Master’s Degree: Math Education \\
\hline
\end{tabular}




\section{Data Analysis and Reduction Procedure}

A systematic data analysis and reduction process was followed for both novice and experienced teachers. A within-case analysis of data collected for the three novice teachers was conducted to answer Research Question 1: How do novice elementary, middle, and high school teachers make instructional technology decisions? A within-case analysis of data collected for the three experienced teachers was conducted to answer Research Question 2: How do experienced elementary, middle, and high school teachers make instructional technology decisions? A cross-case analysis of data collected for the novice and experienced teachers was conducted to answer Research Question 3: What are the similarities and differences between how novice and experienced elementary, middle, and high school teachers make instructional technology decisions?

Procedure for Within-Case Analysis

The within-case data analysis and reduction process for both novice and experienced teachers began with open coding. An overview of the data analysis and reduction process is listed below and visualized in Figure 4. Figures and tables mentioned in the list below are referenced and described in detail throughout the chapter.

1. Open coding began when the researcher transcribed then read all of the data sources for the novice teachers (initial and exit interview, observations, and informal conversations) and continued with constant comparison of data for similarities and differences (Strauss \& Corbin, 1990). Conceptual labels were assigned to the data sources, which are terms and phrases (Strauss \& Corbin) created by the researcher to describe teachers' decision-making. From these concepts emerged descriptive codes 
that were used to identify similar concepts (Strauss \& Corbin). The same process was conducted for experienced teachers.

2. Descriptive codes were listed for all six teachers and organized by the three decisionmaking phases (see Tables 6-8 \& 11-13). Based on these lists of descriptive codes and the transcribed data, a case study narrative was written for each teacher that portrayed his or her preactive, interactive, and postactive decision-making.

3. Descriptive codes for the three novice teachers were synthesized into a matrix (see Appendix F); descriptive codes for the three experienced teachers were also synthesized into a matrix (see Appendix G). Definitions of the descriptive codes, for both novice and experienced teachers, are listed in Appendix H.

4. Descriptive codes were tallied and described for the three decision-making phases for novice teachers (see Figure 5) and for experienced teachers (see Figure 7).

5. Axial coding was used to look for connections within the descriptive codes and develop main categories (Strauss \& Corbin, 1990). This procedure grouped the 55 descriptive codes into 7 pattern codes (see Appendix F for novices; Appendix G for experienced teachers).

6. Pattern codes were tallied and described according to the three decision-making phases for novice teachers (see Figure 6) and for experienced teachers (see Figure 8). 


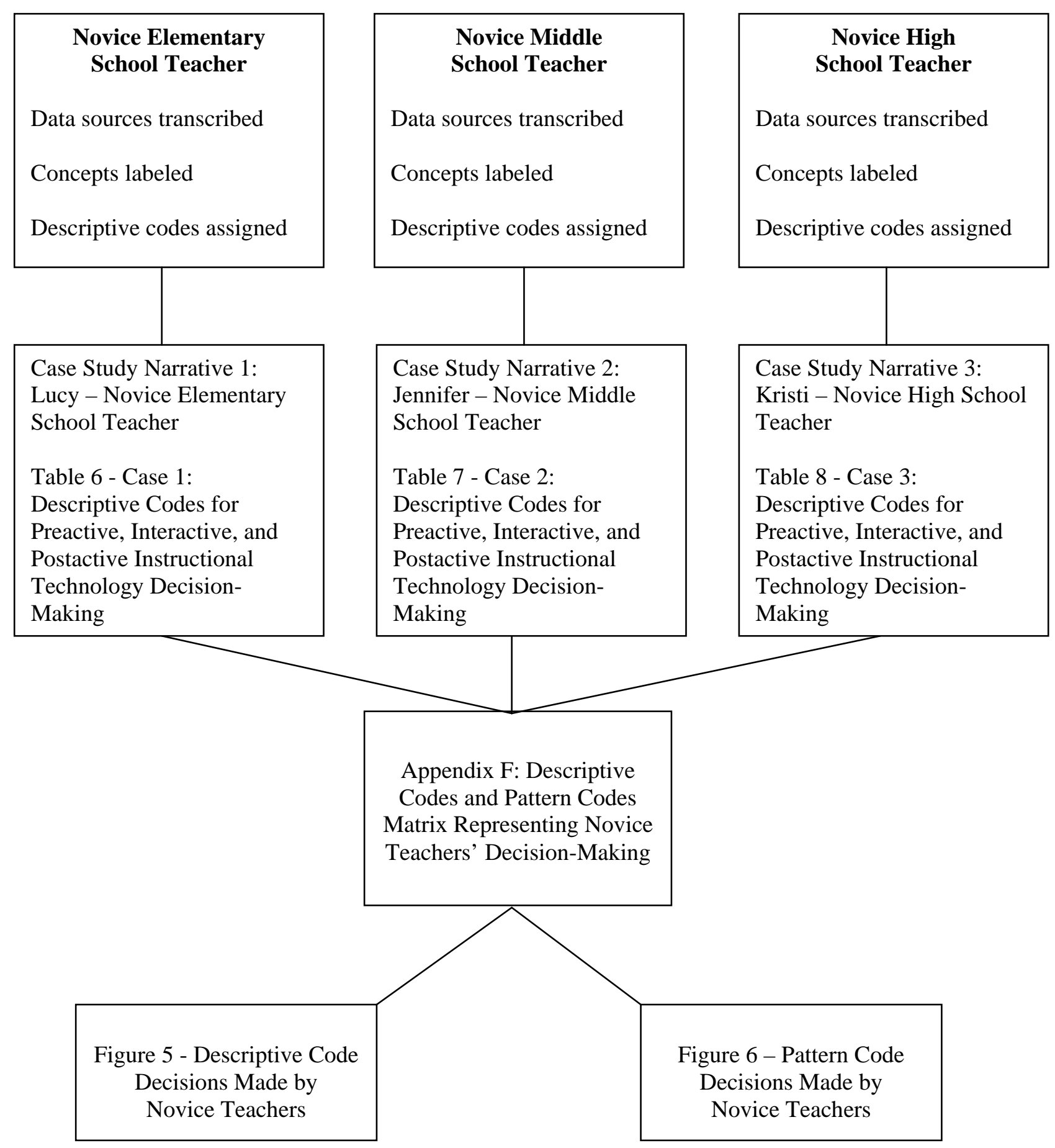

Figure 4. Within-case data analysis and reduction for novice teachers.*

*This figure represents the data analysis and reduction process for novice teachers. The same procedure was conducted for experienced teachers. 


\section{Procedure for Cross-Case Analysis}

Data used to answer research question 1 and research question 2 were combined and analyzed to determine similarities and differences between how novice and experienced elementary, middle, and high school teachers make instructional technology decisions.

\section{Within-Case Analysis of Novice Teachers}

A case study has been created for each of the three novice teachers. Each case study is introduced through a narrative describing the teacher's learning environment, educational beliefs, and preactive, interactive, and postactive teaching decisions. Descriptive codes are embedded within each case study narrative, represented in italics and enclosed within parentheses. Descriptive codes that appear within quotation marks are "in vivo” codes (Strauss \& Corbin, 1990), created with terms and phrases used by the teachers during interviews and observations. An alphabetized list of descriptive codes and definitions is located in Appendix H.

Following each teacher's case study narrative is a corresponding table of descriptive codes organized by the three decision-making phases. For ease of use, codes within each teacher's table are listed in the order in which they appear within the case study narrative. Some descriptive codes appear more than once within a narrative, but for the purpose of simplicity, codes are listed in the table only the first time they appear within the preactive, interactive, and postactive phases.

\section{Case Study 1 Narrative: Lucy - Novice Elementary School Teacher}

This case study describes Lucy, a novice first grade teacher, and how she makes instructional technology decisions. Lucy earned her Bachelor's Degree in Child Development and Master's Degree in Elementary Education. She is in her $2^{\text {nd }}$ year of full-time teaching, but only the first year where she has her own classroom because previously she was a traveling 
teacher. Lucy finds her first year with her own classroom to be "so much harder than I thought it would be,” but also says that she loves her job.

Lucy’s case study is introduced through insight into her learning environment and her educational beliefs, followed by decisions she made prior to teaching, during teaching, and after teaching. Italicized words enclosed within parentheses are the open codes that identify her instructional technology decisions. Following Lucy’s case study is Table 6, which summarizes the data analysis of her preactive, interactive, and postactive teaching decisions with regard to using technology.

\section{Learning Environment}

Inside the school and Lucy's classroom. The elementary school where Lucy teaches offers abundant resources. Each teacher’s classroom contains an overhead projector and at least one computer. The school library is packed with books and the adjoining computer lab houses up-to-date computers for students, a data projector connected to a computer, and copies of educational software on CD-ROM. Computers within the computer lab and classrooms are connected to the Internet.

Lucy has arranged her classroom into different learning areas. The reading corner is partially enclosed by bookshelves, creating a secluded and quiet area for reading. In this reading area are pillows, a throw rug, and baskets and bookshelves of books. An open area in the back of the room has a large red throw rug where students sit when parents and other guests come to read and share artifacts. Work from “Lucy’s Star Students” is posted on a bulletin board. Colorful posters and charts about the alphabet, numbers, and shapes cover all the walls of her classroom. Her desk sits on one side of the room, surrounded by shelves containing various types of learning materials. 
Educational philosophy. Lucy is introducing a lesson on reptiles. She begins by telling her students that they are going to be learning about reptiles and asks them what they know about this topic. Her students are not afraid to answer questions or express their opinions. Her educational philosophies are evident in the way she teaches and the way she treats her students: Lucy wants her students to be able to think for themselves, gain independence and selfconfidence, and express themselves freely. As a teacher, she believes that she should respect her students.

\section{Preactive Decision-Making}

Technology planning approach. As Lucy plans her curriculum for the school year, she does not focus on technology but it is always in the back of her mind. She is "always thinking about it, but it is just not a priority.” When creating her yearly plans, she focuses on the content areas, which consist of social studies, science, math, and language arts (content first). As the school year progresses, she decides how she will use technology in her units and lessons.

Outside influences. Outside factors that influence Lucy’s decision to use technology are statewide standards and other faculty at her school. In order to prepare her students for the next grade, Lucy follows West Virginia’s Content Standards and Objectives (CSOs), which include standards for using technology (standards). Her school has a technology plan that is not enforced, but the teachers take pride in the abundant technology available (availability) and expect one another to use it (peer expectations).

Another outside influence on Lucy's decision to use technology was the presence of the researcher. After teaching a lesson, during an informal conversation with the researcher, Lucy admitted that she used a certain piece of technology because the researcher was going to be observing (researcher's presence). 
Teaching and learning decisions. When designing her lessons, Lucy’s decisions to use technology are grounded in her belief that technology should be used to benefit her students. She observes that her students like to do new and different things, so she uses technology to "mix things up” and "break up the monotony” (variation from routine) because "anything different engages them” (student engagement). One of many occasions where Lucy used technology to engage her students was when she used transparent coins on the overhead projector. She used these manipulatives to introduce the concept of money (introduce content) by placing coins on the projector and talking about the value of each (direct instruction) and to review money by asking students for the value of the coin that was being displayed (review \& practice). Lucy also helped students learn to count change by a) placing the transparent coins on the overhead projector and asking them how much money they counted and how they came up with the total (interactive discussion) and b) calling on them one at a time and asking them to come up to the overhead projector and use the coins to represent specific amounts of money (student engagement).

Another way in which Lucy believes that using technology can benefit her students is to help them learn more quickly (learning efficiency) and retain (retention) what they learned. When she taught her unit on frogs, she used a PowerPoint presentation about frogs that she found on the Internet (teaching efficiency). The PowerPoint slides contained numerous pictures showing the development of a frog from its beginning as a tadpole (visual learning). Using this presentation, Lucy observed that her students learned very quickly about the life cycle of a frog. “All I had to do was show that to them one day and they knew," she stated. She believes that if she chose instead to give them a twenty-minute lecture, she would have probably had to teach about frogs across numerous days by showing them pictures in their science book, drawing on 
the board, asking students to complete worksheets, and then telling students to draw pictures. She says, "you achieve so much more using technology and achieve it in a faster manner, more efficiently” (learning efficiency; teaching efficiency). Several weeks after learning about the evolution of a tadpole into a frog, a situation occurred where a student recalled how a tadpole’s tail dissolves as it matures into a frog (retention). Lucy believes that using pictures of tadpoles and frogs from the Internet had a different effect than using pictures from a book. "I have their attention (student engagement). It's different (variation from routine). They would have had their hands in their desk instead of looking at the book. They would have been looking out the window, looking out the door. I had them looking at the screen. That's what you want” (classroom management).

Another reason Lucy decides to use technology is because it provides opportunities for students and the teacher to see things (visual learning) that otherwise they might never see (enhanced learning opportunity). An example is when Lucy found pictures on the Internet of the tsunami that occurred in Indonesia in 2004. She says that these real life ("real life”) pictures allowed her to teach about something that would otherwise be difficult to teach (enhanced learning opportunity) because it was so much easier to find pictures on the Internet as opposed to within printed materials (teaching efficiency).

Using technology at the end of a lesson or unit allowed Lucy to review information and informally assess her students’ learning. She created a PowerPoint, using pictures that she found on the Internet, to display photographs of amphibians and reptiles (visual learning). As she showed a picture of a reptile or amphibian, she asked her students, "What is this?” (review and practice). Then she would question them as to why they thought it was a reptile or amphibian. This allowed Lucy to determine if her students were thinking about the characteristics they 
learned about each (informal assessment). As her students responded, Lucy informally assessed them to determine if they were prepared for their upcoming test on this subject.

Other pictures that Lucy used in teaching are those she captured using a digital camera. She took pictures of her students, printed them, and asked them to select a picture and write about what they were doing in the photograph. She said, "students see you take pictures but they don’t realize there is a product. Students get a kick out of seeing themselves" ("real life”). Lucy also took pictures of her kitten, Carl, and asked her students to write a story about Carl. She used photographs that she took and also ones that she found on the Internet because she believes that her students can relate to real-life pictures as opposed to looking at pictures in a textbook, on worksheets, or posters on the wall (“real life”).

Lucy sometimes used technology for practicing concepts that her students were learning (review and practice). Commercially developed software programs, such as Compass and Performance Math, allowed her students to practice their keyboard skills (technology skills), which Lucy pointed out was one of the statewide standards (standards), and also to practice their math skills (review and practice). Another way Lucy used technology was when she set up learning stations for her students. One station featured an audiotape and a cassette player. Students put on headphones and read along in the corresponding book (auditory learning; review and practice). A student practiced reading and spelling (review and practice) using a software program titled "Reader Rabbit” at another station.

Control and classroom management are sometimes part of the intent behind Lucy’s decision to use technology. For example, instead of passing around pictures of the tsunami that she found on the Internet, she used a document camera to display the pictures on the television so her entire class could see them at the same time. She said that if she passed the pictures around 
and let her students look at them, they would not have listened to her (classroom management) or engaged in the discussion (interactive discussion) as she talked about the photos (direct instruction).

Timing impacted Lucy’s decisions of how and why to use technology during the school year and during the school day. Lucy opted to use technology more often during the second half of the year because her students were in a routine and everything was "coming easier and moving along smoother” (timing within school year). Lucy noticed, as other teachers had told her, a big difference in her students after the December holiday break. She talked about how she could do things with her students during the second half of the academic year that she could never do during the first half. In turn, this increased her motivation because it allowed her "more time to plan and create exciting things.” “Now that I'm knocking down a lot of educational things that they need to learn (content first), I'm starting to branch out and do more experimental things” (experimentation). The time of day also influenced Lucy’s decision-making behind using technology. Sometimes in the afternoon (timing within school day) her students became tired, restless, and bored, so she used technology because it was new and exciting to them (variation from routine) and got their attention (student engagement).

The examples above illustrate how and why Lucy chose to use technology. There are also reasons behind her decisions not to use technology. If she thinks there is a situation where using technology is just something to do, she is more likely not to use it (applicability). There have been times where she had planned to go to the computer lab for something “extra,” but then decided not to because she needed to "fit something in that had to do with reading or math" or another content area (content first). Another situation in which Lucy chooses not to use technology is if the preparation on her part is too time consuming and her efforts will not be 
worth what her students will learn (time vs. benefit). Lucy wishes she could design activities where her students search for information on the Internet, but states that because of the danger of her students accidentally discovering inappropriate information, she chooses not to let them (student welfare).

Interactive Decision-Making

Interactive decisions were evident during a lesson Lucy taught about the weather. She videotaped the local forecast from the Weather Channel and the local news station. Her intent was just to show various sources for getting weather forecasts, but she ended up covering weather forecasts in detail. She said, “the train just started going faster and faster, so I went with it. That blew up into something more than I expected and it was great.” Lucy said she had no idea "it was going to be so educational” (experimentation). She talked about how her students used context clues to figure things out about the weather (critical thinking) and how she could “see them deducting it all."

When Lucy taught a lesson about tsunamis, she used pictures she found on the Internet that were taken by a couple who were vacationing in Indonesia at the time. She told her students that unfortunately the people who took the pictures had died. When her students became sad, she talked about how what these people did could be used to learn from and perhaps save the lives of others in the future. She talked about how character education became a part of this lesson that she had not originally planned (incidental learning).

\section{Postactive Decision-Making}

One day during the first half of the school year, Lucy asked her students to type a story about their photographs using the computers. She took them to the computer lab and said "type a story.” They said, “We don’t have pencils.” She said, “Type it. Type up a story.” She found that 
there was no quality and it was "really hard for them to do" (informal assessment). So she modified this activity by asking her students to write a story about their photographs using pencils, then they typed their stories. Now Lucy always asks her students to write a draft using paper and pencil, do peer editing, and then rewrite before they go to the computer lab to type (content first).

Toward the beginning of the school year, Lucy played an audiotape of a book and asked her students to read along in their books. She did not feel that it worked very well, so she did not use this activity again until April (informal assessment). When her students read along with the audiotape of Two Greedy Bears in April, she discovered that they did follow along (student engagement). Lucy thinks the reason this activity was challenging early in the school year but successful later in the year was because her students were better at reading (student readiness) during the second half of the school year (timing within school year).

After using Performance Math for her students to improve their keyboard skills and also to improve their math skills, Lucy decided that she would use the program again the next week because her students "were really getting into it" (student engagement) and she thought that it would really help them with their math (applicability).

Lucy follows through with her plans to use technology because designing lessons that use technology and making sure the equipment is working is time consuming. She says, "If I actually take time to plan it, I might as well do it” (teacher investment). She uses technology in her classroom because she is familiar with it and used it when she was going to college, but she "never received any sort of training or education on technology in order to use it." She does not believe there is enough information available for teachers on how to use technology. She says 
“there’s no scholastic teacher handbook on technology. They have one on reading...but there’s nothing on how to incorporate technology in your classroom.”

Reflecting on her use of technology, Lucy said, "I had no idea that I used technology as much. I had no idea how efficient and just the advantages of it all. I had no idea that it provides so much (experimentation). So this was an absolute learning experience and I plan on using technology regularly.” She believes that using technology “might not be more efficient in time for you [the teacher], but that extra twenty minutes of working on something to prepare for the kids” is worth it (time vs. benefit). 
Table 6

Case 1: Descriptive Codes for Preactive, Interactive, and Postactive Instructional Technology Decision-Making

\begin{tabular}{|c|c|c|}
\hline Preactive Decision-Making & Interactive Decision-Making & Postactive Decision-Making \\
\hline $\begin{array}{l}\text { - Content First } \\
\text { - Standards } \\
\text { - Availability } \\
\text { - Peer Expectations } \\
\text { - Researcher's Presence } \\
\text { - Variation from Routine } \\
\text { - Student Engagement } \\
\text { - Introduce Content } \\
\text { - Direct Instruction } \\
\text { - Review and Practice } \\
\text { - Interactive Discussion } \\
\text { - Learning Efficiency } \\
\text { - Retention }\end{array}$ & $\begin{array}{l}\text { - Experimentation } \\
\text { - Critical Thinking } \\
\text { - Incidental Learning }\end{array}$ & $\begin{array}{l}\text { - Informal Assessment } \\
\text { - Content First } \\
\text { - Student Engagement } \\
\text { - Student Readiness } \\
\text { - Timing within school year } \\
\text { - Technology Skills } \\
\text { - Review and Practice } \\
\text { - Applicability } \\
\text { - Teacher Investment } \\
\text { - Experimentation } \\
\text { - Time vs. Benefit }\end{array}$ \\
\hline
\end{tabular}




\begin{tabular}{|l|l|l|}
\hline Preactive Decision-Making & Interactive Decision-Making & Postactive Decision-Making \\
\hline - Teaching Efficiency & & \\
- Visual Learning & & \\
- Enhanced Learning Opportunity & & \\
- “Real Life” & \\
- Informal Assessment & \\
- Technology Skills & \\
- Auditory Learning & \\
- Timing within school year & \\
- Timing within school day & & \\
- Experimentation & & \\
- Applicability & & \\
- Time vs. Benefit & & \\
- Student Welfare & & \\
\hline
\end{tabular}


Case Study 2 Narrative: Jennifer - Novice Middle School Teacher

This case study describes Jennifer, a novice middle school teacher, and how she makes instructional technology decisions. Jennifer earned her Bachelor's Degree in Multi-disciplinary Studies and Master's Degree in Education. She is in her $2^{\text {nd }}$ year of teaching and her classes include $6^{\text {th }}$ grade reading and $7^{\text {th }}$ grade math. Jennifer does not think she is "always the best resource" or that she can "explain everything the best.” She thinks that students can learn from other students because they "can sometimes say it better," so she believes cooperative learning to be one of the best approaches to teaching.

Jennifer's case study is introduced through insight into her learning environment and her educational beliefs, followed by decisions she made prior to teaching, during teaching, and after teaching. Italicized words enclosed within parentheses are the open codes that identify her instructional technology decisions. Following Jennifer’s case study is Table 7, which summarizes the data analysis of her preactive, interactive, and postactive teaching decisions with regard to using technology.

\section{Learning Environment}

Inside the school and Jennifer's classroom. Jennifer's school is brightly lit and the floors in the classrooms are covered with carpet. Between classes, the hallways are filled with students going to their lockers to get materials for their next class. The walls in Jennifer's classroom are accented with brightly colored posters pertaining to math, reading, writing, study skills, and test taking. Her students' desks are arranged in seven groups of four or five students each, with the desks facing one another. Jennifer's desk is angled in the right corner of the room. The wall on the left is lined with tables that contain two computers and work space for projects. Three of the walls in the classroom are nearly covered with large whiteboards. On the whiteboard at the front 
of the room, Jennifer always writes the daily agenda, such as "Math Today" with a bulleted list below. Her students like this because they know what they will be doing. Both Jennifer and her students use this whiteboard and the one on the right side of the room throughout class.

Educational philosophy. Jennifer has created an atmosphere that is welcoming and comfortable, through special touches such as the smell of apple pie filling the air from the scented oil she has plugged into the wall, and by her teaching style. She lets her students know that she cares about them and also lets them know "that it's okay to be wrong," which is evident when they are solving math problems and are not afraid to offer solutions. She balances reading and literacy and creates math classes that involve manipulatives, self-discovery, and problem solving. Jennifer believes that "every child has somewhere they can excel” and part of her job is "to find that and help them to capitalize on that." In addition to teaching content, she thinks, "part of her job is to teach her children how to be a learner and survive in the community. This involves teaching them responsibility, problem solving, and sometimes temporarily putting aside math and talking about what they're really interested in.” In both her reading and math classes, she challenges her students to think. She doesn't just want them to tell her the answer, but also wants to know how they arrived at that answer and their thinking behind it.

\section{Preactive Decision-Making}

Technology planning approach. Jennifer thinks about using technology as she plans her lessons. She knows what technology is available as she thinks about her curriculum for the year, but decisions on the use of technology are made as she designs her lessons.

Outside influences. Outside factors that influence Jennifer’s decision to use technology are statewide standards and the availability of technology in her school. She follows West Virginia’s Content Standards and Objectives (CSOs), which include standards for using 
technology (standards). Her school does not have formal requirements for using technology, but resources are available so Jennifer and the other faculty are constantly being told by administration officials to use it (administration's requirements).

Despite the resources available at her school, Jennifer often finds it difficult to take advantage of the computer labs. There are three computer labs available, one each for the $6^{\text {th }}, 7^{\text {th }}$, and $8^{\text {th }}$ grades, but “so many people are signed up for the technology lab” that Jennifer says "time is a big issue" and often she cannot get the lab for the amount of time she needs (availability).

Teaching and learning decisions. When she can schedule the computer lab for the amount of time she needs for a particular lesson, Jennifer takes her students to it so they can gain computer experience (technology skills) and work on projects that are similar to "kinds of things they're going to be expected later in life to do (life skills).” For example, at the end of a geometry unit, instead of giving a test, she had her students "create a poster comparing two polygons” using commercially produced publishing software (formal assessment). She gave them class time to create their posters because not all of her students had technology at home. The reasons Jennifer choose to have her students create their posters on the computers as opposed to creating them by hand was because 1) it is easier for her as the teacher (teaching efficiency); and 2) "it looks much more professional than a handwritten poster." She says, "this is advanced preparation, I guess” because “you can’t hand in a handwritten paper...for your job” (life skills).

Sometimes Jennifer takes her students to the computer lab to type final drafts of papers they are working on because this gives them more computer experience (technology skills). She asks her students to hand write their rough drafts "because they're so slow [at typing], especially 
slow typers who haven't had typing skills yet. So instead of putting them on the computers first, for the sake of time (teaching efficiency), rough drafts are handwritten and then the second and final drafts are typed (content first).”

Technologies that are readily available include calculators and graphing calculators. At the beginning of the school year, Jennifer does not allow her students to use calculators because she wants to know "who can do what and where weaknesses are” (informal assessment). Jennifer does not want her students to use calculators for basic skills because she wants them to know how to do basic skills on their own (content first). She asks them to show her using paper and pencil that they can do the basic skills and write out the solutions to problems involving basic skills. After they have mastered the basic skills and she wants them to "move onto something bigger”, then she'll “definitely let them use the calculator” for the basic skills (learning efficiency) so they can focus on the more involved math (critical thinking). She wants them to “see that higher-level thinking.” An example is when Jennifer talked about using the graphing calculators with linear equations. "You make one small change in the equation and they can see it right away, the change that it makes in the graph (visual learning; discovery learning). They really get excited about it” (student engagement).

Using the Internet to learn more about Dr. Seuss was one of the stations in a reading lesson that Jennifer taught. Since it was Dr. Seuss’s birthday, she wanted her students to learn more about him. She had "some newspaper articles," but "thought that using the web sites would be more interesting” (student engagement; variation from routine). So Jennifer pre-selected two web sites for her students to use and printed them on a worksheet, along with instructions for the activity that she wanted her students to do (direct instruction). Rather than her students just 
reporting back what they read, Jennifer asked them to complete an acrostic poem based on what they learned about Dr. Seuss (critical thinking).

One of Jennifer's educational beliefs is that she should do a lot of modeling, especially in reading, so her students can learn what a good reader does and hopefully "catch on to that and do it as they read more.” For one of her reading lessons, she chose to use technology to help her model good reading (modeling). Jennifer divided her students into groups and they went from station to station, one of which was to read along in a book while listening to it on an audiocassette. The five students at this station had an audiocassette player with headphones. She decided to use audiocassette technology because her students could "hear how a good reader sounds and hear how unfamiliar words that they read in the book are pronounced” (auditory learning; modeling). She said, "This will teach them about tone, flow, speed, and increase their vocabulary power.” Other stations in this reading lesson included one where the students followed along in their books while Jennifer read, allowing her to model and discuss good reading strategies with her students (interactive discussion). She said that she based her class on the concept of Balanced Literacy, where "students work on vocabulary, listen to audiotape books to hear what a good reader sounds like and learn new vocabulary, read books on reading level, hear and see the teacher model good reading strategies through shared reading, and apply skills learned through reading good literature to their own writing, and increase independent reading through presenting a variety of books to the students for them to choose for independent reading.”

Jennifer also models by using the overhead projector. She says, “That's where I do a lot of modeling. I tell my students right now I am thinking...or right now I would do...” Jennifer believes that helps to make what they are learning clearer to them and that they "get more out of 
it" (learning efficiency). Another reason Jennifer uses the overhead projector is because she knows it is better to draw on transparencies "where she can face her students, as opposed to using the whiteboard and having her back turned to them.” If her back is turned to her students, Jennifer “can’t really see them and their expressions and how they are responding to what I'm saying” (informal assessment). She finds “it’s much easier to be looking at them, using the overhead, modeling for them, and watching how they react.” She says this allows for better discussion from her students (classroom management; interactive discussion). Jennifer says the overhead projector is also beneficial when she wants her students to take notes because she thinks "they have an easier time taking notes from a transparency than from the whiteboard (learning efficiency) and she doesn't “like to write all over the whiteboard all day” because she has to erase it and rewrite the same thing over and over for different classes (teaching efficiency). When designing her lessons, Jennifer sometimes decides to use technology because it is different and her students enjoy using different tools (variation from routine). She says, "They get tired of the traditional approach. They get tired of worksheets.” A technology that her students enjoy using is the whiteboard, both the large whiteboards mounted to the walls and the mini-whiteboards they use individually.

Another reason Jennifer decides to use whiteboards is to model. She says, "I get up there sometimes and do it wrong. And I say it's no big deal. It's how we learn (modeling).” Jennifer also asks her students to use the whiteboards when she wants feedback as the teacher (informal assessment). She uses both the wall-mounted whiteboards and mini-whiteboards to see "who's getting it and who's not." She says it is "sort of like an informal assessment" and she "gets a really good feel of who's getting it and who's not right away.” 


\section{Interactive Decision-Making}

While teaching, there were situations when Jennifer added a technology at the last minute and circumstances when she chose to eliminate a technology she had planned to use. When teaching a lesson on cubed roots, Jennifer decided “at the last minute” to connect her calculator to the overhead projector because she thought “telling them the buttons [to press] wasn't going to be sufficient” because she couldn't get feedback from them and wouldn't know if they got it right (informal assessment). So she thought, "if they could see what they were supposed to see on their calculators (visual learning), then it would be clear. Oh no, my screen doesn’t look like that, and they could put their hand up” (“instant feedback”; informal assessment).

Jennifer's decision to eliminate the use of specific technology was usually due to limited time (time limitation). For example, she planned to have her students do line graphing on their calculators, but "with the WESTEST and all of the end of the year activity" she did not get to it. She still taught the content (content first) using paper and pencil, the whiteboard, the overhead projector with transparencies, but they did not get to use the calculators, which would have provided "that immediate viewing of how a different X coefficient changes the slope.” Another circumstance where she altered her plan to use calculators occurred when she was teaching a unit on probability. The calculators will do “chance activities for you. It'll flip a coin a hundred times. It'll roll a die a hundred times,” but she and her students never got to use the calculators "because of time” (time limitation). Again, she covered all of the content using other approaches, but never "got to the calculator to play the game" (content first).

There were days when Jennifer was going to use the mini-whiteboards, the individual whiteboards, for her students to "write their answers for homework and hold it up,” but instead decided to ask her students to "take turns at the front board, just for the sake of keeping control" 
(classroom management) because she noticed some students not paying attention and doing artwork on their mini-whiteboards. Another reason she opted to send her students one at a time to the large whiteboard was because she was aware that some of her students were not sure of their answers and tended to sit back and "wait until a lot of the kids held up their boards" and then wrote down the answer that the majority had written (informal assessment). She said her students would say, "I'm thinking," but she could see their eyes roaming and knew "exactly what they were doing."

\section{Postactive Decision-Making}

Jennifer commented on how much her students like using the whiteboard. She thinks her students enjoy going to the big whiteboards to work through a problem because "they like having the teacher position for just those few minutes. I think they like being able to explain themselves (“voice”) and being sort of in control for a few minutes” ("relinquish control”). Another observation Jennifer made when her students were using the wall-mounted whiteboards is that they liked the feedback ("instant feedback"). She explained that "when those kids are at the board and they do something wrong, you better believe that someone in this classroom is not going to let it go.” This does not occur in a negative way, because Jennifer has “created an environment where they don’t worry about saying something like that and the kids aren’t offended by something like that. I think this is a really friendly environment where you don’t feel pressured if you did it wrong.” Jennifer tells her students that it is important to learn from their mistakes.

Looking at her students’ acrostic poems they created after reading about Dr. Seuss on the Internet, Jennifer said, “They were terrible. Horrible.” She was not sure "if it was just the group of kids that I had and their work ethic.” She thought she had structured the activity enough 
because her worksheet directed her students to "go to specific web sites, read specific articles, and fill out the acrostic poem." She discovered that her students "copied one another" and gave "one-word answers." She thinks her students focused more on the fact that they were on the Internet getting to read rather than the writing portion of the activity (novelty). Jennifer said "the after part” is what she wanted, so the activity "wasn’t as successful as I would have liked.” In the future when Jennifer asks her students to use Internet resources and create acrostic poems, she will provide more detailed directions and ask her students to work independently as opposed to working in groups (classroom management).

Another activity Jennifer planned that did not go as she had hoped and will revise in the future was a lesson on West Virginia authors. She was out of school that day and created the lesson plan for the substitute teacher to use. Her students had read selections written by several West Virginia authors and then she wanted them to research these authors on the Internet. She asked her students to write the questions based on what they wanted to know about the authors and what they thought would be important to know. Rather than let them search any web site they wanted, Jennifer found approximately ten web sites for them to access. The intent was for all of her students to do the activity, but the school changed the schedule and all of her students could not get to the computers. For the six students who did this activity it was successful and Jennifer plans to use this lesson again. She says, "I'll definitely use it again. I'll do it sooner than the end of the year" (time limitation) so that all of the students have the chance to work on this activity.

Technology doesn’t always function as expected, so Jennifer says, “you have to be prepared for that.” During her unit where her students rotated between reading stations, some of her students struggled getting their tape players to work. There were times when her students 
wanted to rewind their tapes but "walkmans do not have a rewind button, which students are accustomed to.” So Jennifer had to explain how to flip over the tape and fast forward instead (comfort level). Some of her students did not understand that, so in the future she will "have it set up so that students who do understand are willing to help those who struggle ("relinquish control”; student collaboration).”

Reflecting on using technology, Jennifer says "If they [her students] like it and they get something out of it, I'm going to use it more often. "Jennifer thinks it is important to "try to find unique ways to use it [technology] or new ways to use it (creativity). She doesn't think teachers should say, "oh well, my kids type on the computer, so I am using technology.” She says as the teacher, “you have to invest the time” to find ways to use it (teacher investment). 
Table 7

Case 2: Descriptive Codes for Preactive, Interactive, and Postactive Instructional Technology Decision-Making

\begin{tabular}{|c|c|c|}
\hline Preactive Decision-Making & Interactive Decision-Making & Postactive Decision-Making \\
\hline $\begin{array}{l}\text { - Standards } \\
\text { - Administration's Requirements } \\
\text { - Availability } \\
\text { - Technology Skills } \\
\text { - Life Skills } \\
\text { - Formal Assessment } \\
\text { - Teaching Efficiency } \\
\text { - Content First } \\
\text { - Informal Assessment } \\
\text { - Learning Efficiency } \\
\text { - Critical Thinking } \\
\text { - Visual Learning } \\
\text { - Discovery Learning } \\
\text { - Student Engagement }\end{array}$ & $\begin{array}{l}\text { - Informal Assessment } \\
\text { - Visual Learning } \\
\text { - “Instant Feedback” } \\
\text { - Content First } \\
\text { - Time Limitation } \\
\text { - Classroom Management }\end{array}$ & $\begin{array}{l}\text { - “Voice” } \\
\text { - “Relinquish Control” } \\
\text { - “Instant Feedback” } \\
\text { - Novelty } \\
\text { - Classroom Management } \\
\text { - Time Limitation } \\
\text { - Comfort Level } \\
\text { - Student Collaboration } \\
\text { - Creativity } \\
\text { - Teacher Investment }\end{array}$ \\
\hline
\end{tabular}




\begin{tabular}{|l|l|l|}
\hline Preactive Decision-Making & Interactive Decision-Making & Postactive Decision-Making \\
\hline - Variation from Routine & & \\
- Modeling & \\
- Auditory Learning & \\
- Interactive Discussion & & \\
- Classroom Management & & \\
\hline
\end{tabular}




\section{Case Study 3 Narrative: Kristi - Novice High School Teacher}

This case study describes Kristi, a novice high school teacher, and how she makes instructional technology decisions. Kristi earned her Bachelor's Degree in Mathematics and her Master's Degree in Secondary Education. She is in her second year of teaching and her classes include Applied Math and Algebra. She says, "I have learned so much these two years and it just keeps coming.”

Kristi’s case study is introduced through insight into her learning environment and her educational beliefs, followed by decisions she made prior to teaching, during teaching, and after teaching. Italicized words enclosed within parentheses are the open codes that identify her instructional technology decisions. Following Kristi's case study is Table 8, which summarizes the data analysis of her preactive, interactive, and postactive teaching decisions with regard to using technology.

\section{Learning Environment}

Inside the school and Kristi's classroom. Kristi has arranged her students' desks in rows, all facing the front of the room. Large chalkboards cover the walls at the front, back, and right side of the room. Above the chalkboard in the front of the room is a small television mounted to the wall and a few student-created drawings of the school mascot. A small wooden podium stands at the front of the room. Behind the podium, sitting on a cart with wheels, is an overhead projector. Kristi's desk sits in the back corner of the room by the windows, bordered by filing cabinets and bookshelves. In the opposite corner of the room, across from Kristi’s desk, sits a computer and printer that she uses to submit students' grades and communicate with other teachers via email. 
There are numerous students with special needs in Kristi's class, so the Special Education teacher often assists her. As students enter the classroom, he checks their homework and makes sure they have what is needed for class. While she is teaching, he circulates the room to help students and make sure they are on task. Kristi commented that her students behave better and she has more control when the Special Education teacher is in the room. If Kristi and her students use technology during a class period when the Special Education teacher is assisting, he helps students with the technology, but he does not influence her decision-making to use technology.

Educational philosophy. Kristi believes that "every student can learn whatever you expect them to learn." She says "you can set expectations for different students and get them to reach that point, which is to the best of their ability." She likes to "incorporate as many learning strategies as possible, which includes hands-on learning, cooperative groups, and technology.” This year she said that she had a difficult time using these strategies with the level of students in her classes because "they get off track" and "a lot of them have special needs."

\section{Preactive Decision-Making}

Technology planning approach. At the beginning of the school year, Kristi plans her curriculum by creating a map of what she wants to cover during the year. From this map she determines where she needs to be at certain points, then breaks her year down into months and then weeks. Throughout the school year she revisits her monthly, weekly, and daily plans "because you never know what will happen and where students will struggle” (informal assessment). Her daily plans are written in the form of an outline that she places on the calendar on her desk. As for using technology, Kristi knows what is available and tries to "match it with the topics and lessons” (applicability) she will be teaching. 
Outside influences. An outside factor that influences Kristi’s decision to use technology is statewide standards. Kristi follows West Virginia’s Content Standards and Objectives (CSOs), which include standards for using technology (standards).

Availability of resources also influences Kristi’s decision-making about using technology (availability). Technology resources in her school are not abundant. For example, graphing calculators have to be shared by all the math teachers because there are not enough for every classroom. In the school she taught at last year, every classroom had graphing calculators, so she used them more often. Another limited resource in Kristi’s high school is computers. The entire school shares three computer labs, which makes access difficult. When talking about plans she had to use the computer lab, the Internet, and the I Know web site to help students prepare for the WESTEST, Kristi said "I would have rather used technology to get them more interested and involved” (student engagement), but due to writing assessment and other priorities taking over the computer lab, she helped her students prepare for the WESTEST using paper and pencil instead.

Teaching and learning decisions. When designing her lessons, Kristi’s decisions about how and why to use technology are based on her belief that technology is something new and different (variation from routine) for her students and they become more active learners (student engagement) instead of watching her write numbers on the chalkboard. She also likes to use technology to help her students "see and apply what they have learned," for instance by looking at a graph (visual learning), where "maybe they can use that to connect why $\mathrm{x}$ is equal to 4 (critical thinking), and something is telling them other than the teacher who they don't want to listen to" (variation from routine). 
Kristi also makes decisions about using technology based on the relevance of the innovation to what her students are learning (applicability). Students in all of her classes "have a calculator in their hands" every day and "they're allowed to use it at any time.” Students in her Applied Math classes do not use graphing calculators a lot because there are not many applications for the content she covers. She did use graphing calculators when her students got into graphing and "systems and ideas that will benefit from graphing calculators" (applicability).

For a lesson that she taught about lines and slope, Kristi borrowed handheld computers from the North Central Regional Education Service Agency (referred to as RESA VII). She was entitled to borrow the equipment as a result of attending their professional development on handheld computers. During the first half of the class period, Kristi assigned her students to teams of two or three, and taught everyone how to use the handheld computers. She led them through the process of using features they would need for the activity she planned, such as composing, sending, and receiving messages, taking notes, and capturing photographs and "beaming” them to another handheld computer. Then Kristi told her students to add the following notes to their handheld computers: your name and your partner's name, vertical line undefined slope, and horizontal line - zero slope. She then said, "We are going to the football field. Take two pictures of vertical lines and two pictures of horizontal lines. After that, beam the pictures to me." Her intended use for the handheld computers was for students to capture and share pictures of "real life things that relate to the math that we're doing" ("real life"; applicability). She planned to use the digital images captured by her students to study parallel and perpendicular lines, as well as slope.

Using the overhead projector for Algebra I was a pre-teaching decision Kristi made because she said she is not the best at drawing and "wanted things to be very precise (accurate 
representation) so it was easier to have it on the overhead." She found a coordinate grid that someone else created that was very neat and easy for her students to read as opposed to her drawing one. Kristi thinks that using the overhead projector "helped the kids because it was a different thing" (variation from routine). She found "they were excited (student engagement) because I was using the overhead and they were wondering why.”

Student behavior impacted Kristi's decisions of how and why to use technology during the school year. She talked about when the students returned from the holiday break in December that it was "very hard to get them back on track again because they come back here for about a week and a half, then they're off for about another week for finals.” She said the dynamics of the classes often change because the students change, where students who were once friends are now enemies or there are new students who arrive in January. Kristi waits to use technology until "it will be a good time of the year, after they've adjusted to me and each other and classroom management is better.” At this point, she tries to slowly incorporate technology (timing within school year).

One of Kristi’s classes was "much more advanced than the other two" because they were on task more often and she had fewer discipline problems with them. She commented on how they were usually a day or two ahead of her other classes as a result, so technology was a way for her to "have a day where they're learning something and using critical thinking skills (critical thinking) and to slow them down a little bit” so she could keep all three classes on the same content (pacing).

Another time related factor that influences Kristi’s decision about whether or not to use technology is the class period of the day. She said "that sounds dumb, but some periods we lose more time than we do in other classes. At the end of the day, there are a lot more assemblies, 
announcements, and kids coming late to class.” She explained that during the morning classes there is usually a lot more time to do an activity because there are not as many interruptions as there are during the afternoon (time limitation). Kristi likes to be fair to all of her students, so sometimes she does not use technology as planned because she knows she cannot use it throughout the day and does not want to use it with a few classes and not others (fairness).

There were times when Kristi considered using technology but then chose not to because she feared what her students would do to the equipment (classroom management). A mobile computing lab with laptop computers is dedicated to the floor on which she teaches, but Kristi is "afraid of putting a laptop on the desk" of some of her students because of their lack of attention, discipline and behavior (informal assessment; student readiness). She fears these students will damage the laptop computers. "You just never know what they’re going to do. You have to be very careful and very watchful.” She says that she has had students steal items from her desk, so she hesitates to put a graphing calculator or handheld computer into their hands. "When you have thirty kids, it’s hard to monitor them” (classroom management).

\section{Interactive Decision-Making}

Situations occurred where Kristi planned to use technology but could not because "the kids just had too many questions about their homework” and she spent a greater amount of time reviewing than she had anticipated (time limitation). After reviewing, she had to introduce new material, which precluded using technology (content first). Kristi’s school implements block scheduling, which means that she does not see all of her students every day but every other day. If she had a group on Thursday and not on Friday, that meant she would not see them again until the following Monday or Tuesday, leaving a gap of four or five days. When that happened, she indicated that she needed to spend at least half of the class period reviewing. 
Decisions made during teaching were evident during a lesson where Kristi used graphing calculators for a lesson on rational expressions. She began the lesson by writing an algebraic problem on the blackboard and working through it, asking her students questions to help solve the problem. After they worked through this math problem, Kristi passed out a sheet of paper with five examples of similar algebraic problems and solutions so they could see how the problems were solved. A student said, “I am a kinesthetic learner. I have to do these problems. I cannot read them on a sheet of paper and understand them.” So Kristi wrote another problem on the blackboard, asking her students, "what should we do first? Then what” (interactive discussion)? As she worked through the problem, she explained what to do and why (modeling). Some of her students said that they still did not understand. Kristi said "let's look at these same examples in a different way” and walked to the back of her classroom and picked up a large box filled with graphing calculators. As she handed out graphing calculators to her students, she asked how many had used them before and four students raised their hands. She spent time talking about the different buttons on the graphing calculators and asking her students to press them so they could see what happened (visual learning). Then Kristi helped her students to use their graphing calculators to work through a problem that she had written on the blackboard and they solved previously using paper and pencil ("reinforcement”). She and her students worked through another problem using the graphing calculators that they had previously worked on using paper and pencil. Then Kristi asked her students to return the graphing calculators to their cases and put them back into the big box. At the end of the class period, Kristi said, "I thought using graphing calculators would be helpful, but it wasn't. I decided to put them away and go back to pencil and paper to work through the algebra problems. They just weren't getting it 
(informal assessment). She said it was probably because most of them had never used graphing calculators before” (comfort level).

Kristi designed a lesson where she had teams of students go outside to the football field and take two pictures each of horizontal and vertical lines using handheld computers. She created folders for each team on her handheld computer. After the first team of students finished taking pictures, they beamed them to her. Kristi noticed that it took much longer than she expected for one picture to transfer to her handheld computer due to the size of the image, so she decided rather than asking each team to beam all four pictures to her, she wanted only one photograph from each team (time limitation). Kristi had planned to talk about undefined and zero slope, but ran out of time. She thought she would have time with the next class.

When the next class arrived, Kristi passed out calculators then gave her students a quiz, asking them to solve the problems on a piece of their notebook paper. She told them they were allowed to use calculators during the quiz. While taking the quiz, several students began talking. As a result, Kristi told them they now had another assignment with six questions and had twenty minutes to complete it. After twenty minutes elapsed, Kristi collected their papers, assigned them to groups, and gave a handheld computer to each group. She taught them how to use these computers but they did not have time to go outside and capture images of parallel and perpendicular lines. When I asked Kristi about the changes she made to her lesson plan, she indicated that she "could not allow their talking to go without reprimand" and decided to give them the extra assignment. This meant her students did not have time to go to the football field to take pictures (time limitation). She also said "without teaching assistants (who helped her during the first class), it was pointless to try" (classroom management). She mentioned that if her "class 
gets ways out of hand and they end up getting their three strikes," then she takes away their technology (reward or punishment).

\section{Postactive Decision-Making}

Kristi indicated that she has "to get the concept in" before she can use technology (content first). She said that if she were teaching an upper level class, she would probably use the overhead projector with the calculator connected to it "because they have the basic concepts behind them, whereas in Algebra I, they need to get the basics behind them.” She finds that in her lower level classes that when she tries to use technology to try to reinforce a basic concept, her students “don’t connect the two.” She elaborated, saying that her students remember the technology but not the concepts and basics of what they were learning (novelty).

When teaching, Kristi always had an alternative plan available. If she tried to use technology and found it wasn't "going to work" (learner assessment) or if the class got "way out of hand" (reward or punishment), then she always had a worksheet that did exactly the same problems they were going to solve using technology (backup plan).

Although Kristi perceives benefits to using technology and her students enjoy using technology, she hesitates to use it in her Applied Math classes until later in the year (timing within school year) because her students have attention problems (classroom management; student readiness). She discovered that sometimes her students "enjoy technology too much and they get sidetracked with it, especially when you're initiating it” (novelty), which is one reason that Kristi says she likes to use technology later in the year (timing within school year). "If students have an attention problem and you throw a toy in their hand (technology as toy), you've lost them.” Kristi says you have to gain their respect and they have to understand what you expect from them before you give them technology to use. She thinks if students used technology 
more throughout high school that she would be able to use it more often. Last year when she taught at a different school, her students used technology on a daily basis so they were used to it and she could use it more often (technology as tool).

Kristi talked about the importance of the photocopy machine. Kristi's students like to "have something to hold onto (kinesthetic learning). So if they don't have a sheet of paper” with something on it, such as math problems, and they have to copy the problems from the board, "they get sidetracked. If they have it right there in front of them, they seem to focus better" (“focus”).

“Just give us a worksheet and let us get on with our work" (habits) is how Kristi described her students in her Applied Math classes. She said that she didn't know if they were trained that way or if they just prefer to be left alone and work on their own as opposed to using technology to tie what they are learning to the real world.

Kristi does not believe there is a best way to determine in which lesson she should use technology or not use it. She thinks that in math you can use "technology with anything. It's just a matter of if the kids are going to connect the concepts or are they going to be able to understand why it is you're doing it (critical thinking) and it's not just busy work for them" (applicability). 
Table 8

Case 3: Descriptive Codes for Preactive, Interactive, and Postactive Instructional Technology Decision-Making

\begin{tabular}{|c|c|c|}
\hline Preactive Decision-Making & Interactive Decision-Making & Postactive Decision-Making \\
\hline - Informal Assessment & - Time Limitation & - Content First \\
\hline - Applicability & - Content First & - Novelty \\
\hline - Standards & - Interactive Discussion & - Informal Assessment \\
\hline - Availability & - Modeling & - Reward or Punishment \\
\hline - Student Engagement & - Visual Learning & - Backup Plan \\
\hline - Variation from Routine & • “Reinforcement” & - Timing within school year \\
\hline - Visual Learning & - Informal Assessment & - Classroom Management \\
\hline - Critical Thinking & - Comfort Level & - Student Readiness \\
\hline • “Real Life” & - Classroom Management & - Technology as Toy \\
\hline - Accurate Representation & - Reward or Punishment & - Technology as Tool \\
\hline - Classroom Management & & - Kinesthetic Learning \\
\hline - Timing within school year & & • “Focus” \\
\hline - Pacing & & - Habits \\
\hline - Timing within school day & & - Critical Thinking \\
\hline
\end{tabular}




\begin{tabular}{|l|l|l|}
\hline Preactive Decision-Making & Interactive Decision-Making & Postactive Decision-Making \\
\hline$\bullet$ Fairness & & \\
$\bullet$ Student Readiness & & \\
\hline
\end{tabular}


Data produced by the three novice teachers’ case study narratives and corresponding tables of descriptive codes were synthesized and analyzed for similarities and differences:

1. Descriptive codes for the three novice teachers were compiled into a matrix and analyzed (see Appendix F).

2. Descriptive codes were tallied and analyzed for the three decision-making phases for novice teachers.

3. Pattern codes were developed for novice teachers by looking at relationships within the descriptive codes.

4. Pattern codes were tallied and analyzed according to the three decision-making phases for novice teachers.

\section{Novice Teachers Descriptive Code Analysis}

Descriptive codes for the novice teachers' preactive, interactive, and postactive instructional technology decisions were compiled in a matrix (see Appendix F). In the far left column the descriptive codes for all three novices are listed and the three decision-making phases are identified across the top. To create this matrix, each novice's table of descriptive codes (Table 6, Table 7, and Table 8) was referenced to determine what descriptive code occurred during which decision-making phase, and an $\mathrm{X}$ was placed in the corresponding column. By analyzing the matrix of compiled descriptive codes, the following similarities and differences in novice teachers’ instructional technology decision-making were discovered:

- All three novices made some of the same descriptive decisions within the preactive phase. 
- All three novices made some of the same descriptive decisions at some point within the three phases.

- Some descriptive decisions were specific to only one of the three novices. Same Decisions within the Preactive Phase

Looking at descriptive codes across the three decision-making phases, it is evident that all three novices made some of the same decisions within the preactive phase. The external influences, standards and availability, affected the preactive decisions of all three novice teachers. West Virginia's Content Standards and Objectives (CSOs), which include standards for using technology, have to be implemented by all K-12 teachers. Abundant resources at Lucy's elementary school meant that her decisions to use technology were not based on whether on not she could access the equipment. On the other hand, lack of abundant resources at Jennifer's middle school and Kristin's high school influenced their decisions to use technology. There were times when both Jennifer and Kristin wanted to use the computer labs in their schools but could not because they were being used by other teachers and students.

While planning lessons, all of the novice teachers chose to use technology for variation from routine and as a means of student engagement, both of which fall within the student benefit pattern code. Lucy (elementary school) talked about her decision to use a PowerPoint presentation about frogs she found on the Internet, as opposed to having her students look at pictures in textbooks because it held their attention and they like to do things that are "different." Jennifer (middle school) chose to use the whiteboards and other technologies because her students "get tired of using worksheets" and enjoy different tools. Kristi (high school) decided to have her students use calculators because "technology is something new and different” for her 
students and they are "more active learners" instead of watching her "write numbers on the chalkboard”.

Visual learning, a subcategory within diversity, is another reason why all three novices decided to use technology. Lucy chose to use pictures she found on the Internet and photographs she took using a digital camera because these images allowed her first grade students to see things they were learning. Jennifer and Kristi used calculators and graphing calculators so their middle school and high school students could see what happened when calculations were performed.

Novice teachers' decisions related to instructional strategies are evident in their choices about whether or not to use technology based on classroom management and informal assessment. Lucy (elementary school) used a document camera and Jennifer (middle school) used the overhead projector so they could face their students while teaching, observe their reactions to what they were learning, assess if they were comprehending or not, and control students’ actions when necessary. Kristi (high school) often chose not to use technology, even when she thought it would help her students, because her students' behavior lead her to believe that she could not control their actions when they had technology to use. She was afraid they would break or steal the equipment.

\section{Same Decisions within the Three Phases}

Examining the descriptive codes shows that all three novices, at some point within either the preactive, interactive, or postactive phase, made similar decisions. All of these descriptive decisions were part of the instructional strategies pattern. While planning, the elementary and middle school teacher thought about content first, technology second. During teaching, the middle and high school teacher focused on content first. Following teaching, the elementary and 
high school teacher made revisions to future lessons based on covering content first and technology second.

All three novices considered the use of technology for critical thinking but at different phases. During the preactive phase, the middle and high school teacher thought about using technology to challenge their students to think critically. The high school teacher reflected on critical thinking during the postactive phase as well. The elementary teacher considered critical thinking during the interactive phase.

During the preactive phase, the elementary and middle school teacher planned to use technology for interactive discussion with their students. The high school teacher decided to use technology for this purpose during the interactive phase.

\section{Teacher-Specific Decisions}

There are twenty-nine descriptive decisions that were made by only one of the novice teachers. This information was obtained by analyzing Appendix F: Descriptive and Pattern Codes Representing Novice Teachers' Decision-Making. These teacher-specific decisions were evident in looking at the descriptive codes across the three decision-making phases. Descriptive codes for which an $\mathrm{X}$ appeared only once, or an $\mathrm{X}$ appeared more than once but for only one of the novices, represented a teacher-specific decision. Novice teacher-specific decisions are synthesized in Table 9, which lists the pattern codes and related descriptive codes in the columns on the left. The far right column is divided into three, representing preactive, interactive, and postactive decision-making phases, and Case 1, Case 2, or Case 3 (representing elementary, middle, or high school teacher) was placed in these columns to represent which of the novices made the decision. 
Table 9

Summary of Teacher-Specific Decisions for Novice Teachers

\begin{tabular}{|c|c|c|c|c|}
\hline \multirow[t]{2}{*}{ Pattern Code } & \multirow[t]{2}{*}{ Descriptive Code } & \multicolumn{3}{|c|}{ Decision-Making Phase } \\
\hline & & Pre & Inter & Post \\
\hline \multirow{3}{*}{ External Influences } & Administration's Requirements & Case2 & & \\
\hline & Peer Expectations & Case1 & & \\
\hline & Researcher's Presence & Case1 & & \\
\hline \multirow{11}{*}{ Student Benefit } & Accurate Representation & Case3 & & \\
\hline & Fairness & Case3 & & \\
\hline & "Focus" & & & Case3 \\
\hline & Habits & & & Case3 \\
\hline & "Instant Feedback" & & Case2 & Case2 \\
\hline & Incidental Learning & & Case1 & \\
\hline & Life Skills & Case2 & & \\
\hline & Retention & Case1 & & \\
\hline & Student Collaboration & & & Case2 \\
\hline & Student Welfare & Case1 & & \\
\hline & "Voice" & & & Case2 \\
\hline \multirow{6}{*}{ Instructional Strategies } & Discovery Learning & Case2 & & \\
\hline & Formal Assessment & Case2 & & \\
\hline & Introduce Content & Case1 & & \\
\hline & Pacing & Case3 & & \\
\hline & Review and Practice & Case1 & & Case1 \\
\hline & Reward or Punishment & & Case3 & Case3 \\
\hline Diversity & Kinesthetic Learning & & & Case3 \\
\hline Improvement & Enhanced Learning Opportunity & Case1 & & \\
\hline \multirow[t]{2}{*}{ Technology Readiness } & Technology as Tool & & & Case3 \\
\hline & Technology as Toy & & & Case3 \\
\hline \multirow[t]{5}{*}{ Teacher Change } & Backup Plan & & & Case3 \\
\hline & Creativity & & & Case2 \\
\hline & Experimentation & Case1 & Case1 & Case1 \\
\hline & "Relinquish Control" & & & Case2 \\
\hline & Time vs. Benefit & Case1 & & Case1 \\
\hline \multicolumn{2}{|c|}{$\begin{array}{l}\text { Total Teacher-Specific Decisions for all three Novices by Decision- } \\
\text { Making Phase }\end{array}$} & 16 & 4 & 15 \\
\hline \multicolumn{2}{|c|}{$\begin{array}{l}\text { Total Teacher-Specific Decisions for each Novice by Decision- } \\
\text { Making Phase }\end{array}$} & $\begin{array}{l}\text { 9-Case1 } \\
\text { 4-Case2 } \\
\text { 3-Case3 }\end{array}$ & $\begin{array}{l}\text { 2-Case1 } \\
\text { 1-Case2 } \\
\text { 1-Case3 }\end{array}$ & $\begin{array}{l}\text { 3-Case1 } \\
\text { 5-Case2 } \\
\text { 7-Case3 }\end{array}$ \\
\hline
\end{tabular}

Case $1=$ elementary school teacher Case2 $=$ middle school teacher Case $3=$ high school teacher

Novices made nearly the same amount of teacher-specific decisions during the preactive phase (16) and the postactive phase (15). They made the fewest teacher-specific decisions during the interactive phase (4). The elementary novice made the most teacher-specific decisions overall 
(14). The middle school and high school novice made nearly the same number of teacherspecific decisions (10 and 11 respectively). During the preactive and interactive phases, the elementary teacher made the most teacher-specific decisions ( 9 and 2, respectively). In the postactive phase, the high school novice made the most teacher-specific decisions (7) and the elementary teacher made the fewest (3).

Teacher-specific preactive decisions made by the novices were affected by external influences beyond their control. The middle school teacher was the only one who was required by administration to use technology. The elementary school teacher was the only person who made decisions to use technology because of peer expectations and the researcher's presence.

Decisions made by novice teachers that pertain to their perceived benefit for students are evident. The high school teacher alone made the decision not to use technology because of fairness and habits. On some occasions she chose not to use technology because her students during a particular class period did not have time to use it, so to be fair to her other students, she opted not to use it for any of her classes. She also chose not to use technology sometimes because her students indicated they would rather complete more familiar activities such as worksheets. The high school novice was the only teacher who recognized that technology could be used to help her kinesthetic learners to focus by giving them something to hold or they would become distracted. The middle school teacher alone recognized both while she was teaching and after that the ability of technology to provide instant feedback was beneficial to her students. She was also the only novice teacher who realized the benefit of using technology to help her students learn skills that would be valuable throughout their lives (life skills), to collaborate, and to give her students a voice in the classroom. The elementary school teacher was the only novice who planned to use technology because her students retained information better (retention). She 
is also the only teacher who chose not to use the Internet for research because she did not want her first graders to accidentally discover web sites with inappropriate information (student welfare). The high school novice recognized the difference between technology as a tool and technology as a toy, but chose to use technology as a form of reward or punishment, based on her students’ behavior.

As for recognizing teaching decisions that had to be made differently when using technology, the high school novice is the only one who mentioned that a backup plan is a necessity. The middle school novice mentioned that teachers should find creative ways to use technology instead of just using computers and thinking that was a good use of technology. She also talked about not being afraid to relinquish control of the classroom and let students have more control over their learning. The elementary school novice made decisions to use technology as an experiment to see what would happen. The elementary teacher also made instructional technology decisions by evaluating the amount of time required versus the benefit to students (time vs. benefit).

Improvement in teaching and learning by allowing something to be accomplished that could not be done without it (enhanced learning opportunity), helped the elementary teacher to decide to teach a lesson about tsunamis as part of her weather unit. Lucy found pictures on the Internet of the tsunami that occurred in Indonesia, and says these pictures allowed her to teach about something that would otherwise be difficult to teach.

Instructional strategies, or the ways in which the teachers decided to use technology for teaching and learning, are evident. The elementary teacher is the only novice who planned to use technology to introduce content and for review and practice. The middle school teacher was the only one who decided to use technology to formally assess her students when she asked them to 
create a poster comparing polygons. She was also the only novice who chose to use technology for discovery learning by asking her students to use graphing calculators so they could see what happened when a change was made to an equation. The high school teacher chose to use technology during her planning because she knew she could use it to control the pace of the class and actually used it to "slow down" one class so her students in other class periods could catch up.

The next step in the analysis of novice teachers’ decision-making was to total the number of each descriptive code. Similarities and differences in novice teachers’ instructional technology decision-making are apparent from analyzing the number of descriptive decision codes for each teacher within each decision-making phase (see Appendix H for a complete list of descriptive codes and their definitions). Descriptive codes representing decisions made by each novice teacher prior to teaching, during teaching, and after teaching were totaled by counting the number of times each code occurred (see Appendix F). The number of descriptive decisions made by each teacher, along with the total number for all three novices, is displayed in Figure 5. 


\section{Descriptive Code Decisions Made by Novice Teachers}

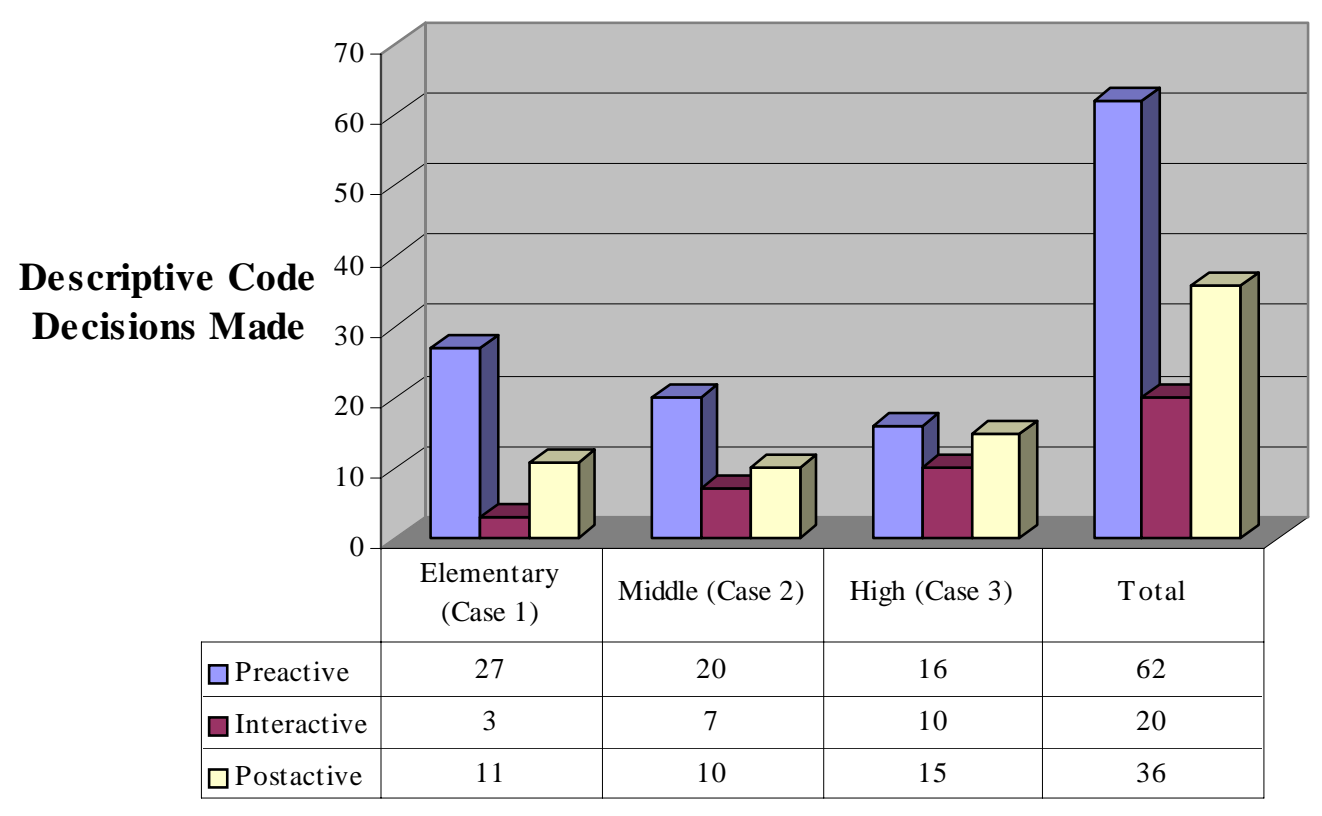

Teacher

Figure 5. Descriptive code decisions made by novice teachers.

Looking at Figure 5, it is apparent that novice teachers collectively made the most instructional technology descriptive decisions during the preactive phase (62) and the least descriptive decisions during the interactive phase (20). During the postactive phase, novice teachers collectively made 36 descriptive decisions. On an individual basis, novice teachers were the same in that each made the majority of her descriptive decisions while planning and the fewest while teaching. Of the three novices, the elementary teacher made the most preactive decisions (27) and the least interactive decisions (3). The high school novice made the fewest preactive decisions (16) but the most interactive (10) and postactive decisions (15). The high school teacher made one more descriptive decision while planning (16) than she did when 
reflecting on her teaching (15). The middle school teacher made half as many descriptive decisions during the postactive phase (10) as she did during the preactive phase (20).

\section{Novice Teachers Pattern Code Analysis}

The descriptive codes for all three novices were examined for relationships, which resulted in the 55 descriptive codes being organized into 7 pattern codes. The pattern codes are listed in the far left column of Appendix F and are identified by bold print and rows that are shaded in gray. Listed beneath each pattern code are the associated descriptive codes. The pattern codes organize the novice teachers' instructional technology decisions into 7 categories:

1. External Influences - aspects beyond the teacher's control that impact decisions to use or not to use technology

2. Student Benefit - decision whether or not to use technology is based on perceived benefit for students

3. Instructional Strategies - ways in which teachers use technology for teaching and learning

4. Diversity - use of technology to reach learners of various abilities

5. Improvement - using technology allows something to be done better than before or to accomplish something that could not be done before

6. Technology Readiness - students and/or teacher must be ready to use technology

7. Teacher Change - use of technology requires a teacher to shift from traditional ways of teaching 
Counting the number of preactive, interactive, and postactive descriptive decisions within each pattern totaled the pattern code decisions made by novice teachers. The number of pattern code decisions made by novice teachers during each decision-making phase, along with the total number of pattern decisions across the three decision-making phases, is displayed in Figure 6.

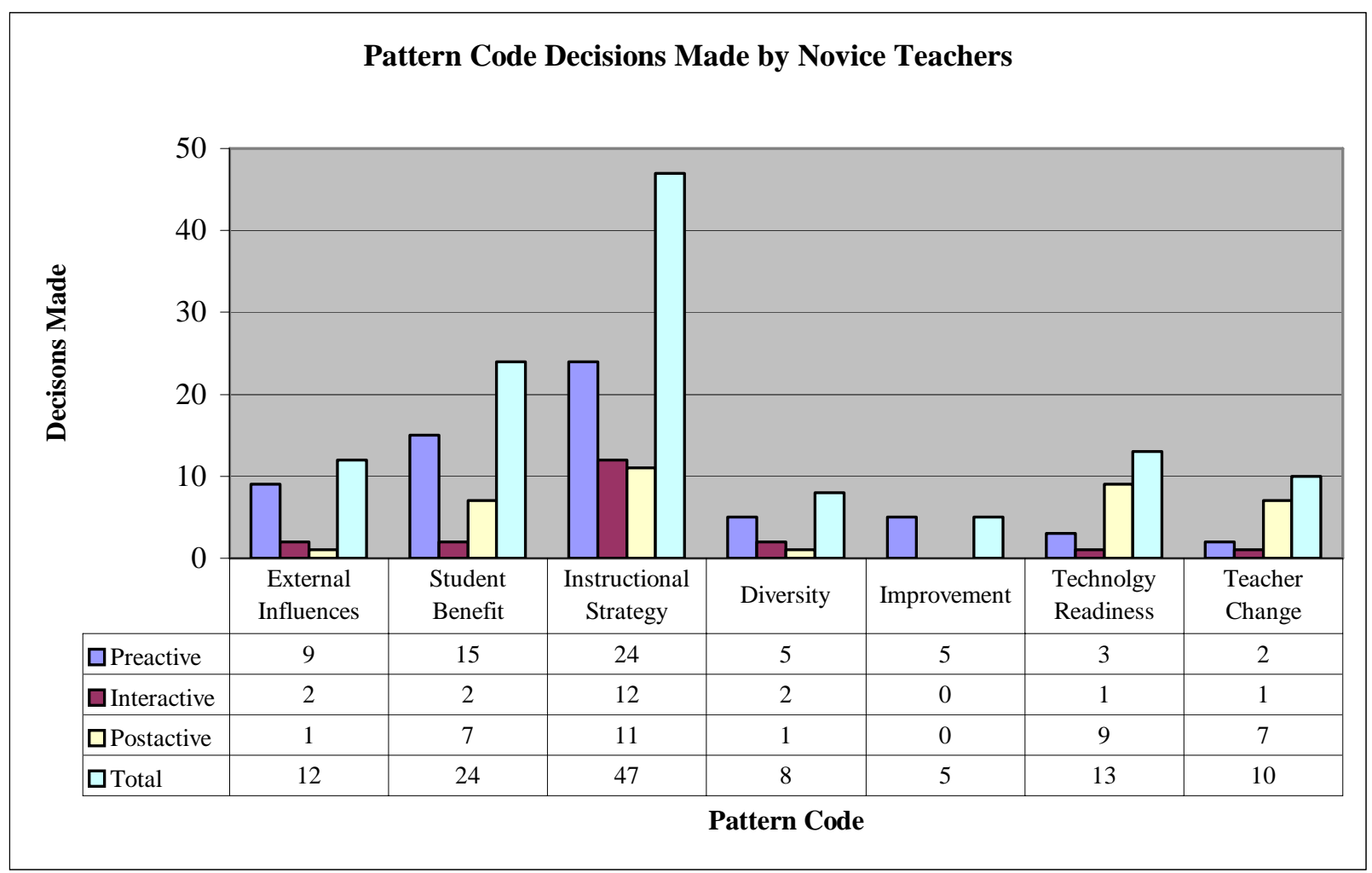

Figure 6. Pattern code decisions made by novice teachers.

Looking at the three decision-making phases collectively, it appears that novice teachers made the most technology-related decisions related to Instructional Strategy (47) and the fewest decisions related to Improvement (5). There were nearly twice as many decisions made concerning Instructional Strategy (47) as there were for Student Benefit (24), the second highest number of preactive decisions. For 5 of the 7 pattern codes (External Influences, Student Benefit, 
Instructional Strategy, Diversity, and Improvement), novice teachers made more preactive decisions than interactive or postactive decisions. Novice teachers made more postactive than preactive or interactive decisions related to 2 of the 7 pattern codes (Technology Readiness and Teacher Change). Slightly more interactive decisions were made than postactive decisions for External Influences, Instructional Strategy, and Diversity. More postactive decisions than interactive decisions were made related to Student Benefit, Technology Readiness, and Teacher Change. Improvement is the only pattern code that indicates the same number of interactive and postactive decisions were made.

\section{Summary of Novice Teachers’ Decision-Making}

Data analysis of novice teachers’ within-case analysis, which are summarized in Table 10, answer research question 1: How do novice elementary, middle, and high school teachers make instructional technology decisions? 
Table 10

Summary of Novice Teachers’ Decision-Making

\begin{tabular}{|c|c|}
\hline \multicolumn{2}{|c|}{ Summary of Novice Teachers’ Decision-Making } \\
\hline Descriptive & Analysis \\
\hline $\begin{array}{l}\text { All three novices made some of the same descript } \\
\text { - Standards (External Influence) } \\
\text { - } \quad \text { Availability (External Influence) } \\
\text { - Variation from Routine (Student Benefit) } \\
\text { - Student Engagement (Student Benefit) }\end{array}$ & $\begin{array}{l}\text { cisions within the preactive phase: } \\
\text { - Visual Learning (Diversity) } \\
\text { - } \quad \text { Classroom Management (Instructional } \\
\text { Strategy) } \\
\text { - Informal Assessment (Instructional } \\
\quad \text { Strategy) }\end{array}$ \\
\hline
\end{tabular}

All three novices made some of the same descriptive decisions at some point within the three phases:

- $\quad$ Content First (Instructional Strategy)

- Critical Thinking (Instructional Strategy)

- Interactive Discussion (Instructional Strategy)

Number of descriptive decisions was different for each decision-making phase:

- Greatest number of descriptive decisions made during preactive phase (62).

- The next highest number of descriptive decisions was made during the postactive phase (36).

- $\quad$ Least number of descriptive decisions made during interactive phase (20).

Some descriptive decisions were specific to only one of the three novices:

- 29 total teacher-specific descriptive decisions

- Nearly the same total amount of teacher-specific decisions during the preactive (16) and postactive phase (15); fewest during interactive phase (4)

- Elementary teacher made the most (14), followed by the high school teacher (11), and the middle school teacher (10).

Number of decisions varied for the 7 pattern codes:

- Greatest number of pattern decisions pertained to Instructional Strategy (47), which was nearly twice as many as the next highest number for Student Benefit (24). Fewest decisions pertained to Improvement (8).

- $\quad$ For 5 of the 7 pattern codes (External Influences, Student Benefit, Instructional Strategy, Diversity, and Improvement), novice teachers made more preactive decisions than interactive or postactive decisions.

- For 2 of the 7 pattern codes (Technology Readiness and Teacher Change), novice teachers made more postactive decisions than preactive or interactive or decisions. 
Novice teachers made some of the same descriptive code decisions within the preactive phase, but not within the interactive or postactive phases. Their preactive decision-making pertained to the pattern codes of External Influence, Student Benefit, Diversity, and Instructional Strategies. The novice teachers did not make preactive decisions related to Improvement, Technology Readiness, or Teacher Change.

Content first, critical thinking, and interactive discussion, all of which fall within the pattern code of Instructional Strategies, were descriptive code decisions that all three novice teachers made at some point within the three phases.

Novice teachers made the greatest number of descriptive code decisions prior to teaching and approximately half as many after teaching. While they were teaching, novice teachers appear to have made considerably fewer descriptive code decisions.

There were 29 teacher-specific descriptive code decisions made by the novice teachers, with nearly the same amount occurring during the preactive and postactive phases and considerably fewer made during the interactive phase.

Looking at novice teachers' decision-making according to pattern codes, they made the most choices regarding Instructional Strategies, which was nearly twice as many as the next highest category of Student Benefit. They made the fewest decisions pertaining to Improvement. Preactive decisions outnumbered interactive and postactive decisions for External Influences, Student Benefit, Instructional Strategy, Diversity and Improvement. Technology Readiness and Teacher Change, however, showed more novice teacher decision-making during the postactive phase than preactive or interactive. 


\section{Within Case Analysis of Experienced Teachers}

A case study was created for each of the three experienced teachers. Each case study is introduced through a narrative describing the teacher's learning environment, educational beliefs, and preactive, interactive, and postactive teaching decisions. Descriptive codes are embedded within each case study narrative, represented in italics and enclosed within parentheses. Descriptive codes that appear within quotation marks are "in vivo” codes (Strauss \& Corbin, 1990), created with terms and phrases used by the teachers during interviews and observations. An alphabetized list of descriptive codes and definitions is located in Appendix H.

Following each teacher's case study narrative is a corresponding table of descriptive codes organized by the three decision-making phases. For ease of use, codes within each teacher's table are listed in the order in which they appear within the case study narrative. Some descriptive codes appear more than once within a narrative, but for the purpose of simplicity, codes are listed in the table only the first time they appear within the preactive, interactive, and postactive phases.

Case Study 4 Narrative: Derk - Experienced Elementary/Middle School Teacher

This case study describes Derk, an experienced teacher in an elementary/middle school, and how he makes instructional technology decisions. Derk earned his Master’s Degree in Elementary Education. He is in his $23^{\text {rd }}$ year of teaching and currently teaches math and science for $6^{\text {th }}, 7^{\text {th }}$, and $8^{\text {th }}$ grade students. When Derk learns new technologies, he says "then I have to think well, where can I fit this in and where can I fit that in? Sometimes it's just an experiment...will this work?”

Derk’s case study is introduced through insight into his learning environment and his educational beliefs, followed by decisions he made prior to teaching, during teaching, and after 
teaching. Table 11 summarizes the data analysis of his preactive, interactive, and postactive teaching decisions with regard to using technology.

\section{Learning Environment}

Inside the school and Derk's classroom. Derk's classroom is packed with bookshelves, storage cabinets, and filing cabinets. The desk he uses is rather small and is sandwiched between filing cabinets and computers that his students use. A total of thirteen computers line half of the right wall and the entire back wall. The entire front wall is covered with a blackboard. Derk has a wooden podium that he uses on occasion. His students' desks are arranged in rows and face the front of the classroom. Sometimes he asks his students to arrange their desks in groups so they can collaborate.

Educational philosophy. As Derk and his students talk about the phases of the moon, he acknowledges everyone's input. When a student's response is not accurate, he helps the student arrive at the right conclusion rather than correct him or call on another student. Derk believes that any student "who wants to learn can learn" and he is willing to try to help them.

\section{Preactive Decision-Making}

Technology planning approach. As Derk plans his curriculum, he is aware of the technology available and recalls what he has used in the past. He makes decisions about how and why to use or not to use technology on a unit-by-unit basis.

Outside influences. The emphasis from the county and the state currently is on test scores, so Derk says his teaching approach for now is to focus on "the bits and pieces" to help students do well on the WESTEST as opposed to doing more project oriented work and teaching the way he thinks he should teach (pressure from county and state). He says, "I know it’s not right, but sometimes you feel like there’s too much pressure.” An additional outside factor that influences 
Derk’s decision to use technology is West Virginia’s Content Standards and Objectives (CSOs), which include standards for using technology (standards).

Another factor beyond Derk’s control is availability of resources. Due to limited classroom space, he cannot "teach the way I think I should teach" and "do a lot more project oriented, a lot more thematic type stuff' (availability). He wanted to use the computer lab for a project his students were conducting using bottle rockets, but the lab was booked by other faculty and there are not enough computers in his classroom for all students to use (availability). Another technology that Derk does not have easy access to is the overhead projector because several faculty share one (availability). If he had an overhead projector in his classroom all the time, he would use it because he thinks it is good to have something visual for students (visual learning).

Teaching and learning decisions. Derk thinks about the technology available and considers possible uses, but plans to use it only if it is going to enhance what his students are learning (enhanced learning opportunity). He does not want the use of technology "to be just some busy work” and he does not want it “just to be fun,” but wants it to help his students and improve their learning (time vs. benefit). He explained that if he is going to teach a unit on plant processes where he and his students “can get outside,” then “we don’t need the technology "because his students can see and touch ("real life”) the grass and the leaves and the trees." For a unit on astronomy, however, he and his students are in school only during the daytime, "so you can't really see the stars, so you have to use technology to see it” (visual learning; enhanced learning opportunity).

Time is an issue when Derk plans his units. He wanted his students to create a video where they presented the process of something they were learning about in science or history. He 
knew that it would take a great deal of time to edit video and therefore would not work during class (time limitation). He does work with students after school to help them learn to create and edit video, as well as use publishing software to create a newspaper. Sometimes students carry what they learn after school into the school day.

When Derk wants his students to conduct research, he often designs lessons where they use the Internet because "the textbooks only go so far and there's so much more information on the Internet” (applicability; enhanced learning opportunity). The Internet allows his students to see things and access information that otherwise they "just can’t see here in the schools" (enhanced learning opportunity). Derk uses information on the Internet quite often for science because there are pictures of space and simulations of the space probe. When his students use the Internet, Derk teaches them how to "look at several different sources" because "often times there are facts on one site that aren't the same on the other, and one site doesn't explain things as well as another” (evaluation of resources). An example is when he created a worksheet to guide his students in finding information about birds on the Internet. In the process, his students "found some pretty cool web sites with bird sounds," which they shared with each other (student collaboration). This was information they could not have found (enhanced learning opportunity) in the sole copy of the field guidebook that his students had to share (availability).

Another way in which Derk uses the Internet is by creating a web site for his classes. His students access the web site to get materials they need for class. Students and their parents access the web site to view assignments and see what they will be learning in the future (communication).

Derk asks his students to use PowerPoint because “it helps the kids focus,” (“focus”) and also helps them to "summarize their information... and put information in sequential order" 
("summarize information"; sequence information). Sometimes he asks them to create only one slide; other times he has them create a series of slides or a presentation. He says there is only so much information that can fit onto one slide, so it helps them "sort out the important stuff." When he tells his students to create a series of slides, he does so because he wants them "to demonstrate a process or demonstrate the sequence of events in a story" (informal assessment; formal assessment). Derk also asks his students to use technology to design presentations because it "gives them a voice" ("voice"). After a field trip toward the end of the school year, Derk asked each student to create a PowerPoint as a way for them to "remember what they saw and experienced" (retention). His students included pictures of the field trip, captured by Derk using a digital camera, and typed captions to describe what they saw and how they felt about it. He said, "When they were on their field trip, they just looked around. Doing this helps them to remember (retention) and focus on what they saw" (“focus”).

Helping his students to gain skills they will need for the future is one reason Derk asks his students to use word processing. He says, "they need to know how to use Word from here on out" because students will be asked by teachers to turn in word processed assignments (technology skills). He says that in some cases "the focus is learning the technology," where "it's not enhancing the story they wrote, but I'm teaching them to use the technology with the language paper they already wrote.” Another motive behind asking his students to word process is that it is neater and easier to read sometimes than students' writing (teaching efficiency).

Derk chooses to use a Student Response System (SRS) because of its benefit to both teachers and students. A SRS consists of wireless, handheld units that students use to send their response to a computer. Students respond to questions created by the teacher, which can be in the form of multiple-choice, true/false, or fill in the blank. Derk created a test on leaf identification, 
where he scanned pictures of leaves into the computer and created accompanying questions. As he projected each leaf picture onto the wall, the question he created also appeared and his students indicated their answers via their response devices and the computer compiled the results. One reason Derk decided to use the student response system was because he liked the "flexibility of it", allowing him to create his own tests as opposed to using a pre-made test (customization). Another benefit to the teacher is the SRS grades each student's responses and saves them into a file for the teacher (teaching efficiency). Derk also chose to use this technology because of the benefit to his students. The SRS provides immediate feedback to students by displaying, for each question, what percentage of the class answered the question correctly and indicates the correct answer. For students who answered incorrectly, they immediately saw the correct answer ("instant feedback"). Another student benefit was using scanned pictures of leaves was "more realistic than just using a worksheet with drawings of leaves” (“real life”).

Both Derk and his students use the SmartBoard, which is a large whiteboard that connects to a computer, displays what is on the computer screen, and allows a person to manipulate the computer by touching the SmartBoard. An example is when Derk was teaching his students about the field trip they were going to take to visit a space simulation lab. He used a PowerPoint presentation that contained pictures of the space lab they would be visiting (visual learning) and also listed and defined the roles the students would be assuming as they guided a space shuttle safely home. As Derk taught this lesson, he touched the screen of the SmartBoard to advance or go back through the PowerPoint slides. The reason Derk chose to use the SmartBoard is because it is more efficient when he is teaching because "you have a lot more control as the teacher standing in the front of the room (classroom management) talking to the kids (direct instruction) rather than sitting with your back to them while clicking and talking.” 
Sometimes he designs activities where his students use the SmartBoard when they are presenting their PowerPoints because "they really like that" (student engagement; variation from routine).

When using calculators, Derk always teaches his students how to perform calculations using paper and pencil first, and "then we show them how easy it is on a calculator" (content first). He encourages his students to use calculators to check their answers to a problem or to perform a calculation that will take too long to solve on paper (learning efficiency).

Derk and another faculty member participated in professional development on ComputerAided Drafting software for students and their school was given 600 licenses for the program. The goal of the organization that provided the software and training is to try to get more students interested in engineering. So far Derk has decided to use the software for enrichment (supplementation) by holding after school sessions for students to work with the software until he becomes more familiar with the software (comfort level). His goal for this software is to “translate it into something that the kids can understand" and he would like to "get to the point of having a project” for students to work on using the software to design a car or something else functional (applicability).

When his students need to practice math (informal assessment), Derk chooses to use computers and math software (review and practice). He feels that using computers "really draws them in a lot more than a board game or a worksheet or an activity” (variation from routine). Additionally, he finds the computer games help his students with their math problems and logic better than any of the other activities (applicability). For example, the "Logical Journey of the Zoombinis is an awesome game that teaches logic and patterns and the scientific process of trial and error.” Derk says this program “is really neat and I could never do that. I couldn’t teach them in that way” (enhanced learning opportunity). 
Sometimes Derk uses technology, along with other more traditional activities, to assess his students. When his students were learning about the phases of the moon, he designed three different activities for his students. One activity was using computers and software that accompanied the textbooks which quizzed students on what they were learning and compiled individual's scores; another activity required students to read in their textbooks and answer questions on a worksheet; and the third activity involved each student going to the board at the front of the room and arranging laminated pictures of phases of the moon, which were attached to magnets, into the correct order. All three activities were designed by Derk to informally assess his students' learning (informal assessment). Derk has used technology for formal assessment as well by asking his students to create PowerPoint presentations about their field trip and then grading them (formal assessment).

\section{Interactive Decision-Making}

Time affects decisions Derk makes while he is teaching. When classes have been delayed or cancelled due to the weather, his students fall behind and he has to eliminate technology to focus on content (content first). For example, Derk had planned to have his students capture video of the rockets they shot off and then use it, by calculating the frames per second, to figure out the speed the rockets were traveling. He didn’t have time (time limitation) because his students were behind (informal assessment). Derk covered the content through having his students read and compute mathematical formulas using data that was already collected for them, but he thinks that capturing and analyzing the video, then applying what they were learning, would have resulted in it "sticking with them a lot longer" (retention). 


\section{Postactive Decision-Making}

When designing units, in addition to thinking about whether or not using technology will enhance his students' learning, Derk also considers the amount of time it will take for students to learn to use the technology (time vs. benefit). He has discovered that his students' learning curve is relatively short for PowerPoint and Word, but with Excel spreadsheet software, "the benefit isn’t there yet.” He finds that PowerPoint and Word are relatively quick for students to learn (comfort level) so he can then use them to enhance what they are learning, whereas he has to spend a lot of time teaching his students how to use Excel before he can ask them to make use of it and apply what they are learning. He wishes that students in the earlier grades would learn how to use Word and PowerPoint so he wouldn't have to spend much time teaching those software programs and could spend more time teaching them how to work with Excel, especially for creating graphs to represent data the students have collected. Derk does use Excel more often with his $8^{\text {th }}$ grade students because he's taught them in $6^{\text {th }}$ and $7^{\text {th }}$ grade how to use PowerPoint and Word, leaving more time for him to teach them how to use Excel.

Derk recalled a situation where using technology was not as beneficial as he had hoped. He designed literature circles where his students got in small groups and read, then discussed their stories. In the past, he asked his students to take notes on their discussions and then come together in a large group to discuss the literature. He decided to try chat rooms instead of face-toface discussions because he thought his students would become freer with their thoughts (build confidence), “instead of being embarrassed to talk in front of people.” Even though he and his students practiced using chat rooms prior to the literature circles activity, his students did not take turns responding in the chat rooms and "yelled at each other and told each other to shut up." Derk thinks this occurred because his students were not mature enough and believes it will work 
for an older group of students (student readiness) or maybe if it was "used enough that the novelty wore off” (novelty). Since this use of technology did not “enhance anything; it wasn’t helping anything," he has not used it since, but is considering using it again in the future "with a different setup,” such as establishing chat rules (classroom management).

Derk suggests that other teachers “just try” using technology and “don’t be afraid to fail” (experimentation). He believes teachers should think of "creative ways to use technology to do the same things you already do on pencil and paper (creativity), but kids really like the technology part" (variation from routine; student engagement). Teachers should not be afraid to try using technology because making mistakes, as he tells his students, is when you learn. "You try to figure out 'what did I do wrong?' and that's where you learn (experimentation). That's where you become a little better.” 
Table 11

Case 4: Descriptive Codes for Preactive, Interactive, and Postactive Instructional Technology Decision-Making

\begin{tabular}{|c|c|c|}
\hline Preactive Decision-Making & Interactive Decision-Making & Postactive Decision-Making \\
\hline $\begin{array}{l}\text { - Pressure from County and State } \\
\text { - Standards } \\
\text { - Availability } \\
\text { - Visual Learning } \\
\text { - Enhanced Learning Opportunity } \\
\text { - Time vs. Benefit } \\
\text { - "Real Life” } \\
\text { - Time Limitation } \\
\text { - Applicability } \\
\text { - Evaluation of Resources } \\
\text { - Student Collaboration } \\
\text { - Communication } \\
\text { - "Focus” }\end{array}$ & $\begin{array}{l}\text { - Content First } \\
\text { - Time Limitation } \\
\text { - Informal Assessment } \\
\text { - Retention }\end{array}$ & $\begin{array}{l}\text { - Time vs. Benefit } \\
\text { - Comfort Level } \\
\text { - Build Confidence } \\
\text { - Student Readiness } \\
\text { - Novelty } \\
\text { - Classroom Management } \\
\text { - Experimentation } \\
\text { - Creativity } \\
\text { - Variation from Routine } \\
\text { - Student Engagement }\end{array}$ \\
\hline
\end{tabular}




\begin{tabular}{|l|l|l|}
\hline Preactive Decision-Making & Interactive Decision-Making & Postactive Decision-Making \\
\hline - Sequence Information & & \\
- Formal Assessment & & \\
- "Voice” & \\
- Retention & \\
- Technology Skills & \\
- Teaching Efficiency & \\
- Customization & \\
- "Instant Feedback" & \\
- Classroom Management & \\
- Direct Instruction & \\
- Student Engagement & \\
- Variation from Routine & & \\
- Content First & & \\
- Searning Efficiency & & \\
\end{tabular}


Preactive Decision-Making

- Comfort Level

- Review and Practice
Interactive Decision-Making

Postactive Decision-Making 
Case Study 5 Narrative: Georgia - Experienced Elementary/Middle School Teacher

This case study describes Georgia, an experienced teacher in an elementary/middle school and how she makes instructional technology decisions. Georgia earned her Bachelor's Degree in English and Social Studies, her Master’s Degree in Gifted Education, and National Board Certification in English Language Arts and Early Adolescence. She is in her 23rd year of teaching and currently teaches language arts for $6^{\text {th }}, 7^{\text {th }}$, and $8^{\text {th }}$ grade students. Since she started teaching, Georgia has found that "technology has become important in the classroom."

Georgia’s case study is introduced through insight into her learning environment and her educational beliefs, followed by decisions she made prior to teaching, during teaching, and after teaching. Table 12 summarizes the data analysis of her preactive, interactive, and postactive teaching decisions with regard to using technology.

\section{Learning Environment}

Inside the school and Georgia's classroom. Reading, grammar, and spelling posters add splashes of color to Georgia's classroom, as do the cases filled with books. Her students' desks face the front of the classroom and Georgia's desk sits behind them in the left corner. On her desk sits a computer and along the wall in front of her desk are three computers that her students use.

Every classroom in this school has at least 4 up-to-date computers, including one on every teacher's desk that is “primarily for them to do Internet research to help support lessons that are taught.” Since there are not enough computers in the classroom for students to use during class, teachers use the "Technology Lab," which is an interesting blend of older and newer innovations, including old iron radiators, a window air conditioning unit, and modern computer desks on top of which are 25 new Internet-connected computers. 
The Technology Lab and computers in each classroom, Internet access, a camcorder, digital cameras, data projectors, and various kinds of software, have been earned through grants written primarily by Georgia, along with other teachers at this school.

Educational philosophy. Georgia believes in having "the student be the center of the learning" and "looks at each student to determine individual strengths or weaknesses." She tries to keep her students "as actively engaged as possible" and finds that technology is "a major part of that.” She also believes that technology catches students' interest. Ever since the day she realized that her daughter, who was then in $5^{\text {th }}$ grade, knew more about technology than she did, Georgia has been learning about and using technology in her lessons. She says, "since I've done that, it's just been a great ride for me and for the students.”

\section{Preactive Decision-Making}

Technology planning approach. Georgia has been using technology for several years, so she has an idea of when she will be using technology throughout the school year. Specific plans to use technology evolve as she creates her lessons, depending on her students' progress and whether or not technology resources are available.

Outside influences. An external influence on Georgia’s decision to use technology is West Virginia’s Content Standards and Objectives (CSOs), which include standards on using technology (standards). Georgia brought the CSO technology standards to other faculty members' attention last year when she helped them learn how to use technology in their teaching. There is not a written technology policy for her school, but Georgia says, "The principal has always strongly encouraged the use of technology” (administration's influence).

Availability of resources affects Georgia's decision about "when to use technology and when not to use it” (availability). The Technology Lab serves all eight grades and cannot always 
be accessed when needed due to heavy usage. If she could, Georgia would be in the Technology Lab more often using other software in addition to word processing to help students "broaden their writing process and their critical thinking skills” (critical thinking).

Teaching and learning decisions. "Time is a four letter word,” says Georgia. Time is another resource that is limited and impacts her decision to use technology (time limitation). When she thinks about what she is going to teach, if she realizes there will not be time, she most likely will not use technology because she views it as "a wonderful way to reinforce, reteach" (“reinforcement”). Georgia introduces new concepts using traditional teaching (content first), such as looking at a textbook. Then she takes her students to the Technology Lab, because "most students don’t learn with just an initial introduction. They need reinforcement.”

Another reason Georgia chooses to use technology is because she finds that technology helps to keep her students actively engaged (student engagement). Cooperative learning activities, where she asks her students to work together in the classroom and initially use paper and pencil, works for some, while other students consider cooperative arrangements to be social time. When she takes her students to the computer lab, she says, “just about every student becomes actively engaged.”

“Our whole new generation of students are visual learners,” so Georgia uses technology to help them to "see” what they are learning (visual learning). One example is when she used Inspiration software with her students as they prepared to write. They used Inspiration's clip art and typed a few words to represent ideas about their stories and then linked related concepts. Then they selected a feature in Inspiration and their concept map turned into an outline, which allowed students to see "the beginning, middle, and end" and "they can visualize how their story will unfold.” Georgia conducted a professional development session for other faculty in her 
school to learn to use Inspiration, because "students can use it in English, social studies, science, and math. You can use that 'across the board'”' (applicability).

Another example of how Georgia used technology to help her students visualize what they were learning was when she designed a lesson that made use of the readability statistic within word processing software (visual learning). One day Georgia’s students used word processing software to compose their "Young Writer's Short Story.” She showed them how to use the readability statistic so they could see how many words they typed and when they have typed in passive as opposed to active voice, which was required for their story. Georgia said that when her students do a similar activity using the textbook, “they don’t visualize it.” When they use the computers for this activity, they "see it on the computer through the readability statistic," which shows her students which sentences are passive (visual learning; “instant feedback”) so they can go back and change them to active voice. Using the readability statistic shows students at what grade level they are writing. If she finds that some students are writing at a third or fourth grade level (informal assessment), she will show them how to begin with "an introductory prepositional phrase and change simple sentences into compound or complex sentences,” and then her students can see that they are now writing at a seventh or eighth grade level ("instant feedback"; enhanced learning opportunity). After that, she shows them how to the word processor to find synonyms and that usually results in their writing level increasing another grade level.

One day after Georgia’s students completed a paper and pencil test, she recorded the web site for the White House and asked her students to go to this web site. She said that taking them to this web site was mainly "just a filler" (time filler) so students had something to do until the 
end of the class period, but the virtual tour of the White House gave them a preview of they would be seeing when they actually went to the White House for a class trip (visual learning).

Georgia prefers a writing process where her students' handwrite their rough draft one day, then self-edit and/or peer-edit in the classroom on another day. After that, Georgia takes her students to the computer lab (content first) either to do peer editing or to work on their final drafts. While her students are working on their final drafts or doing peer editing, she works with students individually at their computers. She and her students “make decisions on how they'd like to change it" and then her students make corrections "right there while we're talking" (“instant feedback”). Georgia says this saves a lot of class time (teaching efficiency) because her students make their corrections while they're discussing their writing with her, which also saves them time (learning efficiency).

Sometimes Georgia chooses to have her students use technology so they can review and practice what they are learning (review and practice). Her students use word processing to practice their spelling words. First she asks them to create a 3 column table. Then she pronounces a word and her students' type how they think it is spelled into column one of the table. If they see a red squiggly line, "they realize they typed incorrectly” (visual learning). After reading all of the words, Georgia pronounces the words again and spells them. In the second column of the table, her students type the word again, correcting them if necessary. Students practice spelling the words for a third time in the last column. Then Georgia asks them to “incorporate their spelling into a writing activity” by typing sentences or a short story underneath the table, using ten of their spelling words ("reinforcement").

In addition to using word processing so her students can review and practice what they have learned, they are also learning to use a tool that they will be using "in the real world" 
(technology skills). Examples Georgia pointed out were when she asked her students to create a table of three columns and four rows. Then she showed them how to split certain cells into two. She also showed them how to use the highlighter tool to make different types of pronouns different colors.

Interactive Decision-Making

As her students walked into the computer lab, Georgia told them they needed their rough draft about the time capsule. She designed an activity where students selected objects they wanted to place into their personal time capsule and had to write about each item, explaining why they selected it, how it works, and “its importance in today's society." She reminded them that their minimum requirement was to "write two paragraphs and use five adjectives and five adverbs.” Then they used Publisher to create a brochure with information about their time capsule. Georgia told her students to go into Publisher and begin. Some of her students started looking at the templates, but many of them did not know what to do. She noticed this and said, “Oh, I thought you knew how to use Publisher. Just a minute and I'll show you” (informal assessment). Georgia turned on the data projector connected to her computer and showed her students how to use Publisher to create their time capsule brochures. As her students worked on their brochures, Georgia reminded them that she was "mainly concerned that you get the writing part done. Next week we'll go back in and start personalizing." She told her students this because they were getting too involved with "the visual aspects, the clip art, the pictures." She wanted them "to focus on the text first and the visual aspects later (informal assessment)." As her students worked on their brochures, Georgia circulated around the room checking on their progress (classroom management), looking at their design and layout, asking them how they were doing (informal assessment), and answering their questions ("instant feedback"). 
The bell rang and this group of students left and another group arrived. Georgia started class by explaining their time capsule assignment and told them they could create a brochure or a postcard. After she showed them how to use Publisher, she said, “One more thing. I don't want you to get hung up on the visual aspects," and explained that they were here today to write about their time capsule and next week they would "make it look pretty." She told the researcher that the previous group of students does better when they do not have many choices because otherwise they spend too much time deciding what they want to pick. The current students, however, do "better at making a decision and getting started.” Georgia says, "You just have to know your students, your class” (informal assessment).

Time is a factor that has caused Georgia to change her lesson plans. When students created an autobiography using PowerPoint, she originally intended for them to create a draft using paper and pencil, but they did not have time because "things have been so hectic right now because of curriculum design, the upcoming WESTEST, and other things going on at the school.” Instead of creating their draft using paper and pencil, she took them to the computer lab and they created their autobiography using PowerPoint (time limitation; teaching efficiency).

\section{Postactive Decision-Making}

Approximately 20\% of the students at Georgia’s school have special needs, have difficulty with reading and math, and are not “overly successful” with traditional teaching approaches. Georgia finds "they get very restless when they have to sit and listen to lecture and work with books." She believes that these students are usually visual or kinesthetic learners and using technology is an approach in which they experience success. She has found that using computers is "another way for them actually to learn because it's more of a hands-on approach" (kinesthetic learning). Georgia also discovered that students with special needs "feel good about 
themselves (build confidence) and are more positive in the classroom” ("positive attitude”) when they are actively engaged on the computer (student engagement). She has noticed that they are confident and successful and feel like they can compete with other students (diversity). She says, “it’s amazing how you can see a difference in their confidence level, how they feel good about themselves” (build confidence). Georgia says it feels good to see students being successful in the computer lab and to know that she is reaching students.

Georgia found that using the readability statistic in word processing helped her students "become much more conscious about their writing” ("positive attitude”) and observed her students becoming competitive but at the same time helping each other (student collaboration). She heard one student say, “I'm writing on a tenth grade level,” while another said "Well, I'm writing on the twelfth grade level.” Then another student said, “I’m still back on the fourth grade level. What can I do?” Other students helped that student to improve her sentences. Georgia noticed her students were having fun using technology without realizing that they were helping each other to learn (incidental learning).

Georgia says “there’s always something new out there” and when students are first introduced to a new technology "it's a novelty to them” (novelty). However, most of the students at Georgia’s school are “technology literate” and “feel comfortable using technology (comfort level) because they start using it in elementary school.” She says some kindergarten teachers design activities that involve their students in using word processing. First and second graders use word processing, and presentation and publishing software are taught in the middle school.

Reflecting on the time capsule assignment where Georgia asked her students to use Publisher to create a brochure about items they included in their time capsules, she said she "had to change because she didn't put as much time into creating the guidelines that they needed with 
that.” As a result, some of her students experienced difficulty using adjectives and adverbs in their brochures. So Georgia changed her approach and instructions based on her students’ feedback (informal assessment). She paid attention to their comments about what was working and was not working. She also acknowledged their feedback saying “you know, you're right,” then worked with her students (student-teacher collaboration) to make changes to the assignment so it was easier to understand (learning efficiency). Her students’ confusion about their required use of adjectives and adverbs was not due to technology, but the result of the task requirements needing to be more clearly explained.

The I Know web site models the WESTEST and allows students to practice for it. In the past, Georgia would project the I Know web site through the data projector connected to a computer in her classroom (direct instruction). Her students would answer the questions using paper and pencil and they were allowed to use a calculator for the math section. Then Georgia would go through the questions again, asking her students for their answers, and helping them to figure out the correct response for questions they missed and why that answer was correct (interactive discussion). This past year, her school was granted permission for all computers in the Technology Lab to connect to the I Know web site so students could practice independently (availability; “instant feedback”). When the researcher asked Georgia about her opinion of the advantages and disadvantages of the I Know online practice test, she said that one nice feature is that it provided feedback to teachers about how students were progressing (informal assessment). A drawback is that the practice test sometimes covered "things that I have not gotten to according to our curriculum mapping because not all students are the same (lack of customization).” Another disadvantage was that technical support is located in California, which caused problems when it was morning and some students could not access their accounts 
(availability). This resulted in make-ups having to be scheduled, but Georgia took it in stride and says, "We do what we have to do (flexibility)."

Every year the seventh graders take a writing assessment. This past year was the first time they took it online. Georgia found that the students really liked taking the writing assessment online because "they got immediate feedback of how well they did" and "of their strengths and weaknesses” ( "instant feedback”).

Georgia uses lessons plans where her students used to use paper and pencil but they now use a modern technological innovation (creativity; applicability). She designs some lessons to use technology because "they love doing it on the computer. It is fun for them" (student engagement), says Georgia. One example was when she asked her students to create a three column table using word processing software in preparation for their spelling pretest. Her students used the columns to type and retype their spelling words, allowing them to practice and review (review \& practice). Another example was when her students created their autobiographies toward the end of the school year. They used to create them using paper and pencil, but now Georgia teaches them to use PowerPoint to create their autobiographies. As they worked on both their spelling and their autobiographies, Georgia said, "You saw how engaged they were and how everyone was working on this instead of talking” (student engagement; classroom management). Another observation Georgia made is that her students were "working on task even though I was working with an individual student.” She says, "I have no discipline problems up in the computer lab” (classroom management).

"Technology has just exploded in the public school system within the last two years," says Georgia, and she feels like she is a pioneer at her school because of her interest in learning about it and the grants that she has written to obtain technology resources. She always wants to 
know more about using technology. She says she would "like some advice from people that have more technology expertise" than she does. She is "always willing to learn" and "would like to get some fresh ideas" because she runs out of ideas. She suggests that one way to accomplish this is to network with teachers in other schools because she learns "from what other people are doing.”

Other teachers need "to know that technology is a powerful tool in reaching all students," says Georgia, and “Technology is not going away. Students need to use technology” (technology skills; life skills). From learning how to use technology in her classroom and from helping other teachers at her school learn how to use technology, she realizes that teachers need time to sit down and look for lesson plans on the Internet and also to look for web sites and other technology they can use with their existing lesson plans (time for planning). "There are powerful reinforcing web sites, virtual tours, Webquests, that can reinforce the learning process,” but teachers need time to look for technology to use in their lessons. Last year Georgia found a web site of the San Diego Zoo and told the third grade teachers about it because their students were learning about baby animals and other features of the zoo. She says that "was a wonderful reinforcer for what students were learning in the classroom" ("reinforcement") and also allowed the students to visit a zoo virtually and for free instead of going to the Pittsburgh Zoo for which they might not have the money (enhanced learning opportunity).

Georgia also found web sites with video clips (visual learning) that were applicable to content the elementary school teachers were teaching. “Teachers really don’t have time to investigate on their own" but "if we could investigate together, we could come up with a myriad of ways to incorporate technology” (teacher collaboration). 
Georgia has written numerous technology-based grants for her school. The majority of the grants she wrote were used to host summer technology camps for students. Most of the students at Georgia's school are “of the lower socio-economic level” and do not have access to a computer at their homes. During these free summer camps, students learned how to use Microsoft Word, PowerPoint, Publisher, and Excel (technology skills). Many of the camps she designed were for elementary students since her school is for kindergarten through eighth graders, with several of the camps specifically for third and fourth graders. The students who attended the camps as third and fourth graders are now in middle school and "are very knowledgeable with technology and using it with education” (comfort level). Georgia has noticed that the students who attended the camps “act as peer tutors” during the school year by helping other students who have not yet mastered computer skills (student collaboration).

Georgia took classes to become a “Technology Integration Specialist” as part of the No Child Left Behind Educational Technology grant she was awarded. This grant also released her from her classroom 2 days a week for one academic year. During this first half of the academic year, she worked with all the other teachers in her school to learn what they were teaching. She "became a model for the teachers” and "actually taught technology-integrated lessons” in their classrooms (modeling). She helped them search the Internet for relevant lessons and suggested technology they could use to enhance their existing lessons, making sure the teachers “didn’t have to stop what they were doing and create a completely different lesson.” The second half of the school year, each teacher used a substitute for one period each week so they could have extra time to "use the Internet to find lessons" and other ideas for using technology with what they were teaching. In addition to working with the teachers during the school day, Georgia also held workshops for the teachers after school and on Saturday mornings. "It was a very worthwhile 
grant. A lot of work, but I think it was very successful with the teachers.” Georgia found that several of the teachers who were uncomfortable with technology in the past are now taking advantage of the technology resources in their school and taking their students to the computer lab (comfort level). Georgia says, "Now we are fighting to get to the lab for our classes," which is evident by the completely filled sign-up sheet hanging on the door of the Technology Lab. Georgia finds that most of the teachers in her school are now comfortable using technology and are no longer "afraid to use it in the classroom."

When Georgia plans a lesson where her students will be using technology, she does "like to follow through with it" (teacher investment). The only reason she could think of when she intended to use technology but then changed her mind was because she could not get access to the computer lab because so many other teachers signed up to use it or she was "kicked out" for county or state testing (availability).

Thinking about her use of technology, Georgia said, “Nobody has taught me how to use technology. Maybe I'll teach a class some day on integrating technology in the classroom. All teachers need that." She finds that "technology is experimental to a certain extent" and says teachers "are like pioneers, I guess, and we take the wrong route sometimes and have to backtrack and take another route that's more workable” (experimentation). If a teacher sees something is not working (informal assessment), "we change and that's part of being a teacher" (flexibility). "If that's not working, then you change it and make it successful for the students" (applicability; learning efficiency). 
Table 12

Case 5: Descriptive Codes for Preactive, Interactive, and Postactive Instructional Technology Decision-Making

\begin{tabular}{|c|c|c|}
\hline Preactive Decision-Making & Interactive Decision-Making & Postactive Decision-Making \\
\hline - Standards & - Informal Assessment & - Kinesthetic Learning \\
\hline - Administration's Influence & - Classroom Management & - Build Confidence \\
\hline - Availability & - "Instant Feedback" & - “Positive Attitude” \\
\hline - Critical Thinking & - Time Limitation & - Student Engagement - \\
\hline - Time Limitation & - Teaching Efficiency & - Diversity \\
\hline • "Reinforcement" & & - Student Collaboration \\
\hline - Content First & & - Incidental Learning \\
\hline - Student Engagement & & - Informal Assessment \\
\hline - Visual Learning & & - Novelty \\
\hline - Applicability & & - Comfort Level \\
\hline • “Instant Feedback” & & - Student-Teacher Collaboration \\
\hline - Informal Assessment & & - Learning Efficiency \\
\hline - Enhanced Learning Opportunity & & - Direct Instruction \\
\hline - Time Filler & & - Interactive Discussion \\
\hline
\end{tabular}




\begin{tabular}{|c|c|c|}
\hline Preactive Decision-Making & Interactive Decision-Making & Postactive Decision-Making \\
\hline $\begin{array}{l}\text { - Teaching Efficiency } \\
\text { - Learning Efficiency } \\
\text { - Review and Practice } \\
\text { - Technology Skills }\end{array}$ & & $\begin{array}{l}\text { - Availability } \\
\text { - “Instant Feedback” } \\
\text { - Lack of Customization } \\
\text { - Flexibility } \\
\text { - Creativity } \\
\text { - Applicability } \\
\text { - Review and Practice } \\
\text { - Classroom Management } \\
\text { - Technology Skills } \\
\text { - Life Skills } \\
\text { - Time for Planning } \\
\text { - “Reinforcement” } \\
\text { - Enhanced Learning Opportunity } \\
\text { - Visual Learning }\end{array}$ \\
\hline
\end{tabular}




\begin{tabular}{|l|l|l|}
\hline Preactive Decision-Making & Interactive Decision-Making & Postactive Decision-Making \\
\hline & & $\bullet$ Teacher Investment \\
& & $\bullet$ Experimentation \\
\hline
\end{tabular}


Case Study 6 Narrative: Frieda - Experienced High School Teacher

The following case describes Frieda, an experienced high school teacher, and how she makes instructional technology decisions. Frieda earned her Master’s degree in Math Education. She is in her $31^{\text {st }}$ year of teaching and has taught a wide range of math classes at the high school level, from beginning math skills to college level algebra and college level trigonometry. She also taught algebra and statistics at nearby institutions of higher education. Currently she teaches math skills, college algebra and college trigonometry. Despite her teaching experience, Frieda is constantly educating herself so she can improve as a teacher and says, "You learn as you go.”

Frieda’s case study is introduced through insight into her learning environment and her educational beliefs, followed by her decisions prior to teaching, during teaching, and after teaching. Table 13 summarizes the data analysis of Frieda’s preactive, interactive, and postactive teaching decisions with regard to using technology.

\section{Learning Environment}

Inside the school and Frieda's classroom. Frieda's classroom is larger than most public school classrooms and the entire right side consists of large windows. The students sit at wooden desks with the chairs attached. The desks are aligned in rows, all facing the front of the room. Classes begin with students at their desks, but then students often work in groups at their desks or at the computers located along the back wall and one side of the classroom.

In the corner of her classroom by the windows sits Frieda’s desk surrounded by bookshelves. Students are welcome to use Frieda’s computer and the computer for her preservice teacher when they are working on their College Algebra labs.

Numerous posters and signs hang on the walls with the overall theme of "thinking and trying.” Every day on the whiteboard at the front of the room, Frieda writes a quote pertinent to 
achieving goals or thinking. One day the quote read, "Dreams are not something to wait for. They are something to work for.”

Educational philosophy. “Good morning. How are you today?” Frieda greets each of her students as they walk into the room. Frieda treats her students as individuals and not just as a class. She says, "It is really important to me how the student does as an individual." Part of recognizing students as individuals is "trying to meet all types, whether they are visual learners or auditory learners." She also believes "students need to know how much you care before they want to know what you're teaching.”

As she teaches, Frieda tries to take them as far as she can in math. "For some it is just getting through the basics, while others need to be challenged." Spending time after school is an important part of helping each student to achieve his or her potential, so Frieda offers after school review sessions.

Frieda believes that thinking is important for her as well as her students. She says it is important for her to remember to be a learner because lifelong learning is important. She attends conferences and workshops to learn new things and bring ideas back to her classroom "to just try to be a better teacher every day.”

Preactive Decision-Making

Technology planning approach. When thinking about using technology, it "has to be in the back of your mind all the time.” Frieda does not think about technology only when sitting down to create lesson plans because the potential exists for overlooking ways to use it. She recommends "talking with other teachers about it to get ideas about how they're using it." 
Outside influences. Outside factors that influence Frieda’s decision to use technology are standards, her school's technology plan, and administration's requirement that faculty use technology in their teaching. Frieda follows West Virginia’s Content Standards and Objectives (CSOs), which include standards for using technology and also keeps in mind the International Society for Technology in Education (ISTE) national level standards (standards). Her high school has a technology committee and a technology plan (school technology plan) that requires students use technology. Every nine weeks administration officials check teachers' lesson plans to make sure they are using technology (administration's requirements).

An issue beyond Frieda’s control is time, a major factor that shapes her decisions on using technology. Her high school is on block scheduling (time limitation), which means she does not see all of her students every day (time limitation) “or I know we would use more technology."

Teaching and learning decisions. As she designs her lessons, Frieda’s decision-making is grounded in her thinking about how technology can improve her lessons and help her students to learn (enhanced learning opportunity). One way she uses technology is to gain students’ interest (student engagement). She says "you always need something in the lesson that is going to grab their attention,” and she thinks that technology is one way to do that because it is something different and “anything different gets their attention” (variation from routine).

Frieda asks her students to use technology because "with technology, you can give them real life situations where they make predictions and it's things that really, you actually do with math” ("real life”; modeling). She talked about how her students are sharp and they can recognize "something that's really going to be useful and they see a way that they are going to be able to apply it to either their lives or their careers or at least know somebody’s using it 
somewhere” (applicability). When students make this connection, Frieda says they become more interested in what they are learning (student engagement).

Another reason Frieda chooses to use technology to help students learn is because it “allows them to go quite a bit beyond what we were able to do before (enhanced learning opportunity) when we had to do everything by hand.” She explains how technology allows her students to cover content more quickly and therefore cover more material (learning efficiency). She says that if you had to work problems by hand and create graphs by hand, as opposed to using a graphing calculator, “you may only get to four or five questions, whereas if you teach using the calculator and the calculator is doing all the tedious work, then you can ask twenty [questions].” When applicable, Frieda tells her students they are doing things, such as solving more advanced algebra problems, which she did not learn until college. During her College Algebra class, she told her students, “when I was going to school, it took us a few days or a week to solve a problem like you did last night. Graphing calculators allow you to do higher math and do it more quickly because it gives you a visual representation (visual learning) without having to do it by hand” (learning efficiency). Frieda thinks this helps to build their confidence (build confidence).

Frieda sometimes decides to use technology because it allows students to explore and ask questions that she thinks they would not have thought of if they weren't using technology. When I asked Frieda what she meant by this, she explained the tediousness of solving a problem using paper and pencil does not allow students to see the whole picture. When they work on the same problem using a calculator, they can "extend the window and look at what happens when you go to infinity” (visual learning; enhanced learning opportunity). Another benefit of students’ making changes to their calculators or graphing calculators is that they tell her what happens 
instead of her telling them (discovery learning). Frieda thinks this helps students to remember longer (retention).

Although calculators are an integral part of her math classes and can be beneficial, Frieda recognizes the advantages and disadvantages of this technology. She cautions her students that calculators and graphing calculators are not going to be helpful if they do not know their math (content first). During one of her classes, she told her students "We can use this on what you did last night. We can solve some parts of the problem more quickly (learning efficiency), but the calculator helps only if you understand the problem you are solving” (content first). She elaborated, telling her students that their brains combined with the calculator give them math power. "If you take the math that you know and your ability to think, and combine that with the calculator, that is very powerful (critical thinking).”

When designing her lessons, Frieda chooses to use College Algebra Labs (referred to as CA Labs) software to either introduce new material (introduce content) or reinforce material that she has already covered ("reinforcement"). The number of days students spend using the computer-based labs is decided based on Frieda's knowledge of her students and their capabilities (informal assessment; formal assessment). Sometimes she does a preview activity to introduce the lab and transition from what they are learning to the computer-based lab. This decision is based on students' reactions in the past and Frieda's knowledge of her current students (informal assessment; formal assessment).

When thinking about using how and why to use technology, Frieda suggests teachers ask themselves "what can I do with technology that I wasn’t able to do before” (enhanced learning opportunity)? An example she points out is technology can enable them to take their lessons to the next level. She also suggests that teachers ask themselves "Does this allow me the freedom 
now to go back into the room and interact with the kids (student-teacher collaboration) instead of standing at the blackboard? Then I should do that.” Frieda suggests using technology to print notes and give them to the kids so they don't have to focus on taking notes and instead can interact more with their classmates” (student collaboration).

Interactive Decision-Making

Often Frieda begins her lessons using the overhead projector as she and her students review their homework problems. She asks them what problem they want to cover first and then writes it on an overhead transparency. She questions her students as to what step they took first, and proceeds by explaining parts of the problem to her students and asking for their input and what they would do to solve the problem (direct instruction; interactive discussion). This approach also allows Frieda to determine how her students are doing with the current content (informal assessment).

Technology is used by Frieda to informally assess her students during class and observe who is engaged in learning and "who is just staring and nodding as if they are paying attention." She explains, "these kids are so expert at sitting and looking at you like they're listening and you have no idea they're somewhere else. Some of them you can tell, but some of them you can’t.” So she circulates the room when they are working on their computers or calculators to answer questions ("instant feedback") and observe their screens (informal assessment; classroom management). If she walks past and notices that nothing has changed on a student's screen since the last time, she prompts that person to begin working (classroom management). As her students work on problems presented by the College Algebra Labs, Frieda circulates the room to make sure her students "stay on task (classroom management), to help when needed ("instant 
feedback”), and provide guidance but not give the answers because we want some discovery learning” (discovery learning).

There have been times when the use of technology did not go as Frieda had planned and she made modifications. Thinking back, she said this usually happens when she went too fast with technology (pacing). “Usually if things aren’t working it’s because I'm comfortable with the calculator or the technology that we're using and going too fast. I have to slow myself down.” This is why she always asks one of her students to connect their graphing calculator to the overhead projector instead of her. As Frieda and her students work through math problems together, they go at the pace of the student whose calculator is connected to and displayed on the television.

Occasions when Frieda planned to use technology but then changed her mind were sometimes due to faulty technology. Equipment is fairly abundant in her school but because someone currently is not assigned to making sure the equipment works, it often does not function correctly and she does not have time to check it (reliability). An example she pointed out was when some of the calculators were without batteries or had dead batteries, so in the essence of time she opted to teach the lesson using pencil and paper instead (backup plan). Another example is when PowerPoint not does not work on the computer you planned to use. When technology does not function correctly, she says, “you always, always, always have to have a backup. I would never go into a class where you are going to use technology and not have a second lesson plan” (backup plan).

Other times when Frieda changed her plans to use technology were due to issues beyond her control. There were days when she found out in the morning that there was going to be an assembly and she had to change her lesson plans. During the winter, inclement weather often 
caused a delay in the start of school and as a result, classes were often shortened (time limitation).

\section{Postactive Decision-Making}

Frieda spends time after school working with students whose math skills are not on the same level as others (diversity). She uses commercially produced math tutorial software to help them review and practice (review \& practice) because her students a) are comfortable using technology (comfort level); and b) it is not negative or intimidating (build confidence). Her students know they can continue to work until they get the correct answer ( "instant feedback”) and "if they don't get the answer the first time, the only things that know are the computer and them." She explains that "math is a confidence thing” and that is why her students like the software, because “it’s very non-intimidating and non-judgmental” (build confidence). She talks about how most of them have not been successful at math and she can start them on a level in the software where they initially achieve eighty percent (informal assessment). Once they earn one hundred percent at that level, it takes them to the next level on the software. The students never know what level they are working on and do not know what level their classmates are working on, so all students were at a level where "everybody was finding success (diversity; build confidence) and hearing the little bells go off and telling them they did a good job. It's just so important for those kids.”

Frieda does not use technology "just for the sake of using it” or to replace an activity that is better accomplished using more traditional media such as paper and pencil. She says, "I'm not one to use it [technology] because it's something to do. If it actually adds to your lesson or makes your lesson better, then you definitely want to use technology” (enhanced learning opportunity). Frieda elaborated, indicating that she decides if technology will make a lesson 
better by comparing the lesson when she taught it in the past without technology to the same lesson currently when she teaches it using technology.

She also makes her decisions on whether or not to use technology or which technology to use based on her students (informal assessment) because "as a teacher, you know what works with your students.” Choosing how to teach her lessons and deciding how and why to use or not use technology is based on Frieda's assessment of her students. For example, if she has a class where the majority are visual learners, she incorporates the Internet when applicable (visual learning). If she has numerous students who have problems paying attention, she will design more activities "where they are up and moving around (student engagement)."

Frieda says that you have to balance the amount of time getting technology to work versus the benefit for the students (time vs. benefit). "You can easily waste a lot of time that it outweighs the benefit of using technology if you have to spend so much time getting it to work." She said that sometimes it is not worth, for example, the time to spend creating a PowerPoint presentation and loading it onto the teacher's computer. In the past she used some PowerPoint presentations but decided not to continue using them because students have a tendency to "tune out PowerPoints because they are used so much and are so traditional now" (informal assessment).

There were situations where the time initially invested into technology was intense, but she recognized the payoff (time vs. benefit). An example she describes is the amount of time it takes to help students to learn graphing calculators. She says that at first it may take 2 or 3 days to get through what should only take 1 or 2 days because the students have a lot of questions about how to use the technology. After the initial learning curve, though, the students know how to use the technology (technology skills); they do not have as many questions; and she can cover 
more material in less time (teaching efficiency). When students first learn to use technology, it is often a big deal because it is new and exciting (novelty). After a while, they get used to the technology and it becomes just another tool (technology as tool). Frieda talks about students’ use of calculators and that “you don't even have to say get out your calculator. They just know that they're going to do that. They know we're going to use the labs, use the computers. And we go to the labs on the computers about once every two weeks so it's not such a big deal that it's distracting.”

When Frieda taught a lesson that she sensed needed something or she did not "feel that the students were maybe learning it as well as I'd like them to, or maybe they're just memorizing things and I don't really think they understand the concepts,” then she looks for technology to use (enhanced learning opportunity). She does not have time to “redo every lesson,” but she does invest time in those lessons that she can improve (time vs. benefit). She says it all comes down to time because “you can’t do it for every lesson every day. You just don’t humanly have the time to do it” (time limitation).

When she uses the computer in her lessons, Frieda thinks, "One of the biggest success stories would probably be their communication in mathematics.” When they are doing the College Algebra Labs, she has her students work in teams and they have to talk to each other about math, which is something that they did not do before (incidental learning). If a student is having trouble with something on the computer, she will say, “Joey, you go help them.” She reflected on the past, indicating that “the kids didn't talk about math, they just kind of did it on their own.” She believes that talking about math and working together to solve problems better prepares them for life after high school because most jobs require you to "work with other people and communicate with other people and use a lot of different skills” (life skills). Frieda believes 
this is "a really big advantage of technology." She tells her students "Businesses have told us in the past that we prepare bright children, but it's always been that they worked alone. Now, of course, we get out in the real world and how often do we work alone? Doctors don't. Teachers don’t. Engineers certainly don’t. They have to be able to work with each other.” She says that working together is a skill that math teachers "haven't taught in the past and it's a really important skill that you can communicate mathematics. Just doing mathematics is wonderful, but being able to communicate mathematically is certainly very important,” and she thinks, “technology is a catalyst for making it happen” ("technology as catalyst”).

Using the computer-based tests that accompany the College Algebra Labs has advantages and disadvantages. The computer-based test does not give partial credit, which emulates the SAT \& ACT tests that students will have to take in the future and most likely some tests they will take once they are in college (life skills). Frieda finds that her students do like the instant response ("instant feedback"). The computer gives them instant feedback, "which is a heightened teaching moment as opposed to passing the test back days later.” She notices that students’ interest is high at the time of the test, but if she waits a few days to pass back a test they took using paper and pencil, students just want to know what grade they got and they don't care as much about what they missed. When taking the test on the computer, she noticed that students asked questions about the problems that they missed (student engagement).

Thinking about the impact of technology on her teaching and the decisions she makes, Frieda says that when she started her career, teachers were "supposed to be the know it all and have the solution to everything” but in today's world it is not possible. She sees teachers of today more as facilitators and she thinks it is good for students to see that teachers “don't know everything” and they are "learning as well as them." She says the "one big thing that's changed 
for those of us who are experienced" is that "you have to relinquish control" ("relinquish control"). When an educator teaches in a more traditional way, such as mainly direct instruction, there is control over the students. When technology is used, she says that teachers have to relinquish control because “you can’t be everywhere; you can’t control what happens to the machines. So you have to have confidence in your teaching ability. You have to have confidence in your students to be able to do it. She says that "you still have to be the teacher, it's just a different role that you have to take on" ("technology as catalyst”). 
Table 13

Case 6: Descriptive Codes for Preactive, Interactive, and Postactive Instructional Technology Decision-Making

\begin{tabular}{|c|c|c|}
\hline Preactive Decision-Making & Interactive Decision-Making & Postactive Decision-Making \\
\hline - Standards & - Direct Instruction & - Diversity \\
\hline - School Technology Plan & - Interactive Discussion & - Review and Practice \\
\hline - Administration's Requirements & - Informal Assessment & - Comfort Level \\
\hline - Time Limitation & - "Instant Feedback" & - Build Confidence \\
\hline - Enhanced Learning Opportunity & - Classroom Management & - "Instant Feedback” \\
\hline - Student Engagement & - Discovery Learning & - Informal Assessment \\
\hline - Variation from Routine & - Pacing & - Enhanced Learning Opportunity \\
\hline - "Real Life" & - Reliability & - Visual Learning \\
\hline - Modeling & - Backup Plan & - Student Engagement \\
\hline - Applicability & - Time Limitation & - Time vs. Benefit \\
\hline - Learning Efficiency & & - Technology Skills \\
\hline • Visual Learning & & - Teaching Efficiency \\
\hline - Build Confidence & & - Novelty \\
\hline - Discovery Learning & & - Technology as Tool \\
\hline
\end{tabular}




\begin{tabular}{|l|l|l|}
\hline Preactive Decision-Making & Interactive Decision-Making & Postactive Decision-Making \\
\hline - Retention & & • Time Limitation \\
- Critical Thinking & & • Incidental Learning \\
- Introduce Content & & • "Tife Skills \\
- "Reinforcement" & • "Relinquish Control" \\
- Informal Assessment & \\
- Formal Assessment & \\
- Student-Teacher Collaboration & & \\
- Student Collaboration & & \\
\hline
\end{tabular}


Data produced by the three experienced teachers' case study narratives and corresponding tables of descriptive codes were synthesized and analyzed for similarities and differences:

1. Descriptive codes for the three experienced teachers were compiled into a matrix and analyzed (see Appendix G).

2. Descriptive codes were tallied and analyzed for the three decision-making phases for experienced teachers.

3. Pattern codes were developed for experienced teachers by looking at relationships within the descriptive codes.

4. Pattern codes were tallied and analyzed according to the three decision-making phases for experienced teachers.

\section{Experienced Teachers Descriptive Code Analysis}

Descriptive codes for experienced teachers' preactive, interactive, and postactive instructional technology decisions were compiled into one table (see Appendix G). In the far left column the descriptive codes for all three experienced teachers are listed and the three decisionmaking phases are identified across the top. To create this matrix, each teacher's table of descriptive codes (Table 11, Table 12, and Table 13) was referenced to determine what descriptive code occurred during which decision-making phase, and an X was placed in the corresponding column. By analyzing the matrix of compiled descriptive codes, the following similarities and differences in experienced teachers' instructional technology decision-making were discovered:

- All three experienced teachers made some of the same descriptive decisions within the preactive, interactive, and postactive phases. 
- All three experienced teachers made the same descriptive decisions at some point within the three phases.

- Some descriptive decisions were specific to only one of the three novices. Same Decisions within Preactive Phase

Looking at descriptive codes across the three decision-making phases, it is evident that all three experienced teachers made similar decisions within the preactive phase. Within the external influences pattern code, standards and time limitation affected the preactive decisions of all three experienced teachers. West Virginia’s Content Standards and Objectives (CSOs) have to be implemented by all K-12 teachers, which include standards for using technology. Derk, one of the teachers in the elementary/middle school wanted his students to capture and edit video for a science project, but he knew it would take a great deal of time to do this and therefore could not be accomplished during class. Georgia, the other teacher at an elementary/middle school, considers what she is going to teach, if she realizes there will not be time, she most likely will not use technology because she views it as "a wonderful way to reinforce." The experienced high school teacher, Frieda, would use more technology if her class periods were longer than fifty minutes and she saw her students every day. Because her school is on block scheduling, there are days when she does not see all of her students.

While planning lessons, all three experienced teachers chose to use technology as a means of student engagement, which is a descriptive code within the student benefit pattern category. Derk (elementary/middle school) decided to have his students use the SmartBoard and PowerPoint because they really like to use technology and it engages them. Georgia (elementary/middle school) plans to take her students to the computer lab because "just about 
every student becomes actively engaged.” Frieda (high school teacher) decides to use technology because it gains students' attention and interest.

Applicability, content first, and informal assessment, preactive descriptive decisions within the instructional strategy pattern code, were reasons why the experienced teachers decided to use or not to use technology. All three teachers selected technology that was applicable to the lessons they were planning and did not use it just as something for their students to do. Derk, Georgia, and Frieda thought about content first, technology second. When using calculators, Derk and Frieda teach their students how to perform calculations using paper and pencil first, and then shows them how to perform the same calculation using the calculator. Georgia prefers to introduce new concepts using traditional teaching, such as looking at a textbook, and then to use technology to reinforce the content. The experienced teachers make plans to use technology to informally assess their students because they can see how their students are doing by looking at the screens on their computers or calculators.

Visual learning, a subcategory within the diversity pattern code, is another reason why all three experienced teachers decided to use technology. Derk makes plans to use technology so his students can see things that they otherwise might not be able to see. Georgia thinks about using technology while planning because "our whole new generation of students are visual learners," so she uses technology to help them to "see" what they are learning. One reason why Frieda asks her students to use graphing calculators is because they provide a visual representation of problems they are solving.

Enhanced learning opportunity and learning efficiency are descriptive code decisions within the improvement pattern code that all three experienced teachers made when planning. Derk, Georgia, and Frieda planned to use technology to help their students do something better 
or do something that they could not do without it. They also designed technology into their lessons because it could allow their students to accomplish something more efficiently than without it. After their students learn how to perform calculations using pencil and paper, both Derk and Frieda ask their students to use calculators to check their answers and/or to perform more complex calculations in less time. Georgia takes her students to the computer lab and works with them as they are correcting their papers on the computers, which saves them time from writing another draft and then typing it.

Same Decisions within the Interactive Phase

Decisions made by all experienced teachers during the interactive phase, time limitation and informal assessment, were also made during their planning. Time limitation, a descriptive code within the external influences pattern code, affected the interactive decisions of all three experienced teachers. Derk, Georgia, and Frieda often decided not to use technology as planned because they would not have as much class time as they hoped due to inclement weather, their students not progressing as quickly as hoped, and/or unplanned school events.

The other interactive decision that all three experienced teachers made was informal assessment, a descriptive code within the instructional strategies pattern category. As Derk informally assessed his students while teaching, he sometimes had to choose to eliminate plans to use technology due to lack of time. While teaching her students how to create their time capsule brochures using a publishing program on the computer, Georgia realized that her students did not know how to use the program, so she took class time to teach them how to use it. Frieda uses technology while teaching to assess if her students are paying attention or not and if they understand the problems on which they are working. 
Same Decisions within the Postactive Phase

The experienced teachers thought about the use of technology during their postactive decision-making to build students' confidence. Build confidence is a descriptive code within the student benefit pattern. Derk, Georgia, and Frieda noticed that technology helped to build their students' confidence because it was not intimidating to them and students could find success at different levels when using technology.

Student engagement, also a category with in the student benefit pattern, is another reason experienced teachers decided to use technology during the postactive phase. All three teachers also thought about technology and student engagement during the preactive phase as well. When reflecting on their teaching and their students, the experienced teachers recognized how technology engaged their students and planned to use it for this purpose in the future.

Two postactive descriptive decisions that experienced teachers thought about during postactive decision-making were comfort level and novelty. Both of these decisions are classified within the technology readiness pattern. Derk, Georgia, and Frieda knew from using technology in their lessons that students and teachers must be comfortable using technology or a lesson would not go as well as planned. They also knew that time had to be invested in getting students comfortable with using the technology so the novelty of using it would wear off and the student would focus on what they were supposed to be learning as opposed to playing with the technology "toy."

Same Decisions within the Three Phases

Examining the descriptive codes shows that all three experienced teachers, at some point within either the preactive, interactive, or postactive phase made similar decisions. Three of these descriptive decisions, "instant feedback", student collaboration, and technology skills were part 
of the student benefit pattern. Derk, Georgia, and Frieda made decisions to use technology because it could provide immediate feedback to their students, which Frieda referred to as a “heightened teaching moment,” because students are more interested in learning when they receive "instant feedback" from using modern technology as opposed to having to wait for feedback the next day in the form of paper. Derk and Georgia thought about technology and "instant feedback" during the preactive phase. Georgia and Frieda considered immediate feedback and technology during their interactive and postactive planning. All three experienced teachers decided to use technology based on the potential for it to promote student collaboration. Derk and Frieda made technology decisions related to student collaboration while planning and Georgia made these decisions while reflecting and revising lesson plans. Helping their students to improve their technology skills, such as using a calculator, graphing calculator, or computer, was part of experienced teachers' decision-making. Derk and Georgia, the elementary/middle school teachers, thought about technology skills during the preactive phase. Georgia and Frieda, the high school teacher, considered technology skills during the postactive phase.

All three experienced teachers considered the use of technology for classroom management, direct instruction, and review and practice, all of which are instructional strategies. Georgia and Frieda considered the use of technology for classroom management during the interactive phase, and Derk and Georgia thought about it during the postactive phase. Decisions to use technology for direct instruction were thought about by Derk while planning, by Frieda while teaching, and by Georgia when reflecting. Derk and Georgia chose to use technology for review and practice during their preactive phase of decision-making, and Georgia and Frieda decided to use technology for their students to review and practice content during the postactive phase. 
Within the improvement pattern, the experienced teachers made decisions to use technology for teaching efficiency. While they were planning, Derk and Georgia recognized the potential for technology for technology to improve teaching by allowing them to cover more within less time. Georgia thought about teaching efficiency while she was teaching, and Frieda considered it after she taught and was planning for the future.

\section{Teacher-Specific Decisions}

There are twenty-eight descriptive decisions that were made by only one of the experienced teachers. This information was obtained by analyzing Appendix G: Descriptive and Pattern Codes Representing Experienced Teachers’ Decision-Making. Teacher-specific decisions were evident in looking at the descriptive codes across the three decision-making phases. Descriptive codes for which an X appeared only once, or an X appeared more than once but for the same teacher, represented a teacher-specific decision. Teacher-specific decisions are synthesized in Table 14. 
Table 14

Summary of Teacher-Specific Decisions for Experienced Teachers

\begin{tabular}{|c|c|c|c|c|}
\hline \multirow{2}{*}{ Pattern Code } & \multirow{2}{*}{ Descriptive Code } & \multicolumn{3}{|c|}{ Decision-Making Phase } \\
\hline & & Pre & Inter & Post \\
\hline \multirow{6}{*}{ External Influences } & Administration's Influence & Case5 & & \\
\hline & Administration's Requirements & Case6 & & \\
\hline & Lack of Customization & & & Case5 \\
\hline & Pressure from County and State & Case4 & & \\
\hline & Reliability & & Case6 & \\
\hline & School Technology Plan & Case6 & & \\
\hline \multirow{9}{*}{ Student Benefit } & Communication & Case4 & & \\
\hline & Customization & Case4 & & \\
\hline & Evaluation of Resources & Case4 & & \\
\hline & "Focus" & Case4 & & \\
\hline & "Positive Attitude" & & & Case5 \\
\hline & Sequence Information & Case4 & & \\
\hline & "Summarize Information" & Case4 & & \\
\hline & Supplementation & Case4 & & \\
\hline & "Voice" & Case4 & & \\
\hline \multirow{4}{*}{ Instructional Strategies } & Discovery Learning & Case6 & Case6 & \\
\hline & Introduce Content & Case6 & & \\
\hline & Pacing & & Case6 & \\
\hline & Time Filler & Case5 & & \\
\hline Diversity & Kinesthetic Learning & & & Case5 \\
\hline Improvement & \multicolumn{4}{|l|}{ No teacher-specific decisions } \\
\hline \multirow[t]{2}{*}{ Technology Readiness } & Student Readiness & & & Case4 \\
\hline & Technology as Tool & & & Case6 \\
\hline \multirow[t]{7}{*}{ Teacher Change } & Backup Plan & & Case6 & \\
\hline & Flexibility & & Case5 & \\
\hline & "Relinquish Control" & & & Case6 \\
\hline & Teacher Collaboration & & Case5 & \\
\hline & Teacher Investment & & Case5 & \\
\hline & "Technology as Catalyst" & & & Case6 \\
\hline & Time for Planning & & Case5 & \\
\hline \multicolumn{2}{|c|}{ Total Teacher-Specific Decisions by Decision-Making Phase } & 14 & 7 & 7 \\
\hline \multirow{3}{*}{\multicolumn{2}{|c|}{$\begin{array}{l}\text { Total Teacher-Specific Decisions for each Experienced Teacher by } \\
\text { Decision-Making Phase }\end{array}$}} & 9-Case4 & 0-Case4 & 2-Case4 \\
\hline & & 2-Case5 & 4-Case5 & 2-Case5 \\
\hline & & 3-Case6 & 3-Case6 & 3-Case6 \\
\hline
\end{tabular}

Case 4 = elementary school teacher Case $5=$ middle school teacher Case $6=$ high school teacher 
Experienced educators made the most teacher-specific decisions during the preactive phase (14), and the same amount during the interactive (7) and postactive phases (7). Derk, one of the experienced elementary/middle teachers, made the most teacher-specific decisions (11). Georiga, the other elementary/middle teacher, and the high school teacher made nearly the same total amount of teacher-specific decisions (8 and 9 respectively). During the preactive phase, Derk (case study 4) made the most teacher-specific decisions (9) and Georgia (case study 5) made the fewest (2). In the interactive phase, Georgia made the most teacher-specific decisions (4) and Derk made the fewest (0). All three experienced teachers made approximately the same number of teacher-specific decisions during the postactive phase (Derk [2], Georgia [2], and Frieda [3]).

Teacher-specific preactive decisions made by the experienced teachers were affected by external influences beyond their control. One of the teachers in an elementary/middle school, Derk, was the only one who made decisions because of pressure he felt from the county and state. He indicated that he felt this was wrong and did not allow him to teach the way that he believed in teaching, but he felt too much pressure to help his students increase their standardized test scores. Georgia is the only experienced teacher (elementary/middle school) who indicated there was an influence by administration to use technology. She is also the only experienced teacher who talked about lack of customization while reflecting on the use of a required technology and how she could not adapt it to fit the needs of her students. The high school teacher was the only person who made decisions to use technology because administration in her school required it and her school had a technology plan as well. Frieda also is the only experienced teacher who made an interactive decision about using technology based 
on its reliability. She said that technology must be functioning properly and reliable or it is not worth using.

Decisions made by the experienced teachers pertaining to their perceived benefit for students are evident. Derk (elementary/middle school teacher) made numerous preactive decisions about using technology based on his perceptions of benefit for his students. He created a web site to increase communication between him, his students, and their parents. He decided to use the Student Response System because he could customize it based on what his students were learning. He asked his students to use the Internet to compare and evaluate resources. Derk is the only experienced teacher who asked his students to use technology because it helped them to “focus,” sequence information, “summarize information,” and gave them a "voice.” Allowing students to use a new Computer-Aided Drafting software program after school was a decision Derk made because of the enrichment provided by using this supplementary technology. Using the Computer-Aided Drafting software after school also allowed Derk to learn more about the program and think of ways for his students to use it during classes. Georgia was the only experienced teacher who decided to use technology based on her postactive observation that students often had a "positive attitude” when using it.

Instructional strategies that were specific to one of the experienced teachers are evident in Frieda's (high school teacher) preactive decision to use technology to introduce content. She is also the only experienced teacher who opted to use technology to pace the delivery of content. This occurred while she was teaching a lesson. She asked a student to connect her graphing calculator to the overhead projector and work through the problems with the class, rather than Frieda connecting her calculator and working through the problems. The reason Frieda did this was because a student would work at a pace similar to other students, whereas Frieda would 
most likely solve the problems too quickly. Another decision made by Frieda, but neither of the other two experienced teachers, was to use technology to promote discovery learning for her students. She thought about this instructional strategy through the use of technology during teaching and after. Georgia (elementary/middle school) was the only experienced teacher who talked about using technology on occasion primarily as a way to fill time. For example, one time she told her students they could play games on the Internet after completing their assignment; another time she asked them to search for information on the Internet regarding an upcoming field trip after completing their test.

The decision to use technology based on diversity of students was specific to Georgia, one of the experienced elementary/middle schoolteachers. She indicated that her postactive choices to use technology were sometimes grounded in her observations that it helped kinesthetic learners. No teacher-specific decisions existed within the category of improvement.

One of the experienced elementary/middle school teachers (Derk) and the high school teacher (Frieda) made teacher-specific postactive decisions pertaining to technology readiness. Derk talked about how students need to be ready to use technology in order for it to be used effectively. Frieda recognized that students had to come to recognize technology as a tool, as opposed to a toy, so she made sure to invest time at the beginning of the school year to expose her students to various technologies so they became just another learning tool.

As for recognizing teaching decisions that had to be made differently when using technology, the high school teacher (Frieda) is the only experienced teacher who mentioned that a backup plan is a necessity. Frieda is also the only experienced teacher who reflected on teachers needing to learn to "relinquish control" and become more of a facilitator when using technology in the classroom. She is also the only one who spoke of "technology as a catalyst" 
based on her belief that technology can help students to learn differently and teachers to teach differently. Georgia, one of the experienced teachers in an elementary/middle school, made interactive technology decisions pertaining to teacher change. She mentioned the need for teachers to be flexible when using technology because how it functions and how students use it cannot always be predicted. Time for planning is something that Georgia says teachers need in order to become invested in technology and collaborate on finding ways to use it in the classroom.

The next step in the analysis of experienced teachers' decision-making was to total the number of each descriptive code. Similarities and differences in experienced teachers’ instructional technology decision-making are apparent from analyzing the number of descriptive decision codes for each teacher within each decision-making phase (see Appendix $\mathrm{H}$ for a complete list of descriptive codes and their definitions). Descriptive codes representing decisions made by each experienced teacher prior to teaching, during teaching, and after teaching were totaled by counting the number of times each code occurred (see Appendix G). The number of descriptive decisions made by each teacher, along with the total number for all three experienced teachers, is displayed in Figure 7. 


\section{Descriptive Code Decisions Made by Experienced Teachers}

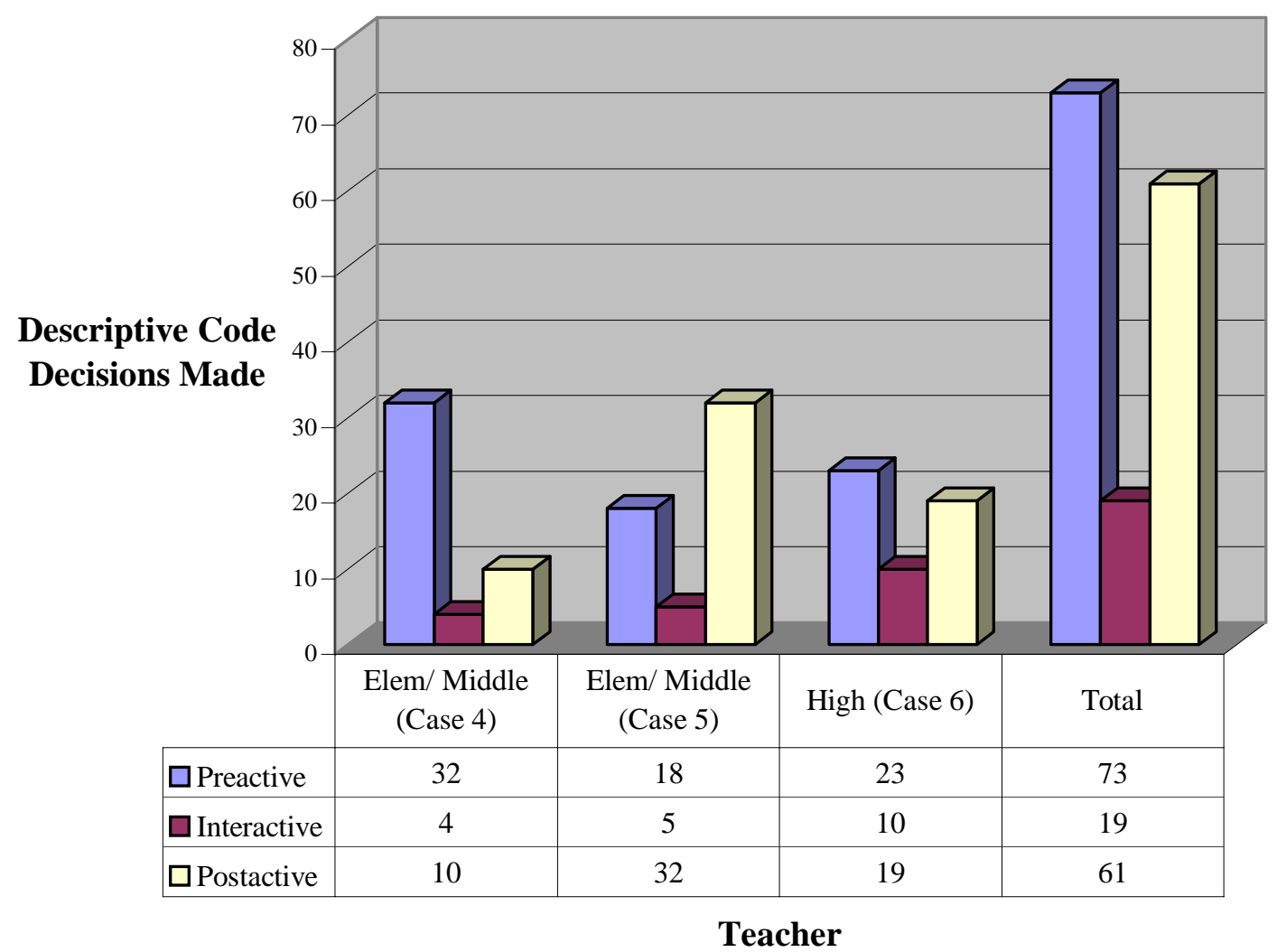

Figure 7. Descriptive code decisions made by experienced teachers.

Looking at Figure 7, it is apparent that experienced teachers collectively made the most instructional technology descriptive decisions during the preactive phase (73) and the least descriptive decisions during the interactive phase (19). During the postactive phase, experienced teachers collectively made 61 descriptive decisions. On an individual basis, all three experienced teachers were similar in that they all made the majority of their descriptive decisions while planning and the least while teaching. Elementary/middle Case 4 teacher and the high school teacher made more preactive than postactive decisions. In contrast, elementary/middle 
teacher Case 5 made more postactive decisions (32) than preactive decisions (18). Of the three experienced teachers, elementary/middle teacher Case 4 made the most preactive decisions (32) and the fewest interactive decisions (4). The experienced high school teacher made the most interactive decisions (10) of the three educators.

\section{Experienced Teachers Pattern Code Analysis}

The descriptive codes for all experienced teachers were examined for relationships, which resulted in the 65 descriptive codes being organized into 7 pattern codes. The pattern codes are listed in the far left column of Appendix G and are identified by bold print and rows that are shaded in gray. Listed beneath each pattern code are the associated descriptive codes. The pattern codes organize the novice teachers’ instructional technology decisions into 7 categories:

1. External Influences - aspects beyond the teacher's control that impact decisions to use or not to use technology

2. Student Benefit - decision whether or not to use technology is based on perceived benefit for students

3. Instructional Strategies - ways in which teachers use technology for teaching and learning

4. Diversity - use of technology to reach learners of various abilities

5. Improvement - using technology allows something to be done better than before or to accomplish something that could not be done before

6. Technology Readiness - students and/or teacher must be ready to use technology

7. Teacher Change - use of technology requires a teacher to shift from traditional ways of teaching 
Counting the number of preactive, interactive, and postactive descriptive decisions within each pattern totaled the pattern code decisions made by experienced teachers. The number of pattern code decisions made by experienced teachers during each decision-making phase, along with the total number of pattern code decisions across the three decision-making phases, is displayed in Figure 8.

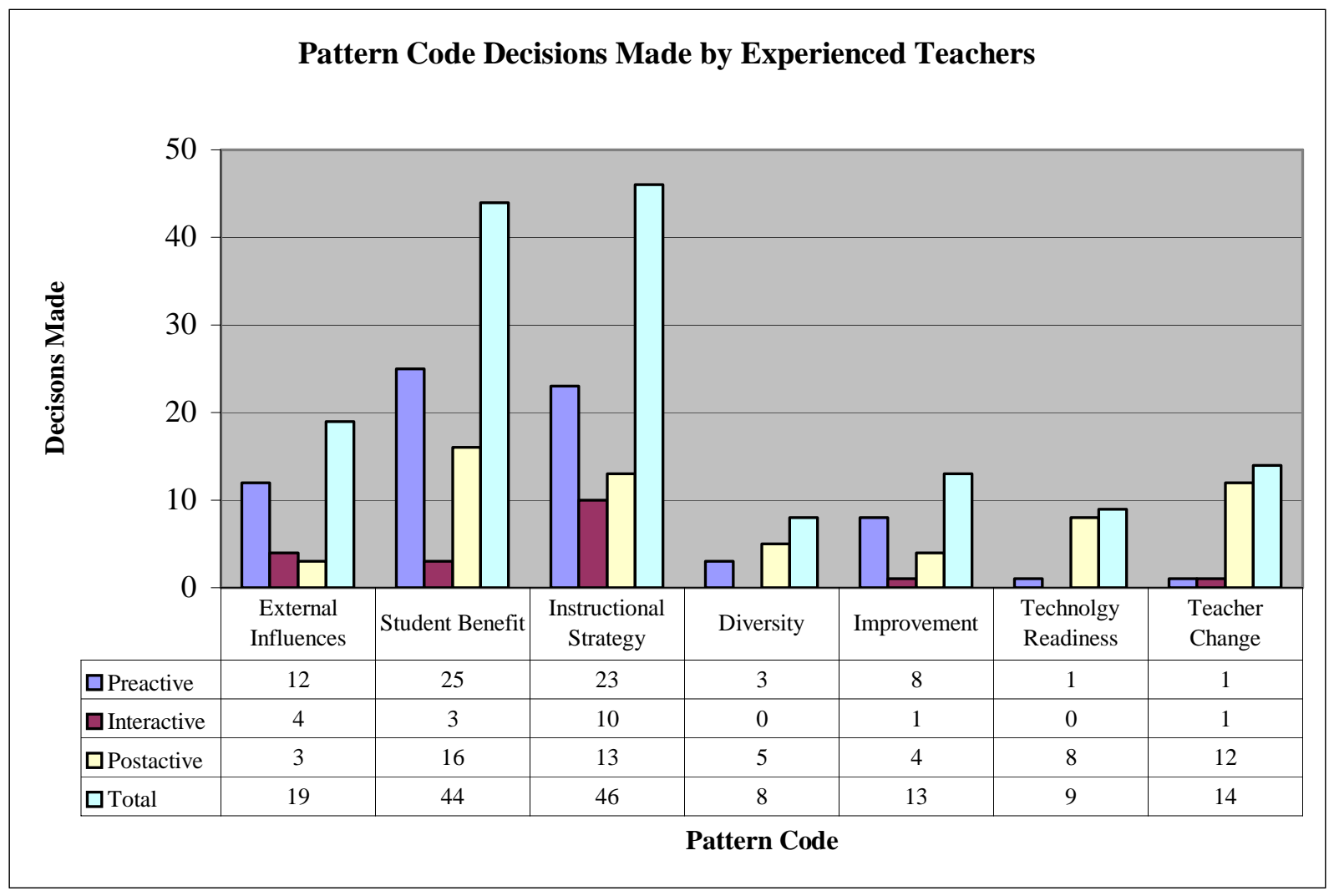

Figure 8. Pattern code decisions made by experienced teachers.

Looking at the three decision-making phases collectively, there is evidence that experienced teachers made the most technology-related decisions related to Instructional Strategy (46) and the fewest decisions related to Diversity (8). Experienced teachers made only two fewer decisions concerning Student Benefit (44) than Instructional Strategy (46). For 4 of the 7 pattern codes (External Influences, Student Benefit, Instructional Strategy, and 
Improvement), experienced teachers made more preactive decisions than interactive or postactive decisions. Experienced teachers made more postactive than preactive or interactive decisions related to 3 of the 7 pattern codes (Diversity, Technology Readiness, and Teacher Change). During the interactive phase, experienced teachers made zero decisions pertaining to Diversity and Technology Readiness.

\section{Summary of Experienced Teachers’ Decision-Making}

The data analysis findings from the experienced teachers' within-case analysis, which are summarized below, answer research question 2: How do experienced elementary, middle, and high school teachers make instructional technology decisions? 
Table 15

Summary of Experienced Teachers’ Decision-Making

\begin{tabular}{|c|c|}
\hline \multicolumn{2}{|c|}{ Summary of Experienced Teachers’ Decision-Making } \\
\hline \multicolumn{2}{|c|}{ Descriptive Code Analysis } \\
\hline \multicolumn{2}{|c|}{ 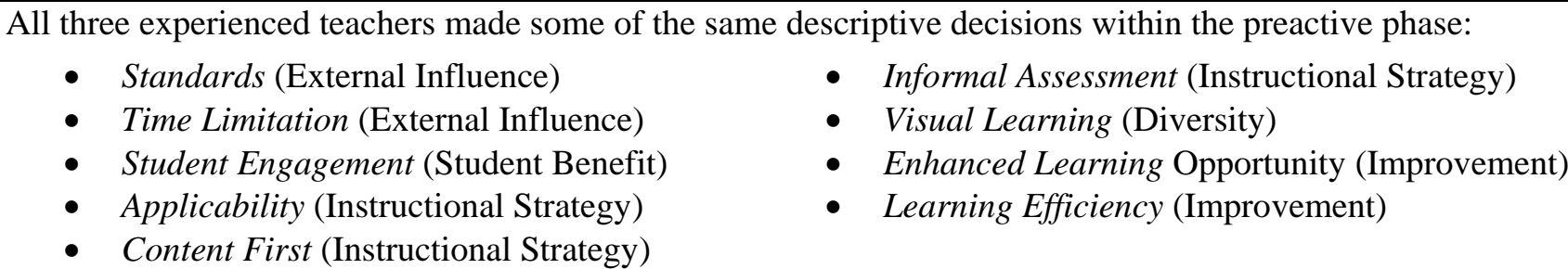 } \\
\hline \multicolumn{2}{|c|}{$\begin{array}{l}\text { All three experienced teachers made some of the same descriptive decisions within the interactive phase: } \\
\text { Time Limitation (External Influence) \& Informal Assessment (Instructional Strategy) }\end{array}$} \\
\hline \multicolumn{2}{|c|}{ 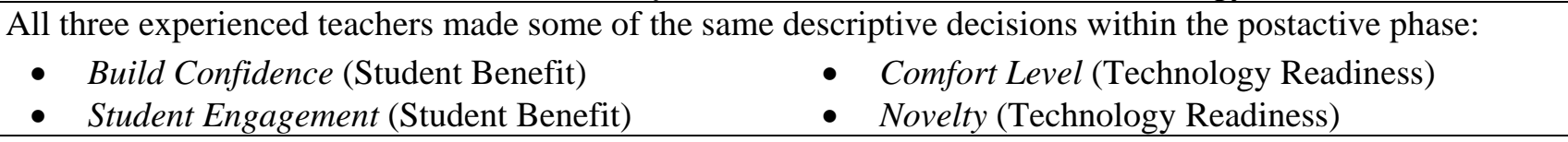 } \\
\hline $\begin{array}{l}\text { All three experienced made some of the same descripti } \\
\text { - } \quad \text { Student Collaboration (Instructional Strategy) } \\
\text { - } \quad \text { Direct Instruction (Instructional Strategy) } \\
\text { - } \quad \text { Review and Practice (Instructional Strategy) } \\
\text { - } \quad \text { Classroom Management (Instructional Strategy) }\end{array}$ & e decisions at some point within the three phases: \\
\hline \multicolumn{2}{|c|}{$\begin{array}{l}\text { Number of descriptive decisions was different for each decision-making phase: } \\
\text { - } \text { - Greatest number of descriptive decisions was made during preactive phase (73). } \\
\text { - } \text { - Fewe next highest number of descriptive decisions was made during the postactive phase (61). }\end{array}$} \\
\hline
\end{tabular}

Some descriptive decisions were specific to only one of the three experienced teachers:

- 28 total teacher-specific descriptive decisions

- Total of 14 made during the preactive phase. Half as many made for the interactive (7) and postactive (7) phases.

- Elementary/middle Case 4 teacher made the most (11), followed by the high school teacher (9), and the elementary/middle Case 5 teacher (8). Pattern Code Analysis

Number of decisions varied for the 7 pattern codes:

- Greatest number of pattern decisions pertained to Instructional Strategy (46), which was only 2 greater than the next highest number, Student Benefit (44). Fewest decisions pertained to Diversity (8).

- $\quad$ For 4 of the 7 pattern codes (External Influences, Student Benefit, Instructional Strategy, and Improvement), experienced teachers made more preactive decisions than interactive or postactive decisions.

- $\quad$ For 3 of the 7 pattern codes (Diversity, Technology Readiness, and Teacher Change), experienced teachers made more postactive decisions than preactive or interactive decisions. 
Experienced teachers made some of the same descriptive code decisions within all three decision-making phases. Preactive decisions made by experienced teachers pertained to the pattern codes External Influence, Student Benefit, Diversity, Instructional Strategies, and Improvement. They did not make preactive decisions related to Technology Readiness or Teacher Change. Interactive decisions made by experienced teachers fell within the pattern codes of External Influence and Instructional Strategy. Their postactive decisions related to Student Benefit and Technology Readiness.

Descriptive-code decisions that all three experienced teachers made at some point within the three phases were related to Instructional Strategy (student collaboration, direct instruction, review and practice, and classroom management), Student Benefit (technology skills and “instant feedback”), and improvement via teaching Efficiency.

Experienced teachers made the greatest number of descriptive-code decisions prior to teaching and slightly fewer after teaching. While they were teaching, they appear to have made considerably fewer descriptive code decisions.

There were 28 teacher-specific descriptive code decisions made by the experienced teachers, with twice as many occurring during the preactive phase as the interactive and postactive phases.

Looking at experienced teachers’ decision-making according to pattern codes, they made the most choices regarding Instructional Strategies but only two fewer decisions related to the next highest category of Student Benefit. They made the fewest decisions pertaining to Diversity. Preactive decisions outnumbered interactive and postactive decisions for External Influences, Student Benefit, Instructional Strategy, and Improvement. Diversity, Technology Readiness, and 
Teacher Change, however, show more experienced teacher decision-making during the postactive than preactive or interactive phases.

\section{Cross-Case Analysis of Novice and Experienced Teachers}

Comparing the data analysis from the within-in case analysis of novice teachers and the data analysis from the within-in case analysis of experienced answered research question 3:

What are the similarities and differences between how novice and experienced elementary, middle, and high school teachers make instructional technology decisions?

Table 16

Summary of Novice and Experienced Teachers' Decision-Making

\begin{tabular}{|c|c|}
\hline \multicolumn{2}{|c|}{ Summary of Novice and Experienced Teachers’ Decision-Making } \\
\hline \multicolumn{2}{|c|}{ Descriptive Code Analysis } \\
\hline $\begin{array}{l}\text { All six teachers made some of the same descripti } \\
\text { - } \quad \text { Standards (External Influence) } \\
\text { - } \quad \text { Student Engagement (Student Benefit) } \\
\text { - } \quad \text { Informal Assessment (Instructional Strategy }\end{array}$ & $\begin{array}{l}\text { isions within the preactive phase: } \\
\text { - Visual Learning (Diversity) }\end{array}$ \\
\hline $\begin{array}{l}\text { The six teachers made different descriptive decis } \\
\text { Novice: } \\
\text { - Availability (External Influence) } \\
\text { - Variation from Routine (Student Benefit) } \\
\text { - Classroom Management (Instructional } \\
\quad \text { Strategy) }\end{array}$ & $\begin{array}{l}\text { ithin the preactive phase: } \\
\text { Experienced: } \\
\text { - } \quad \text { Time Limitation (External Influence) } \\
\text { - } \quad \text { Applicability (Instructional Strategy) } \\
\text { - } \quad \text { Content First (Instructional Strategy) } \\
\text { - } \quad \text { Enhanced Learning Opportunity (Improvement) } \\
\text { - } \quad \text { Learning Efficiency (Improvement) }\end{array}$ \\
\hline $\begin{array}{l}\text { The novice teachers did not make any of the sam } \\
\text { All three experienced teachers made some of the } \\
\text { Time Limitation (External Influence) \& Informal }\end{array}$ & $\begin{array}{l}\text { iptive decisions during the interactive phase. } \\
\text { descriptive decisions within the interactive phase: } \\
\text { sment (Instructional Strategy) }\end{array}$ \\
\hline $\begin{array}{l}\text { The novice teachers did not make any of the sam } \\
\text { All three experienced teachers made some of the } \\
\text { - Build Confidence (Student Benefit) } \\
\text { - Student Engagement (Student Benefit) }\end{array}$ & $\begin{array}{l}\text { iiptive decisions during the postactive phase. } \\
\text { descriptive decisions within the postactive phase: } \\
\text { - Novelty (Technology Readiness) } \\
\text { - Comfort Level (Technology Readiness) }\end{array}$ \\
\hline
\end{tabular}


Summary of Novice and Experienced Teachers’ Decision-Making

Descriptive Code Analysis

The novice teachers made some of the decisions at some point across the three phases, as did the experienced teachers, but there was no overlap between the two groups.

Novice: $\quad$ Experienced:

- Content First, Critical Thinking, \& Interactive Discussion (Instructional Strategies)
- "Instant Feedback" \& Technology Skills (Student Benefit)

- Teaching Efficiency (Improvement)
- Student Collaboration, Classroom Management Direct Instruction, \& Review and Practice (Instructional Strategies)

Both novice and experienced made the greatest number of descriptive decisions during the preactive phase, the second greatest number during the postactive phase, and the fewest number of descriptive decisions during the interactive phase.

Preactive: $\quad$ Novice $62 \quad$ Experienced 73

Interactive: Novice $20 \quad$ Experienced 19

Postactive: Novice $36 \quad$ Experienced 61

29 total novice teacher-specific descriptive decisions

28 total experienced teacher-specific descriptive decisions

Preactive phase: novices 16 and experienced 14

Interactive phase: novices 4 and experienced 7

Postactive phase: novices 15 and experienced 7

Some teacher-specific descriptive decisions were made by both a novice and experienced teacher:

- Administration's Requirements (External Influence)

- “Focus” \& "Voice” (both Student Benefit pattern codes)

- Introduce Content \& Pacing (both Instructional Strategy pattern codes)

Greatest number of pattern decisions pertained to Instructional Strategy for both novices (47) and experienced (46). Next highest number of pattern decisions for both novices (24) and experienced (44) was related to Student Benefit.

Fewest pattern decisions differed between novice and experienced:
Novices - Improvement (8)
Experienced - Diversity (8)

For 5 of the 7 pattern codes (External Influences, Student Benefit, Instructional Strategy, Diversity, and Improvement), novice teachers made more preactive decisions than interactive or postactive decisions.

For 4 of the 7 pattern codes (External Influences, Student Benefit, Instructional Strategy, and Improvement), experienced teachers made more preactive decisions than interactive or postactive decisions.

For 2 of the 7 pattern codes (Technology Readiness and Teacher Change), novice teachers made more postactive decisions than preactive or interactive or decisions.

For 3 of the 7 pattern codes (Diversity, Technology Readiness, and Teacher Change), experienced teachers made more postactive decisions than preactive or interactive or decisions. 
All six of the teachers made some of the same descriptive code decisions within the preactive phase. Preactive decisions made by both novice and experienced teachers pertained to standards (External Influence), engaging students by capturing their interest and attention (Student Benefit), informal assessment (Instructional Strategy), visual learning (to reach different learners), enhanced learning opportunity and learning efficiency provided by technology (both related to the Improvement pattern code). Within the preactive phase, all three novice teachers made descriptive code decisions that the experienced teachers did not: availability (External Influence); variation from routine (Student Benefit); and classroom management (Instructional Strategy). All three experienced teachers made preactive technologyrelated decisions that the novice teachers did not: time limitation (External Influence); and applicability and content first (Instructional Strategies). The experienced teachers made some of the same descriptive decisions within the interactive and postactive phases, but the novice teachers did not.

Both novice and experienced teachers made the greatest number of description code decisions during the preactive phase, the second greatest number during the postactive phase, and the fewest during the interactive phase. Novices and experienced teachers made close to the same number of preactive and interactive decisions, but the experienced teachers' postactive decisions were close to double the number made by the novice teachers.

Comparing teacher-specific descriptive code decisions for all six teachers reveals that both a novice and an experienced teacher made some of these decisions. The middle school novice and the high school experienced teacher both made preactive decisions to use technology based on the requirements of administration at their respective schools. The high school novice 
and one of the elementary/middle school experienced teachers chose to use technology because of the benefit to students in helping them to "focus.” Another Student Benefit, "voice”, was behind the middle school novice's and one of the elementary/middle school teacher's decisions. Instructional Strategy decisions made by both a novice and an experienced teacher were to use technology to introduce content and pace their classes. The elementary novice used the overhead projector to introduce content, as did the experienced high school teacher. The novice high school teacher used graphing calculators to slow down the amount of content covered during some of her classes so that other sections could catch up, whereas the experienced high school teacher asked one of her students to connect a graphing calculator to the overhead projector and solve problems because she knew that she would go through the problems too quickly. The high school novice recognized the difference between using technology as a tool and as a toy, but often used the equipment as a form of reward or punishment for her students. The experienced high school teacher realized that technology had to be used often enough by students that it became just another learning tool as the excitement of using it wore off. Both high school teachers, novice and experienced, talked about always deciding to have a backup plan when using technology, because they never knew if the technology would function correctly. The novice high school teacher also had a backup plan because she never knew if her students would behave when using technology and if she would have to take it away from them. Relinquishing control, a change in teaching, was considered by both the novice middle school teacher and the experienced high school teacher. Both talked about sometimes putting control into the hands of their students when using technology and acting more as learning facilitators.

Comparing and contrasting pattern code decisions made by novice and experienced teachers reveals that both made the greatest number of decisions pertaining to Instructional 
Strategies and the next highest number pertaining to Student Benefit. The fewest pattern code decisions were within the Improvement category for novices and Diversity for experienced teachers. Preactive pattern code decisions were greater than interactive or postactive decisions for novice and experienced teachers in the categories of External Influences, Student Benefit, Instructional Strategy, and Improvement. Decisions related to Diversity were made by both novice and experienced teachers, but the experienced teachers thought about reaching different learners after teaching and the novice teachers thought about differences in learners prior to teaching. Readiness of teachers and students to use technology, along with teacher change, was considered by novice and experienced teachers primarily during the postactive phase. 


\section{CHAPTER FIVE - DISCUSSION}

The purpose of this research was to better understand novice and experienced public school teachers' decision-making in the use of instructional technology (IT). This study was not designed as yet another investigation into the instructional technologies teachers use or to persuade teachers to use technology, but rather focused on teachers' decision-making to promote students’ learning and the role of instructional technologies in this educational process.

Novice and experienced elementary, middle, and high school teachers participated in this study. Data pertaining to their decision-making in the use of instructional technology were collected and analyzed using Clark and Peterson’s (1986) research as a platform. Their research revealed teachers make preactive (prior to teaching), interactive (during teaching), and postactive (after teaching) decisions. Primary sources of data included initial interviews, observations, informal conversations, and exit interviews. Secondary sources included artifacts such as lesson plans, technology mandates, and student work. As data were analyzed, descriptive and pattern codes emerged that represented the teachers' decision-making in the use of instructional technology. Descriptive codes identified similar concepts in teachers’ instructional technology decision-making and pattern codes represented connections between the descriptive codes.

Chapter five discusses the conclusions of this research based on analysis of the data regarding novice and experienced public school teachers' decision-making in the use of instructional technology. Implications are then discussed, followed by limitations of this study and suggestions for further research. 


\section{Conclusions}

Conclusions are addressed according to the three research questions. Within each research question, conclusions are organized according to Clark and Peterson’s (1986) research that found teachers make preactive (prior to teaching), interactive (during teaching), and postactive (after teaching) decisions. After the research questions are addressed, the use of the case study approach to investigate teachers’ decision-making is discussed.

\section{Research Question 1}

How do novice elementary, middle, and high school teachers make instructional technology decisions? Novice teachers made most of their descriptive decisions pertaining to the use of technology during the preactive phase. Their descriptive decisions were primarily related to fundamentals of teaching, such as curriculum requirements, covering content, and classroom management, and they focused decisions on keeping students on task and directing the delivery of content. This is not surprising considering research has revealed that novice teachers are most concerned with classroom management (Fogarty et al., 1983; Westerman, 1991). Novice teachers' descriptive decisions were also grounded in the availability of technology and their perception of it as an addition to their teaching as opposed to just another tool. I expected to find that novices, due to lack of teaching experience, would make many changes to their lessons resulting in more postactive than preactive decisions. One reason they made more preactive than postactive technology decisions is that they were more focused on immediate demands of teaching. Another possibility is the novice teachers needed more time to reflect on their use of technology and think about changes they would make in the future.

Novices made the fewest technology descriptive decisions during the interactive phase. Their interactive decisions were concerned with external influences and instructional strategies. 
As they were teaching, novices were informally assessing their students and considering content to be covered. When they determined time was limited, novices chose to eliminate technology in favor of more traditional methods for covering content. I expected to find novices make a great deal of technology descriptive decisions and changes to their lessons while teaching because they did not have an extensive knowledge base on which to base their planning or predict how lessons would go. One reason for the small number of descriptive decisions during teaching could be because novices thought more about the use of technology while planning. Another possible reason is that their thoughts while teaching were concerned with issues such as student behavior, which sent technology-related changes to the background. A third reason could be due to the challenges of capturing teachers' thoughts and decisions while they were teaching. It would not have been appropriate to interrupt teachers while they were teaching to ask about decisions they were making.

As they reflected on their teaching, novice teachers' postactive descriptive decisions shifted from using technology to vary routine and engage students, to using it to provide “instant feedback", to help students to "focus”, and to give them a "voice.” Based on informal assessment of their students and their teaching, novice teachers realized that technology was enhancing students learning. This shift in thinking from using technology to make learning more exciting to recognizing how it helped students to learn is not unexpected, considering novices’ limited teaching experience.

\section{Research Question 2}

How do experienced elementary, middle, and high school teachers make instructional technology decisions? As this research question is addressed, it is relevant to keep in mind that experienced teachers in this study are invested in the use of technology for teaching and learning, 
which impacts their decisions to use instructional technology (IT). They are perceived as leaders in technology in their schools and have written or contributed to the writing of grants to acquire technology resources for their schools. They have been involved in instructional technology professional development as both participants and instructors.

Experienced teachers made most of their descriptive decisions pertaining to the use of technology during the preactive phase, except for Georgia, one of the elementary/middle school teachers, who made most of her IT descriptive decisions during the postactive phase. Compared to the other two experienced teachers, she spent more time helping faculty in her school use technology and her postactive decisions were made in the context of what was needed for other teachers to learn to use technology, such as planning time and teacher collaboration. Another reason is that her school includes elementary and middle grades and the teachers tend to work together. One reason the other two experienced teachers made most of their decisions during the preactive phase is, due to their years of experience teaching with technology, what once were postactive decisions had now become preactive decisions. Another reason for this finding is that postactive decision-making is difficult to capture as a distinct process from preactive thinking. Clark and Peterson (1986) found that preactive and postactive phases often blend together, where decisions made by teachers following instruction are often implemented within or become preactive planning for future lessons.

Technology descriptive decisions made by experienced teachers during the preactive phase took into consideration student engagement, informal assessment, and visual learning, but their planning was primarily based on their recognition of the value of using technology to do something better than before or do something they could not achieve without it. They also considered the applicability of the technology for student learning and stressed that they did not 
use it just because it was available. Based on past experiences, they were able to think about the amount of time needed to accomplish activities that involved technology versus teaching the same content using more traditional methods. Experienced teachers preactive descriptive decisions were grounded in making sure students mastered the content first and then asked them to use technology. For example, Derk, one of the elementary/middle school teachers, and Frieda, the high school teacher, made this decision because they believe students need to master the basics of math first and solve problems using their brains before using calculators or computers to expedite the solving of problems and to think more critically about math.

Experienced teachers made the fewest technology descriptive decisions during the interactive phase. They made these decisions by assessing their students and considering time available, often deciding to eliminate the use of technology and revert to more traditional activities when time was limited. This indicates that experienced teachers continue to view the use of instructional technology based on learning efficiency. As with novice teachers, the low number of interactive technology decisions could have been due to the challenge of capturing teachers' thoughts and decisions while they were teaching. This could also have been because they have been teaching for many years and have an in-depth knowledge on which they based their planning, reducing changes needed during teaching.

As they reflected on their teaching, experienced teachers’ postactive technology decisions were related to how they could use instructional technology in the future to build students' confidence because they realized that when students used technology they were not intimidated and that it could be used in such a way that every student would experience success. Experienced teachers also thought that technology should be embedded into learning so that students no longer view it as a novelty and it becomes just another learning tool as opposed to a toy. These 
postactive decisions are not surprising, considering experienced teachers have years of teaching to reflect upon and compare how students learned in the past without a lot of technology to how students learn with ITs. Experienced teachers were able to think about the use of technology in a broader context, recommending students begin to use technology in the early grades and continue throughout their academic careers. This is supported by Hogan et al. (2003), who found that experienced teachers plan for the long-term.

\section{Research Question 3}

What are the similarities and differences between how novice and experienced elementary, middle, and high school teachers make instructional technology decisions? There were few similarities but many differences in the instructional technology (IT) decision-making of novice and experienced teachers. As similarities and differences are discussed, the context of this research must be taken into account. Both novice and experienced teachers’ decision-making in the use of instructional technology was affected by external influences, such as availability of technology, standards, and expectations and requirements of administration. External influences such as these cannot be eliminated, so they were addressed in order to understand and describe the context, but were not a focus of this study.

The researcher asked teachers during their initial interviews to talk about their educational beliefs. Clark and Peterson (1986) found teachers’ theories and beliefs represent knowledge they have and affect planning and interactive decisions. They also discovered that teachers develop theories and beliefs as a result of decisions made during teaching and planning. Educational beliefs or philosophies were not the focus of this study, but it was important to recognize them and be aware of how teachers’ educational philosophies affected their teaching style and their decisions to use technology. For example, Derk (experienced elementary/middle 
school), Jennifer (novice middle school), and Frieda (experienced high school) encouraged their students to participate and created very open, non-threatening learning environments where they learned from their students and their students were not afraid to make mistakes. I believe their educational beliefs are evident in their decision-making with regard to the use of technology because each of them made decisions to have their students use technology in order to give them a “voice,” realizing they would have to teach differently by relinquishing control.

\section{Similiarities}

Technology was considered by both novice and experienced teachers at the elementary, middle, and high school levels as they planned curriculum for the year, but "use” versus "do not use” decisions as well as how and why to use it, were made as they planned lessons and units. The reason teachers waited until planning their lessons and units to make technology decisions was due to the dynamic nature of teaching; plans never go exactly as expected and must be modified based on assessment of students, unanticipated events, and time available.

During the interactive phase, all six teachers made the fewest technology descriptive decisions. I expected to find this for experienced teachers but not novice teachers. I thought novices would make a great deal of decisions while teaching because they did not have extensive teaching experience. The small number of interactive decisions for both novices and experienced teachers could be due to the challenge of capturing teachers' thoughts and decisions while they were teaching.

\section{Differences}

All three experienced teachers made preactive descriptive decisions to use technology because it would provide an enhanced learning opportunity for their students. Only one novice, the elementary school teacher, talked about this decision. Experienced teachers have taught many 
of the same lessons for years without technology and then with technology to enhance students' learning. This knowledge base helped experienced teachers realize that technology sometimes allows them to teach something better than before or teach something that they could not teach without it, whereas novice teachers did not have a basis for comparison.

When making preactive decisions regarding the use of technology, novices focused on classroom management and other fundamentals of teaching, such as covering curriculum, whereas experienced teachers were less concerned with the basics of teaching. The experienced teachers took more time to learn about, experiment with, and use technology. This corresponds with Westerman’s (1991) findings that novices tended to follow the curriculum literally, where experts used curriculum guidelines to accomplish what was expected, but also found ways of interpreting objectives and making instruction their own. Another reason the experienced teachers did not focus on basics of teaching is because they had mastered fundamentals such as classroom management and established routines. Leinhardt \& Greeno’s (1986) research, which found that the routines of experienced teachers provided structure, allowing them to creatively design lessons to meet the needs of their students, supports this finding.

During the postactive phase, the three experienced teachers decided technology could benefit students by helping to build confidence. None of the novice teachers mentioned this during any decision-making phase. The experienced educators had years of teaching to reflect upon and compare how students learned in the past with how students were learning using technology, whereas novice teachers did not have anything for comparison.

All six teachers, except for the elementary school novice, recognized during the postactive phase that the novelty of using technology must wear off before students use it as a learning tool and focus on content as opposed to the technology. Not all teachers took the time to 
invest in helping students become comfortable using technology. The experienced high school teacher spent the time at the beginning of every academic year to help her students learn to use and become comfortable with using technology so that it became just another tool to them. The high school novice did not invest this time and she used technology more as a reward or punishment, depending on her students' behavior. Both of the elementary/middle school experienced teachers talked about the importance of students learning to use technology in their school during the early grades so that students' use of technology could increase throughout the years.

The two experienced elementary/middle teachers reflected on not being afraid to try new technology and create new ways to use technology with their students. As for the novices, the elementary teacher is the only one who talked about deciding to experiment with technology. Two of the three experienced teachers talked about experimenting with technology, perhaps because they realized that a lot of what teachers do can be classified as experimenting: a teacher never knows what will happen, regardless of whether or not technology is being used, until a lesson is taught. One of the experienced teachers also mentioned that she was never taught how to use technology in teaching, causing her to experiment on her own. As for the novices, the fact that only one of them discussed experimentation is because all three had been using technology and did not even consider their decisions to use it as an experiment. Another reason that two novices did not talk about experimentation with technology is because being graduates of the five-year teacher education program at West Virginia University they were taught to use and expected to use technology by teacher education and Professional Development School faculty. The elementary school novice teacher graduated from a university where technology was not as embedded in her schooling and had to learn about it on her own. 
Looking across the decision-making phases, the novice teachers made the majority of their decisions pertaining to their use of technology based on how it impacted themselves as teachers. The experienced teachers' decisions related to technology were focused more on how they could use technology to benefit their students and how it could be used "as a catalyst" to transform the way that they taught. This reflects experienced teachers' consideration of the "bigger picture" as opposed to concentrating on details and logistics of teaching.

\section{Case Study Research}

A major goal of research on teacher thought processes has been to increase understanding of the process of teaching and how and why it looks and works as it does (Clark \& Peterson, 1986). Yin (2003) advocated that case studies are preferred when "how" or "why" questions are being posed, when the investigator has little control over what occurs, and when the focus is on a phenomenon within real-life context. Using a multiple case study framework approach for this research allowed investigation into the phenomenon of teachers' decision-making within their classrooms and revealed how and why teachers decided to use technology.

\section{Implications}

Three implications emanated from this study. First, teacher education students can learn from experienced teachers how to make literate decisions in the classroom and in the use of instructional technology. Second, experienced teachers who do not use technology at all, or who do not use technology in ways that enhance students' learning, can learn to make literate decisions in the use of instructional technology. Both of these statements have implications for teacher education and professional development, which will be discussed below. Third, the case study approach is appropriate for revealing teachers' decision-making in the use of instructional technology. 


\section{Teacher Education and Professional Development}

The goal of education is no longer as much about acquiring skills as it is about helping learners develop the ability to think (Bransford et al., 2000) and acquire other "skills" that business are seeking, such as the ability to problem-solve, communicate, work collaboratively, and learn on the job (Bruer, 1993). This research revealed that teachers realize the benefits of technology in helping students acquire these new types of "skills" that companies and organizations require. The question becomes, "How can we help novice teachers and experienced teachers who are not familiar with using technology learn to use it to enhance learning and help students to acquire these $21^{\text {st }}$ century skills?”

Learning why and how teachers teach as they do will help to understand better what it means for students to learn specific content areas, such as math, science, reading, and writing (Bruer, 1993). Bruer believes that if we can describe experts' implicit knowledge explicitly, we can incorporate it into teacher training programs. The insight of novice and experienced teachers who use technology can be incorporated into professional development and teacher education programs to help in-service and pre-service teachers learn to use technology to improve student learning.

If pre-service teachers can learn from experienced educators how to master classroom management early in their teaching careers, then they can focus on other aspects of teaching, such as using technology as just another tool. Capturing information about experienced teachers’ establishment of routines and decision-making during the preactive phase, and then transferring this knowledge to novice teachers through their teacher education courses, will help to move novice teachers concerns from immediate needs of teaching, such as classroom management and 
making learning fun for students, to making decisions focused on effective teaching and learning.

Examining how and why experienced teachers make decisions to use technology to enhance learning can be used to design professional development for experienced teachers who are not yet using technology for teaching and learning. Experienced teachers who are using technology effectively can conduct professional development where they begin by sharing how they taught particular lessons and units in the past without technology, and continue with how they now teach these same lessons using technology, focusing on the benefits to students. Included in professional development should be discussions of how and why the experienced teachers choose to use or not to use technology. Also included should be experienced teachers' knowledge about how to make technology decisions that will increase learning and teaching efficiency, provide learning opportunities that would not exist without it, and use technology for new and creative ways of teaching.

\section{Use of Case Study}

A substantial body of research exists on teacher decision-making, but until now, what was lacking was evidence and insight into teachers' decisions when designing instruction that uses instructional technology (Loveless, 2000). Prior research revealed “what” influenced teachers to use technologies and "which" technologies they used (Zeichner, 1999). The use of the multiple case study approach in this investigation provided information about "how" and "why" (Yin, 2003) teachers made decisions in the use of instructional technology. The case studies allowed the researcher to study teaching and learning from a naturalistic perspective by spending time within the classrooms environment, interviewing teachers, conducting observations, and examining secondary data sources such as lesson plans and student work (Merriam, 1998; 
Patton, 2002). Knowledge about teachers' decision-making in the use of instructional technology could not be captured in as much depth or breadth by conducting a survey.

\section{Limitations}

Limitations of this study are organized by researcher and participants, data collection, and data analysis.

\section{Researcher and Participants}

In a naturalistic study, the researcher is the primary instrument, which means all research information is filtered through that person (Merriam, 1998). The researcher's knowledge and experience in conducting this type of study, along with knowledge of technology and experience in using technology to teach, was a limitation. Although the researcher took steps to reduce biases (addressed and summarized in chapter 3), her opinions may have influenced the study, beginning with participant selection through data collection and analysis.

Six teachers were purposefully selected to participate in this research, providing a limited number of participants (Patton, 2002). Recommendation and selection of participants was attempted without bias, but the opinions of those who selected the participants and their experiences in working with these teachers influenced their choices.

The selected participants’ knowledge of technology and experience in using technology to teach was a limitation. External influences beyond teachers' control, such as administrations' requirements and availability of technology, influenced their decisions to use technology. The teachers' ability to communicate their thinking and decision-making as they designed, taught, and revised their lessons and units impacted the data collected. Experienced teachers have implicit knowledge that they no longer are aware of because it is automatic (Bruer, 1993), making it difficult to capture. 


\section{Data Collection}

The length of time for this study was limited to approximately one grading period (nine weeks) or slightly longer for each teacher. This resulted in a narrow window of opportunity for capturing data pertaining to teachers’ decision-making. Further insight into teachers’ preactive, interactive, and postactive decision-making might be captured if more time were spent in their classrooms.

When the methodology of this study was planned, it was hoped that teachers' lesson plans would be available to serve as supporting documentation and provide insight, along with initial interviews and informal conversations, into the decisions they made prior to teaching. As Clark and Peterson (1986) discovered in their research on teacher decision-making, lesson plans were minimal or existed within the minds of the teachers and written details were not available. As a result, the researcher did not have written documentation that could be referred to when developing questions and talking with teachers about their preactive decisions.

Interactive decision-making, which refers to decisions teachers make while teaching, was challenging to capture for several reasons. One reason was the naturalistic design of this study where the researcher studied the teachers within their natural environment and attempted to be as unobtrusive as possible so as not to influence the teachers' actions and decisions. It would not have been appropriate for the researcher to interrupt teachers while they teaching in order to ask about decisions they were making as they were teaching.

Observations were designed to help capture insight into teachers' interactive decisionmaking. The researcher and teacher would agree upon dates/times for the researcher to visit the classrooms and observe. These observations were limited by the teachers' communication of 
upcoming observation opportunities and by the amount of time spent observing. This may have resulted in missed opportunities to collect further data.

Another reason it was challenging to capture interactive decisions was due to the narrow time frame for capturing teachers' interactive thoughts. The researcher attempted to asked questions about their interactive decision-making immediately following a lesson, but the amount of time a teacher could spend sharing interactive decisions was limited because they had to transition to the next lesson or another group of students was arriving. As a result, the researcher often sent email to the teachers later that day, asking questions pertaining to their decision-making while teaching. The teachers responded, but their thoughts were most likely not as clear as they were while they were teaching or immediately following.

Another challenge to capturing teachers' interactive decisions is that teachers often are not consciously aware that they are making decisions. Decision-making is an implicit characteristic of teaching and while teaching, teachers quickly evaluate options and make decisions on how to proceed, which is referred to as “reflection-in-action” by Schön (1987). Schön describes "reflection-in-action" as what a teacher does when he/she pauses in the middle of an action to think.

Postactive decision-making, the phase that occurs when teachers reflect upon and assess the effectiveness of their teaching, was difficult to capture as a distinct process from preactive thinking. Clark and Peterson (1986) found that preactive and postactive phases often blend together, where decisions made by teachers following instruction are often implemented within or become the preactive planning for future lessons. It was challenging to determine which decisions made by teachers were based strictly on planning for the future as opposed to what happened during a previously taught lesson. This was most noticeable with the experienced 
teachers. Years of teaching experience blurred the distinction between preactive and postactive decision-making because it often occurred concurrently.

\section{Data Analysis}

Data analysis was limited by the researcher's decisions pertaining to data reduction and data analysis. If the data were analyzed differently, perhaps other meaning would be revealed. The potential for "lost" data exists because of the large quantity of data that were captured. In order to analyze the data, it was reduced more than once and there was a chance that some was "lost" or overlooked during the process. It is also possible that the researcher overlooked subtle yet significant findings that were masked by more obvious findings.

In the process of reducing the data and looking for patterns, the number of descriptive code decisions and pattern code decisions were totaled. Caution had to be exercised not to let these numbers mask the meaning of the data. After reducing and analyzing data, the researcher focused on the meaning behind the numbers and considered the "bigger picture" represented by the data.

\section{Further Research}

The number of teachers studied and the amount of time spent with each was a limitation of this research. Spending more time with each teacher would allow for collection of more indepth data and provide more information about teachers' preactive, interactive, and postactive decision-making in the use of instructional technology. To ensure that opportunities to capture data were not missed, rather than the researcher and participant scheduling observations, the researcher could consider spending entire days or half days with a teacher over a more extended period of time rather than one grading period. 
A comparatively small amount of data pertaining to interactive decisions was captured as compared to preactive and postactive decision-making data. One method of capturing more interactive data is to videotape teachers while they are teaching and then use the videotapes for stimulated recall. This approach has been used in other research with teachers, such as a study conducted by Leinhardt and Greeno (1986), where the researcher and teachers viewed the videotape together and the researcher prompted them to elaborate on what they were thinking as they were teaching.

A study could be conducted from the aspect of which technology was selected for a particular purpose and why. Thinking about technologies the novice and experienced teachers in this study decided to use, why they used them, and how they used them can be elaborated upon to reveal interesting learning applications for both pre-service and in-service teachers.

Additional insight can be gained if the researcher and participants collaboratively design investigation into teachers' decision-making in the use of instructional technology. Teachers who participated in this study helped validate data by reviewing initial data analysis and evaluating their respective cases for accuracy (Patton, 2002; Stake, 1995), but participants can also be involved in the overall design of the research. In-service teachers will be able to design creative yet non-intrusive means of capturing preactive, interactive, and postactive teaching decisions to better reveal "how" and "why” they use technology. Pre-service teachers can help design inquiry that will capture data to help them learn to master immediate teaching concerns, such as classroom management and covering content, so they can shift their focus to promoting students’ learning. 


\section{References}

Anglin, G. J. (1995). Instructional technology: Past, present, and future. Englewood, CO: Libraries Unlimited.

Angrosino, M. V., \& Mays de Perez, K. A. (2000). Rethinking observation: From method to context. In N. K. Denzin and Y. S. Lincoln (Eds.), Handbook of qualitative research (2nd ed.). (pp. 673-702). Thousand Oaks, CA: Sage.

Association for Educational Communications and Technology (AECT). Retrieved October 26, 2005, from http://www.aect.org/standards/knowledgebase.html

Berliner, D. C. (1994). Expertise: The wonder of exemplary performances. In J. N. Mangieri \& C. Collins-Block (Eds.). Creating powerful thinking in teachers and students. Fort Worth, TX: Holt, Rinehart \& Winston. Also retrieved November 16, 2004, from http://courses.ed.asu.edu/berliner/readings/expertise.htm

Bransford, J. D., Brown, A. L., \& Cocking, R. R. (Eds.). (2000). How people learn: Brain, mind, experience, and school. Washington, D.C.: National Academy Press.

Bruer, J. T. (1993). Schools for thought: A science of learning in the classroom. Cambridge, MA: MIT Press.

Clark, C., \& Lampert, M. (1986, September-October). The study of teacher thinking: Implications for teacher education. Journal of Teacher Education, 27-31.

Clark, C. M., \& Peterson, P. L. (1986). Teachers' thought processes. In M. C. Wittrock (Ed.), Handbook of research on teaching (3rd ed.). (pp. 255-296). New York: Macmillan.

Cochran-Smith, M., \& Lytle, S. L. (1999). The teacher research movement: A decade later. Educational Researcher, 28(7), 15-25. 
Coffey, A., \& Atkinson, P. (1996). Making sense of qualitative data: complementary research strategies. Thousand Oaks, CA: Sage.

Creswell, J. W., \& Miller, D. L. (2000). Determining validity in qualitative inquiry. Theory into Practice, 39(3), 124-130.

Fogarty, J. L., Wang, M. C., \& Creek, R. (1983). A descriptive study of experienced and novice teachers' interactive instructional thoughts and actions. Journal of Educational Research, 77(1), 22-32.

Fontana, A., \& Frey, J. H. (2000). The interview: From structured questions to negotiated text. In N. K. Denzin and Y. S. Lincoln (Eds.), Handbook of qualitative research (2nd ed.). (pp. 645-672). Thousand Oaks, CA: Sage.

Gillespie, F. (1998, Winter). Instructional design for the new technologies. New Directions for Teaching and Learning, 76, 39-52.

Harris, J. (1997). Wetware: Why use activity structures? Learning and Leading with Technology, 25(4), 13-17.

Hatch, A. (2002). Doing qualitative research in education settings. Albany, NY: State University of New York Press.

Hogan, T., Rabinowitz, M., \& Craven III, J. A. (2003). Representation in teaching: Inferences from research of expert and novice teachers. Educational Psychologist, 38(4), 235-247.

International Society for Technology in Education (ISTE). Retrieved November 24, 2004, from http://iste.org

Jackson, P. W. (1968). Life in classrooms. New York: Holt, Rinehart \& Winston.

Kent, T. W., \& McNergney, R. F. (1999). Will technology really change education? From blackboard to Web. Thousand Oaks, CA: Corwin Press, Inc. 
Kysilka, M. L., Geary, M., \& Schepise, S. (2002). The complexity of teaching in the information age school. Curriculum and Teaching Dialogue, 4(1), 59-65.

Lancy, D. F. (1993). Qualitative research in education: An introduction to the major traditions. White Plains, New York: Longman Publishing Group.

Leinhardt, G., \& Greeno, J. G. (1986). The cognitive skill of teaching. Journal of Educational Psychology, 78(2), 75-95.

Loveless, A. (2000). Where do you stand to get a good view of pedagogy? Journal of Technology and Teacher Education, 8(4), 337-349.

Merriam, S. B. (1998). Qualitative research and case study applications in education. San Francisco: Jossey-Bass.

Merriam, S. B., \& Associates. (2002). Qualitative research in practice. San Francisco: JosseyBass.

Miles, M. B., \& Huberman, A. M. (1994). Qualitative data analysis: An expanded sourcebook (2nd ed.). Thousand Oaks, CA: Sage.

National board for professional teaching standards. (n.d.) Retrieved August 22, 2004, from http://www.nbpts.org/

Parker, W. C., \& Gehrke, N. J. (1986). Learning activities and teachers’ decision making: Some grounded hypotheses. American Educational Research Journal, 23(2), 227-242.

Patton, M. Q. (2002). Qualitative research and evaluation methods (3rd ed.). Thousand Oaks, CA: Sage.

Preparing Tomorrow’s Teachers to Use Technology (PT3). Retrieved November 28, 2004, from http://www.pt3.org 
Reiser, R. A., \& Dempsey, J. V. (2002). Trends and issues in instructional design and technology. Upper Saddle River, NJ: Merrill Prentice Hall.

Riel, M. (2000). New designs for connected teaching and learning. White paper presented at the Secretary’s Conference on Technology 2000. Retrieved November 16, 2004, from http://www.gse.uci.edu/mriel/whitepaper/

Sardo-Brown, D. (1990). Experienced teachers’ planning practices: A U.S. survey. Journal of Education for Teaching, 16(1), 57-68.

Schön, D. A. (1987). Educating the reflective practitioner. San Francisco: Jossey-Bass.

Shambaugh, N., \& Magliaro, S. G. (2006). Instructional design: A systematic approach to reflective practice. Boston: Allyn and Bacon.

Shavelson, R. J., \& Stern, P. (1981). Research on teachers’ pedagogical thoughts, judgments, decisions, and behaviors. Review of Educational Research, 51(4), 455-498.

Shulman, L. S. (1986). Those who understand: Knowledge growth in teaching. In L. S. Shulman, The wisdom of practice: Essays on teaching, learning, and learning to teach (pp. 187-215). San Francisco: Jossey-Bass.

Shulman, L. S. (1988). A union of insufficiencies: Strategies for teacher assessment in a period of educational reform. In L. S. Shulman, The wisdom of practice: Essays on teaching, learning, and learning to teach (pp. 351-361). San Francisco: Jossey-Bass.

Shulman, L. S. (1992). Research on teaching: A historical and personal persepctive. In L. S. Shulman, The wisdom of practice: Essays on teaching, learning, and learning to teach (pp. 363-381). San Francisco: Jossey-Bass. 
Shulman, L. S. (1996). Just in case: Reflections on learning from experience. In L. S. Shulman, The wisdom of practice: Essays on teaching, learning, and learning to teach (pp. 461-482). San Francisco: Jossey-Bass.

Somekh, B., \& Davis, N. (Eds.). (1997). Using information technology effectively in teaching and learning: Studies in pre-service and in-service teacher education. New York: Routledge.

Stake, R. (1995). The art of case study research. Newbury Park, CA: Sage.

Strauss, A., \& Corbin, J. (1990). Basics of qualitative research: Grounded theory procedures and techniques. Newbury Park, CA: Sage.

United States Department of Education, Office of Educational Technology. Retrieved June 14, 2005, from http://www.ed.gov/about/ offices/list/os/technology/index.html

United States Department of Education, Office of Educational Technology. (1996). Getting students ready for the $21^{\text {st }}$ century: Meeting the technology literacy challenge. Retrieved June 14, 2005, from http://www.ed.gov/about/offices/list/os/technology/plan/ national/index.html

United States Department of Education, Office of Educational Technology. (2000). E-learning: Putting a world-class education at the fingertips of all children. Retrieved June 14, 2005, from http://www.ed.gov/about/offices/list/os/ technology/reports/e-learning.html United States Department of Education, Office of Educational Technology. (2005). Toward a new golden age in American education: How the internet, the law and today's students are revolutionizing expectations. Retrieved June 14, 2005, from http://www.ed.gov/about/ offices/list/os/technology/plan/2004/index.html 
United States Department of Education. (2003). Department seeks broad input for new national education technology plan. Retrieved June 14, 2005, from http://www.ed.gov/news/ pressreleases/2003/05/05232003.html

Westerman, D. A. (1991). Expert and novice teacher decision making. Journal of Teacher Education, (42)4, 292-305.

Yin, R. K. (2003). Case study research: Design and methods (3rd ed.). Thousand Oaks, CA: Sage.

Zeichner, K. (1999). The new scholarship in teacher education. Educational Researcher, 28(9), 4-15.

Zhao, Y., \& Frank. K. A. (2003). Factors affecting technology uses in schools: An ecological perspective. American Educational Research Journal, 40(4), 807-840. 
Appendix A - Letter to Teachers

February _, 2005

Dear Teacher:

Thank you for taking time to discuss my dissertation research and consider participating. This letter provides some background information about me and more details about my study. Please contact me at 594-1801 (home) or 282-5822 (cell) or amy.kuhn@mail.wvu.edu if you have any questions before making your decision about participating.

I have been working with teachers and the use of instructional technology for teaching and learning for many years. Since 2000, I have been working with schools and faculty in West Virginia's Professional Development Schools (PDSs), first as a Graduate Assistant for a U. S. Department of Education grant and currently with the Benedum Collborative.

The purpose of my dissertation is to investigate novice and experienced teachers' decisionmaking in the use of instructional technology. I would like to learn about instructional technology decisions you make prior to, during, and after teaching. If you choose to be involved, I will ask you to contribute by:

- Participating in an initial and concluding interview. Each interview would last approximately 30-60 minutes at a date/time convenient for you. You may choose not to respond to any of the questions. I will ask your permission to audiotape the interviews, but you have the right to refuse this request. Your audio tapes will not be labeled with your name and only I will have access to the audio tapes.

- Allowing me to visit and observe you and your students within your classroom during mutually agreed upon dates/times. During the observations, I would collect data by writing field notes.

- Informally discussing with you decisions about your planning, teaching, and teaching revisions. These informal discussions would be based on my observations, would be short (approximately 5 minutes), and occur at times convenient for you. During our conversations I would be asking about decisions you made while teaching.

- Sharing your lesson plans and journals only if they exist. I would not ask you to keep a journal or create written lesson plans solely for the purpose of my research.

Participation in my study is entirely voluntary. If you choose to participate, confidentiality will be maintained and your identity will not be revealed. I will provide you with a draft copy of your individual case study and ask for your feedback as to the accuracy, including your revisions in the final document. Information I collect during my research will be used to fulfill research requirements for my dissertation and will potentially be used for scholarly publications and presentations. A copy of my research will be provided to you and your principal at the conclusion of my study.

Sincerely, Amy Kuhn 


\section{Appendix B - Letter to Principals}

February _, 2005

\section{Dear Principal:}

Thank you for permitting to voluntarily participate in my dissertation research. This letter provides some background information about me and more details about my research.

My name is Amy Kuhn and I am a doctoral candidate in education at West Virginia University. I have been working with teachers and the use of instructional technology for teaching and learning for many years. Since 2000, I have been working with schools and faculty in West Virginia's Professional Development Schools (PDSs), first as a Graduate Assistant for a U. S. Department of Education grant and currently with the Benedum Collborative.

For my dissertation I am researching a total of six (2 elementary, 2 middle school, and 2 high school) novice and experienced teachers' decision-making in the use of instructional technology. I have selected teachers on the basis of their active use of technology. Participation in my dissertation research is strictly voluntary.

For my research, I will be spending time in 's classroom during one grading period in the spring of 2005. The number of days and amount of hours I spend will be negotiated individually with . During my study, I will be observing and discussing with her decisions made prior to, during, and after teaching. Specifically I am asking to:

- Participate in an initial and concluding interview

- Allow me to visit and observe their classroom during mutually agreed upon dates/times

- Informally discuss their planning, teaching, and teaching revisions

- Share lesson plans and journals (if available)

I will provide with a draft copy of his/her case study and ask for feedback regarding the accuracy, then include suggestions and revisions in my final document. At the conclusion of my research, I will provide you and with a copy of my study.

The confidentiality of every teacher and school involved in my study will be maintained and identities will not be revealed. Information I collect during my research will be used to fulfill research requirements for my dissertation and will potentially be used for scholarly publications and presentations.

If you have any questions, please do not hesitate to contact me at the Benedum Collaborative 304.293.6762 or amy.kuhn@mail.wvu.edu.

Sincerely, Amy Kuhn 


\section{Appendix C - Initial Interview Protocol}

Thank you for agreeing to participate in my dissertation research. The overall purpose of my study is to better understand novice and experienced public school teachers' decision-making in the use of instructional technology.

Before we get started, I would like to point out:

1. Your participation is entirely voluntary and you do not have to respond to an item or question if you would rather not.

2. Your responses will remain anonymous and confidentiality will be maintained.

Would you mind if I tape record our conversation? Although I will be taking notes, I cannot write quickly enough to capture everything we say and I do not want to miss anything. Your tape will not be labeled with your name.

Today I am interested in learning about decisions you make prior to teaching.

1. Tell me about your career as a teacher (educational background, years of teaching, schools, grade levels, and content areas).

2. Describe your educational beliefs/educational philosophies.

3. List instructional technologies (ITs) you use and describe how you use them.

4. Tell me about technology you will be using during this grading period.

5. Think about when you design your lessons and describe decisions you make during the design process.

6. Explain how you choose to use or not to use technology when you are planning.

7. Is there anything we have not talked about that you think is important for me to know? 
Appendix D - Observation Guide

\section{Date:}

Participant Code:

Location (e.g. computer lab, classroom, library/media center):

Lesson:

Teaching Strategies (e.g. direct instruction, interactive direction, modeling, facilitating/coaching):

\section{Student Activities:}

List student activities \& if/how technology is used

\section{Teacher's use of Technology:}

What IT(s) are being used by the teacher?

How is the teacher using technology?

Does the focus seem to be on the technology or the lesson?

Does the technology seem to be used to support the lesson or does it seem to be distracting from it?

\section{Students' use of Technology:}

What IT(s) are the students using?

How are the students using technology?

\section{Teacher's familiarity with technology:}

Does the teacher seem to be comfortable using technology?

\section{Students' familiarity with technology:}

Do the students seem to be comfortable using technology? 


\section{Appendix E - Exit Interview Protocol}

Thank you for agreeing to this second interview. Today I am interested in learning about decisions you made while teaching during this grading period and decisions/revisions you made or plan to make.

Before we get started, I would like to point out:

1. Your participation is entirely voluntary and you do not have to respond to an item or question if you would rather not.

2. Your responses will remain anonymous and confidentiality will be maintained.

Would you mind if I tape record our conversation? Although I will be taking notes, I cannot write quickly enough to capture everything we say and I do not want to miss anything. Your tape will not be labeled with your name.

1. Talk about this past grading period and your overall thoughts about your teaching and your students' learning.

2. Describe your teaching and your students' learning when you used technology that was successful and why.

3. Describe your teaching and your students' learning when you used technology that was not as successful as you had planned and why. What will you do differently?

4. Tell me about a lesson or lessons where you planned to use technology in a certain way and then changed your plans.

5. What should other teachers think about when planning to use technology?

6. Is there anything we have not talked about that you think is important for me to know? 


\section{Appendix F - Descriptive and Pattern Codes Representing Novice Teachers Decision-Making}

$=$ teacher specific decision made by only one of the novices

$\mathrm{X}=$ decision made by all three novices within a certain decision-making phase

$\mathrm{X}=$ decision made by all three novices at some point within the decision-making phases

Descriptive Codes \&

Pattern Codes*

\begin{tabular}{|c|c|c|}
\hline \multicolumn{3}{|c|}{ Preactive Decisions } \\
\hline $\begin{array}{c}\text { Elementary } \\
\text { Case 1 }\end{array}$ & $\begin{array}{c}\text { Middle } \\
\text { Case 2 }\end{array}$ & $\begin{array}{c}\text { High } \\
\text { Case 3 }\end{array}$ \\
\hline
\end{tabular}

Interactive Decisions

Elementary $\quad$ Middle $\quad$ High

Case 1

Case 2 Case 3

Postactive Decisions

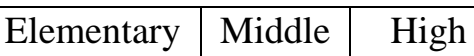

\begin{tabular}{l|l|l} 
Case 1 & Case 2 & Case 3 \\
\hline
\end{tabular}

External Influences - aspects beyond the teacher's control that impact decisions to use or not to use technology

Administration's Requirements

Availability

Peer Expectations

Researcher's Presence

Standards

Time Limitation

\begin{tabular}{|c|c|c|c|c|c|c|}
\hline & $X$ & & & & & \\
\hline$X$ & $X$ & $\mathrm{X}$ & & & & \\
\hline$x$ & & & & & & \\
\hline $\mathrm{X}$ & & & & & & \\
\hline$X$ & $X$ & $X$ & & & & \\
\hline & & & $X$ & $X$ & $X$ & \\
\hline
\end{tabular}

Student Benefit - decision whether or not to use technology is based on perceived benefit for students

Accurate Representation

Fairness

"Focus" **

Habits

"Instant Feedback"

Incidental Learning

Life Skills

"Real Life"

Retention

Student Collaboration

Student Engagement

Student Welfare

Technology Skills

Variation from Routine

"Voice"

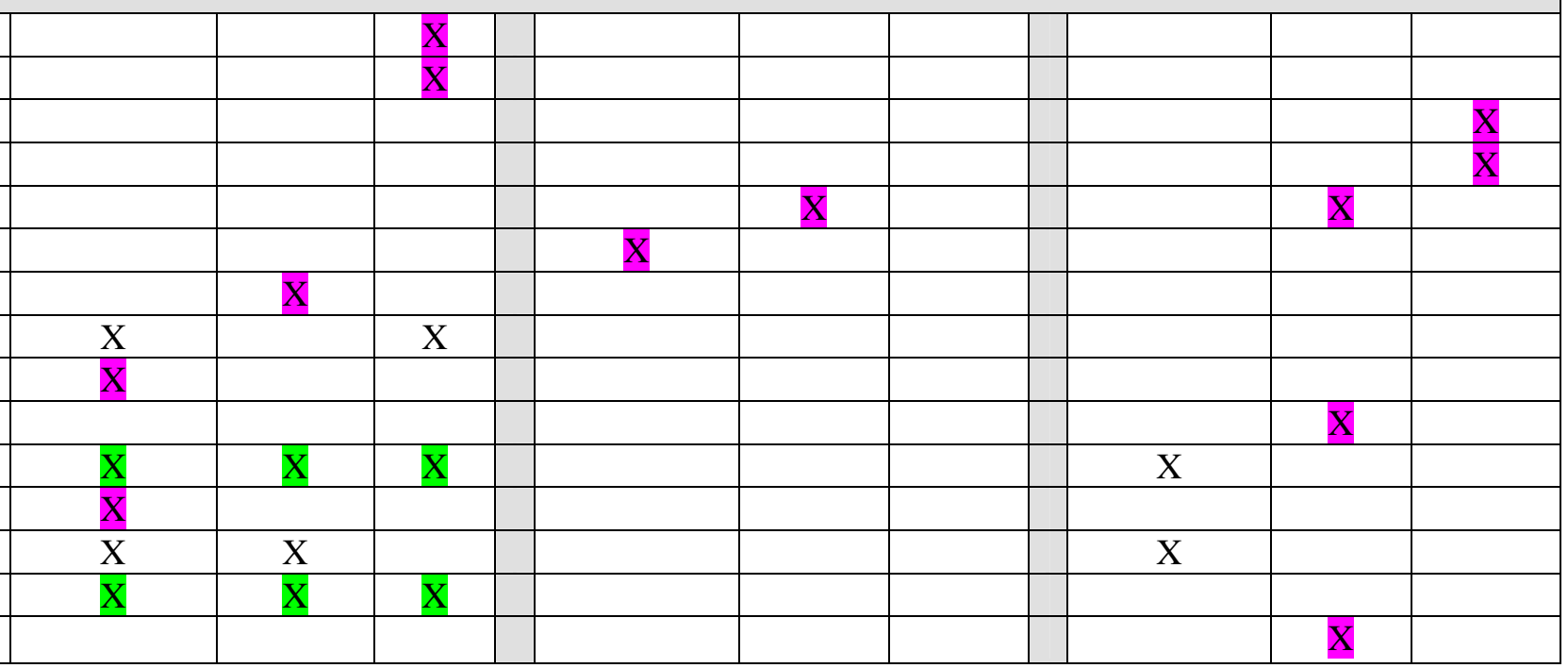


$\mathrm{X}=$ teacher specific decision made by only one of the novices

$\mathrm{X}=$ decision made by all three novices within a certain decision-making phase

$\mathrm{X}=$ decision made by all three novices at some point within the decision-making phases

Descriptive Codes \&

\begin{tabular}{|c|c|c|}
\hline \multicolumn{3}{|c|}{ Preactive Decisions } \\
\hline Elementary & Middle & High \\
Case 1 & Case 2 & Case 3
\end{tabular}

Interactive Decisions

Pattern Codes*

Case $1 \quad$ Case 2 Case 3

\begin{tabular}{c|c|c|} 
Elementary & Middle & High \\
Case 1 & Case 2 & Case 3
\end{tabular}

Postactive Decisions

Instructional Strategies - ways in which teachers use technology for teaching and learning

\begin{tabular}{|c|c|c|c|c|c|c|c|c|c|}
\hline Applicability & $\mathrm{X}$ & & $\mathrm{X}$ & & & & $\mathrm{X}$ & & $\mathrm{X}$ \\
\hline Classroom Management & $\mathrm{X}$ & $\mathrm{X}$ & $\mathrm{X}$ & & $\mathrm{X}$ & $\mathrm{X}$ & & $\mathrm{X}$ & $\mathrm{X}$ \\
\hline Content First & $\mathrm{X}$ & $\mathrm{X}$ & & & $\mathrm{X}$ & $\mathrm{X}$ & $\mathrm{X}$ & & $\mathrm{X}$ \\
\hline Critical Thinking & & $\mathrm{X}$ & $\mathrm{X}$ & $\mathrm{X}$ & & & & & $\mathrm{X}$ \\
\hline Direct Instruction & $\mathrm{X}$ & $\mathrm{X}$ & & & & & & & \\
\hline Discovery Learning & & $\mathrm{x}$ & & & & & & & \\
\hline Formal Assessment & & $\mathrm{X}$ & & & & & & & \\
\hline Informal Assessment & $\mathrm{X}$ & $X$ & $\mathrm{X}$ & & $\mathrm{X}$ & $\mathrm{X}$ & $\mathrm{X}$ & & $\mathrm{X}$ \\
\hline Interactive Discussion & $\mathrm{X}$ & $\mathrm{X}$ & & & & $\mathrm{X}$ & & & \\
\hline Introduce Content & & & & & & & & & \\
\hline Modeling & & $\mathrm{X}$ & & & & $\mathrm{X}$ & & & \\
\hline Pacing & & & $\mathrm{X}$ & & & & & & \\
\hline "Reinforcement" & & & & & $\mathrm{X}$ & $\mathrm{X}$ & & & \\
\hline Review and Practice & $\mathrm{X}$ & & & & & & $\mathrm{X}$ & & \\
\hline Reward or Punishment & & & & & & $\mathrm{x}$ & & & $\mathrm{x}$ \\
\hline Timing within School Day & $\mathrm{X}$ & & $\mathrm{X}$ & & & & & & \\
\hline
\end{tabular}

Diversity - use of technology to reach learners of various abilities

Auditory Learning

Kinesthetic Learning

Visual Learning

\begin{tabular}{|c|c|c|}
$\mathrm{X}$ & $\mathrm{X}$ & \\
\hline $\mathrm{X}$ & $\mathrm{X}$ & $\mathrm{X}$ \\
\hline
\end{tabular}

-

\begin{tabular}{|l|l|}
\hline & \\
\hline $\mathrm{X}$ & $\mathrm{X}$ \\
\hline
\end{tabular}

Improvement - using technology allows something to be done better than before or to accomplish something that could not be done before

Enhanced Learning Opportunity

Learning Efficiency

Teaching Efficiency

\begin{tabular}{|l|l|l|l|l|l|l|l|l|l|l|}
\hline $\mathrm{X}$ & & & & & & & & & & \\
\hline $\mathrm{X}$ & $\mathrm{X}$ & & & & & & & & & \\
\hline $\mathrm{X}$ & $\mathrm{X}$ & & & & & & & & & \\
\hline
\end{tabular}


$\mathrm{X}=$ teacher specific decision made by only one of the novices

$\mathrm{X}=$ decision made by all three novices within a certain decision-making phase

$\mathrm{X}=$ decision made by all three novices at some point within the decision-making phases

Descriptive Codes \&

Pattern Codes*

\begin{tabular}{|c|c|c|c|c|}
\hline \multicolumn{3}{|c|}{ Preactive Decisions } & & \\
\hline $\begin{array}{c}\text { Elementary } \\
\text { Case 1 }\end{array}$ & $\begin{array}{c}\text { Middle } \\
\text { Case 2 }\end{array}$ & $\begin{array}{c}\text { High } \\
\text { Case 3 }\end{array}$ & E & \\
\hline
\end{tabular}

Interactive

Technology Readiness - students and/or teacher must be ready to use technology

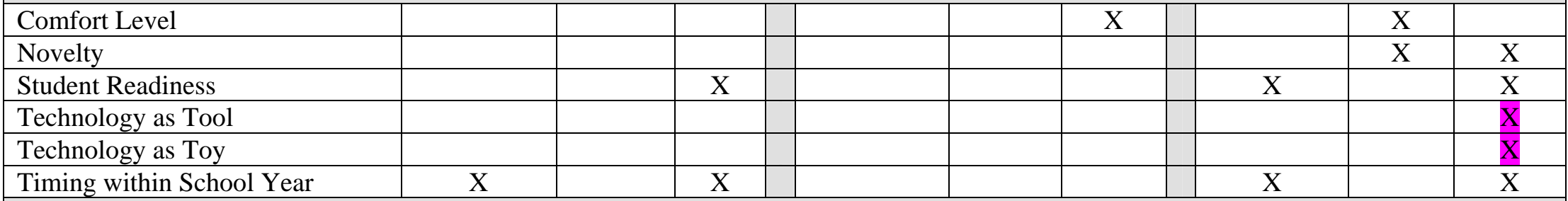

Teacher Change- what teachers do differently when using technology

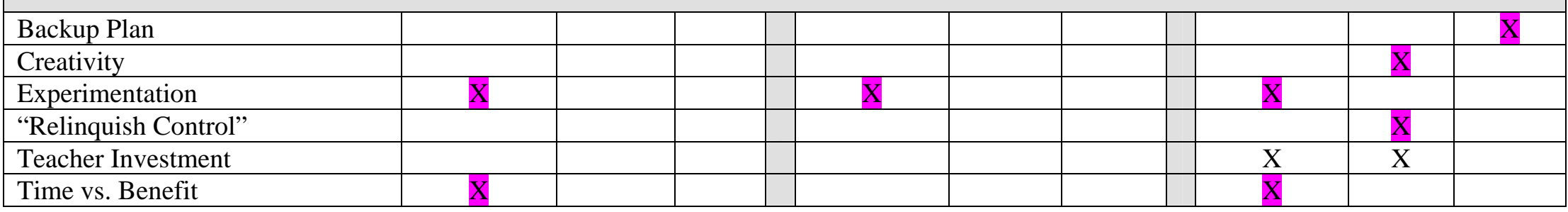

*Pattern codes appear in boldface and within a row shaded in gray. Descriptive codes are listed below each pattern code.

** Codes enclosed within quotation marks are in the words of the teachers who participated in this research. 


\section{Appendix G - Descriptive and Pattern Codes Representing Experienced School Teachers Decision-Making}

= teacher specific decision made by only one of the experienced teachers

$\mathrm{X}=$ decision made by all three experienced teachers within a certain decision-making phase

$\mathrm{X}=$ decision made by all three experienced teachers at some point within the decision-making phases

\begin{tabular}{|c|c|c|c|c|c|c|c|c|c|}
\hline \multirow{2}{*}{$\begin{array}{l}\text { Descriptive Codes \& } \\
\text { Pattern Codes* }\end{array}$} & \multicolumn{3}{|c|}{ Preactive } & \multicolumn{3}{|c|}{ Interactive } & \multicolumn{3}{|c|}{ Postactive } \\
\hline & $\begin{array}{l}\text { Elem/ } \\
\text { Middle } \\
\text { Case 4 }\end{array}$ & $\begin{array}{l}\text { Elem/ } \\
\text { Middle } \\
\text { Case } 5\end{array}$ & $\begin{array}{l}\text { High } \\
\text { Case } 6\end{array}$ & $\begin{array}{l}\text { Elem/ } \\
\text { Middle } \\
\text { Case 4 }\end{array}$ & $\begin{array}{l}\text { Elem/ } \\
\text { Middle } \\
\text { Case } 5\end{array}$ & $\begin{array}{l}\text { High } \\
\text { Case } 6\end{array}$ & $\begin{array}{l}\text { Elem/ } \\
\text { Middle } \\
\text { Case 4 }\end{array}$ & $\begin{array}{l}\text { Elem/ } \\
\text { Middle } \\
\text { Case 5 }\end{array}$ & $\begin{array}{l}\text { High } \\
\text { Case } 6\end{array}$ \\
\hline
\end{tabular}

External Influences - aspects beyond the teacher's control that impact decisions to use or not to use technology

Administration's Influence

Administration's Requirements

Availability

Lack of Customization

Pressure from County and State

Reliability

School Technology Plan

Standards

Time Limitation

\begin{tabular}{|c|c|c|} 
& $\mathrm{X}$ & \\
& & $\mathrm{X}$ \\
$\mathrm{X}$ & $\mathrm{X}$ & \\
$\mathrm{X}$ & & \\
& & \\
& & \\
$\mathrm{X}$ & $\mathrm{X}$ & $\mathrm{X}$ \\
$\mathrm{X}$ & $\mathrm{X}$ & $\mathrm{X}$ \\
\hline
\end{tabular}

\begin{tabular}{|l|l|}
\hline & \\
\hline & \\
\hline & \\
\hline & \\
\hline & \\
\hline & \\
\hline
\end{tabular}

Student Benefi

Build Confidence

Communication

Customization

Evaluation of Resources

"Focus"

Incidental Learning

"Instant Feedback"

Life Skills

"Positive Attitude"

"Real Life"

Retention

Sequence Information

Student Collaboration

Student Engagement

Student-Teacher Collaboration

\begin{tabular}{|c|c|c|c|c|c|c|} 
& & & & & & \\
& & & & & & \\
\hline & & & & & $\mathrm{X}$ & \\
\hline & & & & & $\mathrm{X}$ & \\
\hline & & $\mathrm{X}$ & & & & \\
\hline & & & & & & \\
\hline & $\mathrm{X}$ & $\mathrm{X}$ & & & & \\
\hline
\end{tabular}

\section{decision whether or not to use technology is based on perceived benefit for students

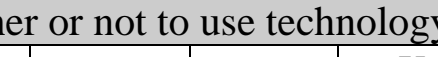




\begin{tabular}{|c|c|c|c|c|c|c|c|c|c|}
\hline \multicolumn{10}{|c|}{$\begin{array}{l}\mathrm{X}=\text { teacher specific decision made by only one of the experienced teachers } \\
\mathrm{X}=\text { decision made by all three experienced teachers within a certain decision-making phase } \\
\mathrm{X}=\text { decision made by all three experienced teachers at some point within the decision-making phases }\end{array}$} \\
\hline \multirow{2}{*}{$\begin{array}{l}\text { Descriptive Codes \& } \\
\text { Pattern Codes* }\end{array}$} & \multicolumn{3}{|c|}{ Preactive } & \multicolumn{3}{|c|}{ Interactive } & \multicolumn{3}{|c|}{ Postactive } \\
\hline & $\begin{array}{l}\text { Elem/ } \\
\text { Middle } \\
\text { Case } 4\end{array}$ & \begin{tabular}{|l|} 
Elem/ \\
Middle \\
Case 5
\end{tabular} & $\begin{array}{l}\text { High } \\
\text { Case } 6\end{array}$ & $\begin{array}{l}\text { Elem/ } \\
\text { Middle } \\
\text { Case 4 }\end{array}$ & \begin{tabular}{|l|} 
Elem/ \\
Middle \\
Case 5
\end{tabular} & $\begin{array}{l}\text { High } \\
\text { Case } 6\end{array}$ & $\begin{array}{l}\text { Elem/ } \\
\text { Middle } \\
\text { Case } 4\end{array}$ & $\begin{array}{l}\text { Elem/ } \\
\text { Middle } \\
\text { Case 5 }\end{array}$ & $\begin{array}{l}\text { High } \\
\text { Case } 6\end{array}$ \\
\hline \multicolumn{10}{|l|}{ "Summarize Information" } \\
\hline \multicolumn{10}{|l|}{ Supplementation } \\
\hline Technology Skills & $\mathrm{X}$ & $\mathrm{X}$ & & & & & & $\mathrm{X}$ & $\mathrm{X}$ \\
\hline Variation from Routine & $\mathrm{X}$ & & $\mathrm{X}$ & & & & $\mathrm{X}$ & & \\
\hline "Voice" & $\mathrm{X}$ & & & & & & & & \\
\hline \multicolumn{10}{|c|}{ Instructional Strategies - ways in which teachers use technology for teaching and learning } \\
\hline Applicability & $\mathrm{X}$ & $\mathrm{X}$ & $\mathrm{X}$ & & & & & $\mathrm{X}$ & \\
\hline Classroom Management & $\mathrm{X}$ & & & & $\mathrm{X}$ & $\mathrm{X}$ & $\mathrm{X}$ & $\mathrm{X}$ & \\
\hline Content First & $\mathrm{X}$ & $\mathrm{X}$ & $\mathrm{X}$ & $\mathrm{X}$ & & & & & \\
\hline Critical Thinking & & $\mathrm{X}$ & $\mathrm{X}$ & & & & & & \\
\hline Direct Instruction & $\mathrm{X}$ & & & & & $\mathrm{X}$ & & $\mathrm{X}$ & \\
\hline Discovery Learning & & & $\mathrm{X}$ & & & $\mathrm{X}$ & & & \\
\hline Formal Assessment & $\mathrm{X}$ & & $\mathrm{X}$ & & & & & & \\
\hline Informal Assessment & $\mathrm{X}$ & $\mathrm{X}$ & $\mathrm{X}$ & $\mathrm{X}$ & $\mathrm{X}$ & $\mathrm{X}$ & & $\mathrm{X}$ & $\mathrm{X}$ \\
\hline Interactive Discussion & & & & & & $\mathrm{X}$ & & $\mathrm{X}$ & \\
\hline Introduce Content & & & $\mathrm{X}$ & & & & & & \\
\hline Modeling & & & $X$ & & & & & $\mathrm{X}$ & \\
\hline \multicolumn{10}{|l|}{ Pacing } \\
\hline "Reinforcement" & & $\mathrm{X}$ & $\mathrm{X}$ & & & & & $\mathrm{X}$ & \\
\hline Review and Practice & $\mathrm{X}$ & $\mathrm{X}$ & & & & & & $\mathrm{X}$ & $\mathrm{X}$ \\
\hline Time Filler & & $\mathrm{X}$ & & & & & & & \\
\hline \multicolumn{10}{|c|}{ Diversity - use of technology to reach learners of various abilities } \\
\hline Diversity & & & & & & & & $\mathrm{X}$ & $\mathrm{X}$ \\
\hline Kinesthetic Learning & & & & & & & & $\mathrm{X}$ & \\
\hline Visual Learning & $\mathrm{X}$ & $\mathrm{X}$ & $\mathrm{X}$ & & & & & $\mathrm{X}$ & $\mathrm{X}$ \\
\hline
\end{tabular}




\begin{tabular}{|l|l|l|l|l|l|l|l|l|l|l|}
\hline $\mathrm{X}=$ teacher specific decision made by only one of the experienced teachers \\
$\mathrm{X}=$ decision made by all three experienced teachers within a certain decision-making phase \\
$\mathrm{X}=$ decision made by all three experienced teachers at some point within the decision-making phases
\end{tabular}

*Pattern codes appear in boldface and within a row shaded in gray. Descriptive codes are listed below each pattern code.

** Codes enclosed within quotation marks are in the words of the teachers who participated in this research. 
Appendix H - Descriptive Codes and Definitions for Novice and Experienced Teachers

Descriptive codes and definitions were created to describe how and why the teachers in this study make instructional technology decisions. These descriptive codes were developed from the data collected and reflect teachers' decisions to use and not to use technology. The codes are listed in alphabetical order.

Accurate Representation - use of a technology produced visual, e.g. a graph, because it is neater and more accurate than creating by hand Administration's Influence - administrative officials encourage the use of technology Administration's Requirements - administrative officials require the use of technology Applicability - used because of relevance to the lesson and "not used just as something to do" Availability - availability of resources, e.g. overhead projectors, calculators, graphing calculators, and computers Auditory Learning - students hear what they are learning, e.g. using a book on tape so students can hear "good reading" Backup Plan - backup plan always exists in case a) technology does not function correctly; b) technology is not available; c) students cannot use technology as planned; or d) students misbehave and technology must be taken away from them Build Confidence - students build confidence while using technology because it is not intimidating

Classroom Management - intent is to control student behavior Comfort Level - students or teachers are comfortable using technology Communication - communicate information about class and assignments to students and parents 
Content First - focus on content first, technology second

Creativity - finding new ways to use technology

Critical Thinking - "combine brain power with technology" to challenge students to think

critically

Customization- ability to customize technology based on what students have learned or need to learn

Direct Instruction - information presented to students under teacher direction

Discovery Learning - students learn through discovery as opposed to being told what they are supposed to learn

Diversity - helps students of all levels and learning styles to learn

Enhanced Learning Opportunity - allows something to be done better than in the past or allows something that could not be done before

Evaluation of Resources - students use technology to conduct research and compare and evaluate resources

Experimentation - see what will happen and "learn as you go"

Fairness - students in all class periods get to use technology

Flexibility - teachers have to be flexible because "you never know what will happen”

"Focus" - helps students focus on what they are learning

Formal Assessment - formally assess students' knowledge and assign a grade

Habits - students are used to learning with traditional methods, such as using worksheets

Incidental Learning - learning occurs that was not planned

Informal Assessment - informally assess students to determine if they are learning as planned 
"Instant Feedback" - students receive immediate feedback from technology alone or combined with the teacher

Interactive Discussion - teacher and students engage in discussion

Introduce Content - introduce topic or subject matter

Kinesthetic Learning - students use technology "hands-on”

Lack of Customization - not being able to customize a technology according to what students have learned or need to learn

Learning Efficiency - allows students to learn more efficiently, requiring less time or effort than in the past

Life Skills - students work on projects and problems similar to what they will experience throughout their school and work careers

Modeling - model what students should be learning

Novelty - "new and different" for students and they focus on technology instead of what they are supposed to be learning. Novelty fades as students use technology over time and eventually it becomes just another learning tool

Pacing - control the speed with which content is covered

Peer Expectations - faculty expect one another to use technology

"Positive Attitude" - students have a positive attitude when using technology

Pressure from County and State - pressure to increase students' standardized test scores

"Real Life" - provides access to "real life" that is occurring outside of the school

“Reinforcement” - reinforces content students' have learned

Reliability - must function correctly when teacher and students need to use it

"Relinquish Control" - provides opportunities for students to have control of their learning 
Researcher's Presence - used because researcher was observing

Retention - helps students to retain information better than by using traditional methods Review and Practice - review and practice content

Reward or Punishment - if students get "out of hand," technology is taken away School Technology Plan - school has a technology plan that teachers are required to follow Sequence Information - students put what they are learning into order Standards - state and/or national level standards teachers are required to follow Student Collaboration - students share information and help each other to learn Student Engagement - captures students' interest and attention Student Readiness - students must be ready to use technology, based on their content knowledge or maturity level

Student Welfare - must not subject students to inappropriate information Student-Teacher Collaboration - students and teacher learn together “Summarize Information" - students summarize what they are learning Supplementation - used after school as an extra-curricular activity

Teacher Collaboration - teachers collaborate to find technology resources and create ways to use them

Teacher Investment - invest time into planning to use technology, "might as well use it" Teaching Efficiency - allows something to be taught more efficiently, requiring less time or effort than in the past

"Technology is a Catalyst" - serves as a catalyst for changing the way we teach and learn Technology as Tool - teacher's perception of technology as a learning tool, as opposed to a "toy" Technology as Toy - teacher's perception of technology as a "toy," as opposed to a learning tool 
Technology Skills - students gain experience and skills using technology

Time Filler - fills a gap in a class period

Time for Planning - teachers need time to create lesson plans that use technology and/or revise existing lesson plans to use technology

Time Limitation - insufficient time to use technology due to class periods, block scheduling, unexpected interruptions

Time vs. Benefit - investment of time in preparing to use technology must be worth the benefit to students

Timing within school day - used during the afternoon to energize students

Timing within school year - students' ability to use technology is related to the time of the school year

Variation from Routine - students like to use technology because it is new and different and they get "tired of using the traditional approach"

Visual Learning - students see what they are learning, e.g. viewing moving images (video) as opposed to still pictures, or watching what happens when a change is made to a math formula "Voice" - students present information or lead a discussion, giving them a means of expressing themselves 